\title{
Evaluation of health care innovations in fibromyalgia
}

Citation for published version (APA):

Kroese, M. E. A. L. (2012). Evaluation of health care innovations in fibromyalgia. [Doctoral Thesis, Maastricht University]. Datawyse / Universitaire Pers Maastricht. https://doi.org/10.26481/dis.20121101mk

Document status and date:

Published: 01/01/2012

DOI:

10.26481/dis.20121101mk

Document Version:

Publisher's PDF, also known as Version of record

\section{Please check the document version of this publication:}

- A submitted manuscript is the version of the article upon submission and before peer-review. There can be important differences between the submitted version and the official published version of record.

People interested in the research are advised to contact the author for the final version of the publication, or visit the DOI to the publisher's website.

- The final author version and the galley proof are versions of the publication after peer review.

- The final published version features the final layout of the paper including the volume, issue and page numbers.

Link to publication

\footnotetext{
General rights rights.

- You may freely distribute the URL identifying the publication in the public portal. please follow below link for the End User Agreement:

www.umlib.nl/taverne-license

Take down policy

If you believe that this document breaches copyright please contact us at:

repository@maastrichtuniversity.nl

providing details and we will investigate your claim.
}

Copyright and moral rights for the publications made accessible in the public portal are retained by the authors and/or other copyright owners and it is a condition of accessing publications that users recognise and abide by the legal requirements associated with these

- Users may download and print one copy of any publication from the public portal for the purpose of private study or research.

- You may not further distribute the material or use it for any profit-making activity or commercial gain

If the publication is distributed under the terms of Article $25 \mathrm{fa}$ of the Dutch Copyright Act, indicated by the "Taverne" license above, 


\section{Evaluation of health care innovations in fibromyalgia}


The research presented in this thesis was conducted at the Maastricht University Medical Centre (MUMC+), Department of Patient and Care, and at the School for Public Health and Primary Care (CAPHRI). CAPHRI participates in the Netherlands School of Primary Care Research CaRe. CAPHRI was classified as 'excellent' by the external evaluation committee of leading international experts that reviewed CAPHRI in December 2010.

The research was funded by MUMC+, Department of Patient and Care, and by Care Renewal Grants by courtesy of health insurance companies (CZ and VGZ).

Financial support for the publication of this thesis was kindly provided by:


(C) Mariëlle Kroese, Maastricht 2012

ISBN : 9789461591722

Cover design:

M.E.A.L. Kroese, Datawyse

Lay out:

Tiny Wouters

Production:

Datawyse I Universitaire Pers Maastricht 


\title{
Evaluation of health care innovations in fibromyalgia
}

\author{
Proefschrift \\ ter verkrijging van de graad van doctor \\ aan de Universiteit Maastricht, \\ op gezag van de Rector Magnificus, Prof. dr. L.L.G. Soete, \\ volgens het besluit van het College van Decanen, \\ in het openbaar te verdedigen \\ op donderdag 1 november 2012 om 16.00 uur \\ door \\ Maria Elisabeth Aafje Lydia Kroese
}

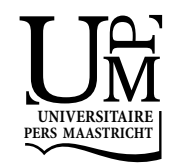




\section{Promotores}

Prof. dr. R.B.M. Landewé (Academisch Medisch Centrum/Universiteit van Amsterdam)

Prof. dr. J.L. Severens (Erasmus Universiteit Rotterdam)

\section{Copromotor}

Dr. G.J.C. Schulpen

Beoordelingscommissie

Prof. dr. J.M.J.P. van der Linden (voorzitter)

Dr. A.E.R.C.H. Boonen

Prof. dr. J.F.M. Metsemakers 
"The LORD is my strength and my shield; my heart trusts in Him, and He helps me. My heart leaps for joy, and with my song I praise Him." Psalm 28:7 



\section{Contents}

Chapter $1 \quad$ General introduction 9

Chapter 2 Specialized rheumatology nurses can substitute for 23 rheumatologists in the diagnostic process of fibromyalgia:

a randomized controlled trial

Arthritis Care \& Research 2008;59:1299-1305

Chapter 3 Specialized rheumatology nurse substitutes rheumatologists in the diagnostic process of fibromyalgia: a cost-consequence analysis alongside a randomized controlled trial The Journal of Rheumatology 2011;38:1413-22

Chapter 4 Diagnosis of fibromyalgia is associated with impaired health outcomes and health care costs after 9 months of follow-up

Submitted

Chapter 5 Therapeutic approaches to fibromyalgia in the Netherlands: where do we stand? Journal of Evaluation in Clinical Practice 2008;14(2):321-5

Chapter 6 The feasibility and efficacy of a multidisciplinary intervention with aftercare meetings for fibromyalgia Clinical Rheumatology 2009;28:923-9

Chapter 7 Challenges in demonstrating effectiveness of multidisciplinary treatment on quality of life, participation and health care utilization in patients with fibromyalgia. A randomized controlled trial Submitted

Chapter 8 General discussion

Summary

Samenvatting

Dankwoord 



\section{Chapter 1}

General introduction 
$10 \mid$ Chapter 1 


\section{Introduction}

Chronic conditions are the health care challenge of this century. As a result of modern health care and health technologies a transition has occurred of the age of acute health problems to the age of chronic illness which is characterized by improved health care, low levels of mortality and relatively high levels of morbidity ${ }^{1}$. The World Health Organization (WHO) defined chronic conditions as health problems that persist and require some degree of health care management across time ${ }^{2}$. Chronic illness is usually characterized by complex causality, multiple risk factors, a long latency period, a prolonged course of illness, functional impairment or disability and rarely completely cure ${ }^{3}$ and includes a wide range of conditions as heart disease, cancer, stroke, diabetes, and musculoskeletal disorders.

\section{Fibromyalgia as a chronic musculoskeletal disorder}

Fibromyalgia (FM) is a complex and often misunderstood chronic musculoskeletal disorder characterized by persistent and widespread pain. FM patients also may experience fatigue, disturbed sleep, stiffness, irritable bowel syndrome, cognitive dysfunction, and depressive and anxious symptoms ${ }^{4,5}$. These symptoms may be part of FM or may be separate comorbid illnesses.

In 1990 the Multicenter Criteria Committee of the American College of Rheumatology (ACR) proposed chronic wide-spread pain and the presence of at least 11 out of 18 tender points as classification criteria for FM, because this combination had the accuracy in distinguishing between FM and other rheumatic conditions ${ }^{4}$. Many of the symptoms of FM reported in clinical practice in addition to the pain and tenderness, however, present a condition with a complexity that is probably beyond the 1990 ACR classification $^{6}$.

Worldwide, FM is recognized as a common syndrome, in the general population as well as in the clinic. The prevalence in the general population has been estimated at $0.5 \%$ to $5 \%$, $5,7,8$ is the diagnosis in 15 to $30 \%$ of the new referrals in a rheumatology outpatient clinic; $5 \%$ to $8 \%$ of primary care consultations are because of this syndrome ${ }^{8-12}$. Most individuals with FM are women that are typically diagnosed during their working years ${ }^{13,14}$.

There is a substantial overlap of FM with other unexplained clinical conditions, such as chronic fatigue syndrome, irritable bowel syndrome, tension headache and migraine ${ }^{15}$. The pathogenesis of FM is still unclear, but there is increasing evidence for the prevailing theory that a dysregulation of pain pathways leads to peripheral and central sensitization which cause an amplification of sensory impulses that may alter pain perception ${ }^{16}$. 


\section{The diagnostic process of fibromyalgia}

An accurate and timely diagnosis seems a critical first step to more effective care and better outcomes for patients with $\mathrm{FM}^{17}$. Diagnosis time averages 5 years ${ }^{18}$. Patients wait a significant period of time before presenting to a physician, adding to the prolonged time to diagnosis. Before a diagnosis of FM is made, patients may repeatedly present to their general practitioner (GP) with a multitude of symptoms, all resulting in a delay in diagnosis and eventual management ${ }^{19}$. This delay may result in repetitive drug prescriptions, multiple diagnostic tests, and referrals to medical specialists and other healthcare providers ${ }^{20}$. Blotman et al. revealed the need for further continuing medical education to help physicians better identify FM and differentiate this syndrome from other medical conditions as well as the need to initiate an explicit teaching effort on chronic pain and $\mathrm{FM}^{21}$. The need for upgrading courses in rheumatology for primary care physicians has been stressed before ${ }^{22,23}$. Schulpen et al. demonstrated that joint consultation, a model based on problem based learning, has a beneficial effect on rheumatological skills of the $\mathrm{GP}^{24}$. The number of patients referred by participating GPs to rheumatologists (RMTs) decreased by $62 \%$ at the end of the study, especially for FM $(P=0.001)^{24}$.

Little is known about the impact and prognosis after a diagnosis of FM. There are two dominant schools of thought regarding the impact of a diagnosis of $\mathrm{FM}^{20}$. According to the first theory, it is possible that making a definite diagnosis will reduce the number of referrals, use of multiple health care providers, and costs ${ }^{20,25}$. According to the second theory, it is possible that acquiring the FM label might lead to increased illness behaviour, dependence on health care providers, and increased health service costs $^{26,27}$.

\section{Personal consequences of fibromyalgia}

For many patients, FM is a debilitating disorder which affects all aspects of daily life and functioning. It often impairs the patient ability to participate in daily activities and work, and has a negative impact on relationships with family, friends, and employers $^{28}$. So, it results in significant disability and loss of function and is, therefore, likely to lead to productivity loss ${ }^{29}$. Limitations caused by pain, fatigue, decreased muscle strength, and endurance influence work capacity ${ }^{30}$. However, $34-77 \%$ of the women work. Individual adjustments in the work situation are reported. When the women find a level that matches their ability, they continue to work and find satisfaction in their work role. Besides degree of impairment or disability, many factors like total life situation, other commitments, type of work tasks, the ability to influence the work situation, and the physical and psychosocial work environment influence whether clients with longstanding pain can remain in their work role or return to work after sickness leave ${ }^{30}$.

The pain, disability, and other symptoms of FM result in a significantly reduced quality of life: FM patients rate their quality of life extremely low compared with other groups 
of patients, like rheumatoid arthritis (RA), osteoarthritis (OA), chronic obstructive pulmonary disease or diabetes mellitus ${ }^{31-35}$.

Some studies assume that the symptoms and disability associated with FM do not change substantially over time ${ }^{36-39}$. Others observed (some) spontaneous improvement in pain reporting and less medication use in FM patients ${ }^{40-42}$. It seems in any case that if symptoms of FM persist, patients appear better able to cope with them ${ }^{36}$.

\section{Economic consequences of fibromyalgia}

FM places a high burden on the health care system and the community. From an economic perspective, everyone pays a toll:

- Patients (and families) pay the measurable monetary costs, including contributions in health care costs, expenses for informal care, reduced workdays, and lost employment. Although FM is quite costly to patients, patient costs are nevertheless poorly documented in the literature ${ }^{43}$.

- Health care payers like health insurers and health care organisations pay most of the costs of medical care, but also bear many of the expenses that hide behind the costs of treatment. FM is characterised by a high use of health care resources ${ }^{44-51}$. Although FM patients are clearly more expensive than healthy controls, comparison with other conditions in the same disease area does not reveal higher costs: direct medical costs are moderately comparable with RA, OA, ankylosing spondylitis and chronic low back pain ${ }^{43,48,50,52}$. Direct medical costs vary between approximately $\$$ US 2000 and nearly \$US 10.000 per year (year 2005 values) ${ }^{43}$.

- Government, employers, and society are confronted with consequences like reduced productivity or ability to work and disability payment. In general, approximately $25 \%$ of the total societal costs of FMS (with or without depression) are related to productivity costs ${ }^{46,53}$. Boonen et al. found that in the Netherlands $33 \%$ of the total costs for FM were due to productivity loss ${ }^{52}$. According to Wolfe et al., $26.5 \%$ of FM patients seen in rheumatology clinics in the United States received some form of disability payment ${ }^{54}$.

\section{Management of fibromyalgia}

Uncertainties regarding pathophysiology and absence of validated objective markers of FM may have limited progress in the therapeutic approaches to $\mathrm{FM}^{16}$. Currently, there are still no curative treatments available for patients with FM. Both pharmacological and non-pharmacological approaches are used to relieve complaints, improve patients' quality of life and coach patients to deal with the disorder.

A lot of pharmacotherapies like antidepressants, antiepileptics, NSAIDs, benzodiazepines, muscle relaxants, opioids and corticosteroids are frequently used for 
$\mathrm{FM}^{55}$. None of these medications were specifically developed for the management of $\mathrm{FM}$, and only for some of them evidence supporting effectiveness in reducing pain and other symptoms is existing. Evidence is found for the efficacy of antidepressants like amitriptyline and duloxetine in reducing pain, sleep disturbances, depressed mood, and fatigue, and for improving health related quality of life $\mathrm{e}^{56-60}$. The recommendations regarding pharmacological treatment of FM are limited by the short study durations, the lack of follow-ups and absence of cost-effectiveness studies ${ }^{60}$. When clinicians decide to use pharmacologic therapy to treat FM patients, the selection of the drug should be based on occurrence of the key symptoms of FM, adverse effect profiles of the drug, comorbidities of the patients, and the patient's preferences ${ }^{58}$. Effects should be re-evaluated at regular intervals to determine whether benefits outweigh side effects $^{57}$.

Concerning non-pharmacological treatments, aerobic exercise and cognitivebehavioural therapies have demonstrated efficacy in alleviating FM symptoms ${ }^{61-66}$. It has been shown that aerobic exercise reduces pain, fatigue, and depressed mood, and improves quality of life and physical fitness at post treatment ${ }^{64}$. The findings of the systematic review of Häuser et al. suggest that the positive effects on depressed mood, quality of life and physical fitness can be maintained at follow-up ${ }^{64}$, although van Koulil et al. concluded that the preservation of these effects is unclear for the long term $^{65}$.

Psychological and behavioural therapies are being applied to patients with FM with increasing frequency. The rationale for including psychological therapies is not because of co-morbid mood disorders, but rather to manage the many nonpsychiatric psychological and social factors that comprise pain perception and its maintenance ${ }^{67}$. Several systematic reviews on this subject exist but have yielded divergent conclusions: some showing substantial efficacy for cognitive behavioural therapy and related approaches ${ }^{56,63,68}$, others reporting somewhat disappointing results $^{65,69,70}$. These contradictory results are probably due to the different study samples with a lot of clinical and methodological differences between the studies. In general, there are relatively few studies on psychological treatments for FM, and many of these are of low methodological quality.

No single treatment seems to be completely effective in relieving all FM-associated symptoms. The multifaceted nature of FM suggests that multimodal or multidisciplinary, individualized treatment programmes may be necessary to achieve optimal outcomes in patients with this syndrome ${ }^{55,71}$. Rossy et al. concluded in their meta-analysis that the optimal intervention for FM should include exercise therapy and a psychological therapy ${ }^{72}$. A number of studies have investigated the effect of multimodal or multidisciplinary therapy for FM. Strong evidence has been found that multicomponent treatment has beneficial short-term effects on the key symptoms of $\mathrm{FM}^{73}$. However, the systematic reviews performed in this area concluded that the evidence is scarce because of few studies, low quality of these studies, and varying elements of therapy ${ }^{65,73-75}$. Besides, the drop-out rates in the studies are generally high $^{76-81}$, suggesting that the treatment was not individualised. Another concern is that the majority of the studies did not include long-term follow-up assessments and if they did, that positive outcomes largely disappear in the long-term ${ }^{65}$. So, strategies 
to maintain the benefits of multicomponent treatment on the long term need to be developed $^{73}$. Notwithstanding these weaknesses in evidence, multidisciplinary interventions are increasingly applied and recommended in the care for patients with $\mathrm{FM}^{62}$, even though the costs of the programmes are substantial.

The importance of early treatment of patients who are at risk of developing persistent pain and related problems is increasingly recognised ${ }^{82}$. A study on patients with chronic fatigue syndrome, another unexplained clinical condition, showed that patients with a relatively short duration of complaints had a more favourable outcome compared to patients with a long illness duration ${ }^{83}$. Intervening early seems important for several reasons. Firstly, in the course of a pain condition, it may help prevent a vicious cycle of long-term physical and psychological suffering. Secondly, patients who have had FM for an extended period might have ingrained maladaptive patterns of pain-coping and illness behaviours that are resistant to treatment, making it more difficult for patients to change their behaviour. Finally, early intervention has the potential to reduce or prevent disability in patients with chronic pain, which, in turn, will reduce societal and medical costs ${ }^{65}$.

\section{Innovation of care}

In the beginning of 2001, the FM care (diagnostics and treatment) in the region Maastricht-Heuvelland showed several bottlenecks and shortcomings. In those days, the rheumatology outpatient clinic had an enormous waiting list. As a result, GPs wrote a pressing letter to the executive board of the Maastricht University Medical Centre because of the difficult accessibility of several outpatient clinics, including the rheumatology outpatient clinic. Analyses of the problem showed that FM patients were the most important bottleneck: 300-350 patients of the 1100-1200 new referrals per year were referred because of (suspicion of) FM. GPs referred especially for diagnostics, but also for treatment or at patient's request.

In order to relief this problem, a stepwise development of a care programme for patients with FM has been proposed. The programme focuses on early diagnosis and early intervention. First, the focus was on improvement of accessibility of the rheumatology outpatient clinic. The high number of patients with FM, the shortage of rheumatologists, and the substantial time demands per patient have prompted us to consider whether the rheumatologist should have the primary role in establishing a diagnosis of FM. Possibly, other trained health care workers, like the specialized rheumatology nurse (SRN), could contribute to the diagnostic process.

As mentioned above, Schulpen et al. demonstrated that joint consultation, a model based on problem based learning, has a beneficial effect on rheumatological skills of the GP. The referral rate for FM decreased significantly $(P=0.001)^{24}$. This suggests that, if GPs learn to manage this topic, they are able to diagnose and coach FM patients self-reliantly. If substitution of GPs concerning FM can be realized in a rather simple 
way, this would perhaps also be possible by putting in SRNs in the diagnostic process of FM.

Over the last decade, the role of specialized nurses has evolved. Apart from their role in providing clinical care and education specialized nurses may also assist the physician in the care for patients with chronic but stable diseases ${ }^{84-93}$. International studies on the role and added value of SRNs show that they can have a feasible and efficacious role in additional care or care substitution ${ }^{84-88}$. Hill et al. for instance found that patients attending a SRN for RA suffered from lower levels of pain $(P<0.05)$, had acquired greater levels of knowledge $(P<0.0001)$ and were significantly more satisfied with their care $(P<0.0001)$ compared to patients attending a rheumatologist ${ }^{84,85}$. However, the studies have concentrated on patients with RA and it is not known if a SRN can have a positive impact on patients with other rheumatological diseases like FM. Besides, the tasks of SRNs can possibly be extended to making a diagnosis.

There are many potential advantages of appointing the SRN in such a new role: the waiting time to a first visit may be shortened and the RMT might dedicate more time to patients who need specialized medical care. So, if SRNs substitute for RMTs, the demand for RMTs will be reduced and shortages of RMTs will be relieved. Furthermore, a timely diagnosis of FM may help in reassuring the patient, in keeping him at work, in preventing loss of participation, and in limiting medical costs. As mentioned before, early diagnosis seems a critical first step in more effective care and better outcomes for FM patients ${ }^{17}$. Next, referring to the SRN's specific competencies, the nurse may be able to provide better care to patients with FM than medical specialists as the SRN is trained to give information, education and support to the patients, aiming to enhance self-management. So, the quality of care can be enhanced. Finally, substitution can reduce costs because nurses are cheaper to hire than physicians.

Additionally to the improvement of accessibility of the rheumatology outpatient clinic to secure an early FM diagnosis, an early treatment is important. As mentioned before, notwithstanding the weaknesses in evidence for this treatment option like the disappearance of positive outcomes in the long-term, multidisciplinary interventions are increasingly applied and recommended in the care for patients with $\mathrm{FM}^{62}$. To meet the need for an early and intensive intervention, and to preserve the benefits of the treatment on the long term, a multidisciplinary programme with aftercare meetings has been developed. The aftercare meetings are aimed at internalisation of the learned skills and maintenance of self-management and daily functioning.

The findings of this thesis should help inform the decisions of health care planners, health insurers, (policy makers), and health care professionals who may be considering health care innovations like role revision and new treatments as a means to improve health care quality, outcomes, and/or efficiency. 


\section{Aim and research questions}

The research in this thesis is aimed at the evaluation of health care innovations in the care for people with FM, from making the diagnosis until the management of this disorder.

The main research questions are

- What is the feasibility of substituting specialized rheumatology nurses for rheumatologists in the diagnostic process of FM?

- What is the cost-consequence of the nurse-led diagnostic process of FM compared to the usual rheumatologist-led consultation from a health care and societal perspective?

- Is there a difference between FM patients and non-FM patients before making the diagnosis and after nine months of follow-up?

- Which interventions are regularly applied for FM by the involved disciplines?

- What is the feasibility of a multidisciplinary intervention with aftercare meetings for FM?

- What are the challenges to demonstrate the effectiveness of a multidisciplinary intervention with aftercare meetings on quality of life, participation and health care utilization in newly diagnosed FM patients?

\section{Outline of this thesis}

In chapter 2 of this thesis the results of the process evaluation, examined in a randomized controlled trial (RCT), are presented in which we assess whether the substitution of SRNs for RMTs in the diagnostic process of FM is feasible with regard to safety, patient satisfaction and diagnostic costs compared with a regular consultation. Chapter 3 describes a cost-consequence analysis of substituting SRNs for RMTs from both a health care and societal perspective. Chapter 4 examines health outcomes and health care costs 9 months after diagnosis for both FM and non-FM patients to see if there is a difference in the course. Chapter 5 reports on two surveys among health professionals involved in FM to get insight in regularly applied interventions for FM. Before the effectiveness and cost-effectiveness of a multidisciplinary intervention with aftercare meetings could be examined in RCT, a study was performed to get an impression about the feasibility of a multidisciplinary intervention in terms of attendance and drop-out rates, as well as about the level of efficacy and sustainability that could be expected. This study is described in chapter 6 . Chapter 7 illustrates the challenges of demonstrating effectiveness in a RCT of a multidisciplinary treatment with aftercare meetings on quality of life, participation and health care utilization in recently diagnosed patients with FM. Finally, in chapter 8 the methods and findings of the different studies are discussed. In addition, implications and recommendations for health care practice and future research are presented. 


\section{References}

1. Omran AR. The epidemiologic transition theory. A preliminary update. J Trop Pediatr 1983;29:305-16.

2. World Health Organization. Innovative Care for Chronic Conditions: building blocks for action. www.who.int/diabetesactiononline/about/icccreport/en/index.html Geneva: World Health Organization; 2003. Assessed May 10, 2011.

3. National Center for Chronic Disease Prevention and Health Promotion. Chronic Diseases, The Power to Prevent, the Call to Control: At A Glance. Atlanta: National Center for Chronic Disease Prevention and Health Promotion; 2009.

4. Wolfe F, Smythe HA, Yunus MB, Bennett RM, Bombardier C, Goldenberg DL, et al. The American College of Rheumatology 1990 Criteria for the Classification of Fibromyalgia. Report of the Multicenter Criteria Committee. Arthritis Rheum 1990;33:160-72.

5. White KP, Harth M. Classification, epidemiology, and natural history of fibromyalgia. Curr Pain Headache Rep 2001;5:320-9.

6. Katz RS, Wolfe F, Michaud K. Fibromyalgia diagnosis: a comparison of clinical, survey, and American College of Rheumatology criteria. Arthritis Rheum 2006;54:169-76.

7. Branco JC, Bannwarth B, Failde I, Abello Carbonell J, Blotman F, Spaeth M, et al. Prevalence of fibromyalgia: a survey in five European countries. Semin Arthritis Rheum 2010;39:448-53.

8. Wolfe F, Ross K, Anderson J, Russell IJ, Hebert L. The prevalence and characteristics of fibromyalgia in the general population. Arthritis Rheum 1995;38:19-28.

9. Goldenberg DL, Simms RW, Geiger A, Komaroff AL. High frequency of fibromyalgia in patients with chronic fatigue seen in a primary care practice. Arthritis Rheum 1990;33:381-7.

10. Martin L, Nutting A, Maclntosh BR, Edworthy SM, Butterwick D, Cook J. An exercise program in the treatment of fibromyalgia. J Rheumatol 1996;23:1050-3.

11. Vanhoof J, Declerck K, Geusens P. Prevalence of rheumatic diseases in a rheumatological outpatient practice. Ann Rheum Dis 2002;61:453-5.

12. Vosse D. Referral patterns to the rheumatology outpatient department of the University Hospital Maastricht. In. Maastricht; 2007.

13. Weir PT, Harlan GA, Nkoy FL, Jones SS, Hegmann KT, Gren LH, et al. The incidence of fibromyalgia and its associated comorbidities: a population-based retrospective cohort study based on International Classification of Diseases, 9th Revision codes. J Clin Rheumatol 2006;12:124-8.

14. White KP, Speechley M, Harth M, Ostbye T. The London Fibromyalgia Epidemiology Study: the prevalence of fibromyalgia syndrome in London, Ontario. J Rheumatol 1999;26:1570-6.

15. Aaron LA, Buchwald D. Fibromyalgia and other unexplained clinical conditions. Curr Rheumatol Rep 2001;3:116-22.

16. Mease P, Arnold LM, Bennett R, Boonen A, Buskila D, Carville S, et al. Fibromyalgia syndrome. J Rheumatol 2007;34:1415-25.

17. Arnold LM, Clauw DJ, McCarberg BH. Improving the Recognition and Diagnosis of Fibromyalgia. Mayo Clin Proc 2011;86:457-64.

18. National Pain Foundation. Fibromyalgia: facts and statistics. http://nationalpainfoundation.org/ articles/849/facts-and-statistics; Assessed May 10, 2011

19. Choy E, Perrot S, Leon T, Kaplan J, Petersel D, Ginovker A, et al. A patient survey of the impact of fibromyalgia and the journey to diagnosis. BMC Health Serv Res 2010;10:102.

20. Annemans L, Wessely S, Spaepen E, Caekelbergh K, Caubere JP, Le Lay K, et al. Health economic consequences related to the diagnosis of fibromyalgia syndrome. Arthritis Rheum 2008;58:895-902.

21. Blotman F, Thomas E, Myon E, André E, Caubere JP, Taieb C. Awareness and knowledge of fibromyalgia among French rheumatologists and general practitioners. Clin Exp Rheum 2005;23: 697-700.

22. Bolumar F, Ruiz MT, Hernandez I, Pascual E. Reliability of the diagnosis of rheumatic conditions at the primary health care level. J Rheumatol 1994;21:2344-8.

23. Sanchez Molla M, Tovar J, Medina MA. [Diagnostic consistency between primary care physicians and rheumatologists]. Aten Primaria 1994;13:446-8. 
24. Schulpen GJ, Vierhout WP, van der Heijde DM, Landewe RB, Winkens RA, van der Linden S. Joint consultation of general practitioner and rheumatologist: does it matter? Ann Rheum Dis 2003;62: 159-61.

25. White KP, Nielson WR, Harth M, Ostbye T, Speechley M. Does the label "fibromyalgia" alter health status, function, and health service utilization? A prospective, within-group comparison in a community cohort of adults with chronic widespread pain. Arthritis Rheum 2002;47:260-5.

26. Ehrlich GE. Pain is real; fibromyalgia isn't. J Rheumatol 2003;30:1666-7.

27. Hadler NM. "Fibromyalgia" and the medicalization of misery. J Rheumatol 2003;30:1668-70.

28. Arnold LM, Crofford LJ, Mease PJ, Burgess SM, Palmer SC, Abetz L, et al. Patient perspectives on the impact of fibromyalgia. Patient Educ Couns 2008;73:114-20.

29. Kurtze N, Gundersen KT, Svebak S. Quality of life, functional disability and lifestyle among subgroups of fibromyalgia patients: the significance of anxiety and depression. Br J Med Psychol 1999;72:471-84.

30. Henriksson CM, Liedberg GM, Gerdle B. Women with fibromyalgia: work and rehabilitation. Disabil Rehabil 2005;27:685-94.

31. Bernard AL, Prince A, Edsall P. Quality of life issues for fibromyalgia patients. Arthritis Care Res 2000;13:42-50.

32. Burckhardt CS, Clark SR, Bennett RM. Fibromyalgia and quality of life: a comparative analysis. J Rheumatol 1993;20:475-9.

33. Picavet HS, Hoeymans N. Health related quality of life in multiple musculoskeletal diseases: SF-36 and EQ-5D in the DMC3 study. Ann Rheum Dis 2004;63:723-9.

34. Verbunt JA, Pernot DH, Smeets RJ. Disability and quality of life in patients with fibromyalgia. Health Qual Life Outcomes 2008;6:8.

35. Wolfe F, Hawley DJ. Measurement of the quality of life in rheumatic disorders using the EuroQol. Br J Rheumatol 1997;36:786-93.

36. Baumgartner E, Finckh A, Cedraschi C, Vischer TL. A six year prospective study of a cohort of patients with fibromyalgia. Ann Rheum Dis 2002;61:644-5.

37. Nöller V, Sprott $H$. Prospective epidemiological observations on the course of the disease in fibromyalgia patients. J Negat Results Biomed. 2003;2:4.

38. Wolfe F, Anderson J, Harkness D, Bennett RM, Caro XJ, Goldenberg DL, et al. Health status and disease severity in fibromyalgia: results of a six-center longitudinal study. Arthritis Rheum 1997;40:1571-9.

39. Ledingham J, Doherty S, Doherty M. Primary fibromyalgia syndrome--an outcome study. Brit J Rheumatol 1993;32:139-42.

40. Granges G, Zilko P, Littlejohn GO. Fibromyalgia syndrome: assessment of the severity of the condition 2 years after diagnosis. J Rheumatol 1994;21:523-9.

41. Kennedy M, Felson DT. A prospective long-term study of fibromyalgia syndrome. Arthritis Rheum 1996;39:682-5.

42. Poyhia R, Da Costa D, Fitzcharles MA. Pain and pain relief in fibromyalgia patients followed for three years. Arthritis Rheum 2001;45:355-61.

43. Annemans L, Le Lay K, Taieb C. Societal and patient burden of fibromyalgia syndrome. Pharmacoeconomics 2009;27:547-59.

44. Berger A, Dukes E, Martin S, Edelsberg J, Oster G. Characteristics and healthcare costs of patients with fibromyalgia syndrome. Int J Clin Pract 2007;61:1498-508.

45. Penrod JR, Bernatsky S, Adam V, Baron M, Dayan N, Dobkin PL. Health services costs and their determinants in women with fibromyalgia. J Rheumatol 2004;31:1391-8.

46. Robinson RL, Birnbaum HG, Morley MA, Sisitsky T, Greenberg PE, Claxton AJ. Economic cost and epidemiological characteristics of patients with fibromyalgia claims. J Rheumatol 2003;30:1318-25.

47. Sicras-Mainar A, Rejas J, Navarro R, Blanca M, Morcillo A, Larios R, et al. Treating patients with fibromyalgia in primary care settings under routine medical practice: a claim database cost and burden of illness study. Arthritis Res Ther 2009;11:R54.

48. Silverman S, Dukes EM, Johnston SS, Brandenburg NA, Sadosky A, Huse DM. The economic burden of fibromyalgia: comparative analysis with rheumatoid arthritis. Curr Med Res Opin 2009;25:829-40.

49. White KP, Speechley M, Harth M, Ostbye T. The London Fibromyalgia Epidemiology Study: direct health care costs of fibromyalgia syndrome in London, Canada. J Rheumatol 1999;26:885-9. 
50. White LA, Birnbaum HG, Kaltenboeck A, Tang J, Mallett D, Robinson RL. Employees with fibromyalgia: medical comorbidity, healthcare costs, and work loss. J Occup Environ Med 2008;50:13-24.

51. Wolfe F, Anderson J, Harkness D, Bennett RM, Caro XJ, Goldenberg DL, et al. A prospective, longitudinal, multicenter study of service utilization and costs in fibromyalgia. Arthritis Rheum 1997; 40:1560-70.

52. Boonen A, van den Heuvel R, van Tubergen A, Goossens M, Severens JL, van der Heijde D, et al. Large differences in cost of illness and wellbeing between patients with fibromyalgia, chronic low back pain, or ankylosing spondylitis. Ann Rheum Dis 2005;64:396-402.

53. Robinson RL, Birnbaum HG, Morley MA, Sisitsky T, Greenberg PE, Wolfe F. Depression and fibromyalgia: treatment and cost when diagnosed separately or concurrently. J Rheumatol 2004;31: 1621-9.

54. Wolfe F, Anderson J, Harkness D, Bennett RM, Caro XJ, Goldenberg DL, et al. Work and disability status of persons with fibromyalgia. J Rheumatol 1997;24:1171-8.

55. Mease P. Fibromyalgia syndrome: review of clinical presentation, pathogenesis, outcome measures, and treatment. J Rheumatol 2005;75:6-21.

56. Goldenberg DL, Burckhardt C, Crofford L. Management of fibromyalgia syndrome. JAMA 2004; 292:2388-95.

57. Hauser W, Bernardy K, Uceyler N, Sommer C. Treatment of fibromyalgia syndrome with antidepressants: a meta-analysis. JAMA 2009;301:198-209.

58. Hauser W, Petzke F, Sommer C. Systematic Review with Metaanalysis: Comparative Efficacy and Harms of Duloxetine, Milnacipran, and Pregabalin in Fibromyalgia Syndrome. J Pain 2010;11:505-21.

59. Nishishinya B, Urrutia G, Walitt B, Rodriguez A, Bonfill X, Alegre C, et al. Amitriptyline in the treatment of fibromyalgia: a systematic review of its efficacy. Rheumatology (Oxford) 2008;47:1741-6.

60. Sommer C, Hauser W, Berliner M, Bruckle W, Ehlers S, Monkemoller K, et al. [Pharmacological treatment of fibromyalgia syndrome]. Schmerz 2008;22:313-23.

61. Busch AJ, Schachter CL, Overend TJ, Peloso PM, Barber KA. Exercise for fibromyalgia: a systematic review. J Rheumatol 2008;35:1130-44.

62. Carville SF, Arendt-Nielsen S, Bliddal H, Blotman F, Branco JC, Buskila D, et al. EULAR evidence-based recommendations for the management of fibromyalgia syndrome. Ann Rheum Dis 2008;67:536-41.

63. Glombiewski JA, Sawyer AT, Gutermann J, Koenig K, Rief W, Hofmann SG. Psychological treatments for fibromyalgia: a meta-analysis. Pain 2010;151:280-95.

64. Hauser W, Klose P, Langhorst J, Moradi B, Steinbach M, Schiltenwolf M, et al. Efficacy of different types of aerobic exercise in fibromyalgia syndrome: a systematic review and meta-analysis of randomised controlled trials. Arthritis Res Ther 2010;12:R79.

65. van Koulil S, Effting M, Kraaimaat FW, van Lankveld W, van Helmond T, Cats $H$, et al. Cognitivebehavioural therapies and exercise programmes for patients with fibromyalgia: state of the art and future directions. Ann Rheum Dis 2007;66:571-81.

66. Williams DA. Psychological and behavioural therapies in fibromyalgia and related syndromes. Best Pract Res Clin Rheumatol 2003;17:649-65.

67. Williams DA. Psychological and behavioural therapies in fibromyalgia and related syndromes. Best Pract Res Clin Rheumatol 2003;17:649-65.

68. Thieme K, Gracely RH. Are psychological treatments effective for fibromyalgia pain? Curr Rheumatol Rep 2009;11:443-50.

69. Bennett R, Nelson D. Cognitive behavioral therapy for fibromyalgia. Nat Clin Pract Rheumatol 2006;2: 416-24.

70. Bernardy K, Fuber N, Kollner V, Hauser W. Efficacy of cognitive-behavioral therapies in fibromyalgia syndrome - a systematic review and metaanalysis of randomized controlled trials. J Rheumatol 2010; 37:1991-2005.

71. Turk DC. Combining somatic and psychosocial treatment for chronic pain patients: perhaps $1+1$ does = 3. Clin J Pain 2001;17:281-3.

72. Rossy LA, Buckelew SP, Dorr N, Hagglund KJ, Thayer JF, Mclntosh MJ, et al. A meta-analysis of fibromyalgia treatment interventions. Ann Behav Med. 1999;21:180-91.

73. Hauser W, Bernardy K, Arnold B, Offenbacher M, Schiltenwolf M. Efficacy of multicomponent treatment in fibromyalgia syndrome: a meta-analysis of randomized controlled clinical trials. Arthritis Rheum 2009;61:216-24. 
74. Karjalainen $K$, Malmivaara A, van Tulder $M$, Roine $R$, Jauhiainen $M$, Hurri $H$, et al. Multidisciplinary rehabilitation for fibromyalgia and musculoskeletal pain in working age adults. Cochrane database of systematic reviews Online Update Software 2000(2):Cd001984.

75. Sim J, Adams N. Systematic review of randomized controlled trials of nonpharmacological interventions for fibromyalgia. Clin J Pain 2002;18:324-36.

76. Astin JA, Berman BM, Bausell B, Lee WL, Hochberg M, Forys KL. The efficacy of mindfulness meditation plus Qigong movement therapy in the treatment of fibromyalgia: a randomized controlled trial. J Rheumatol 2003;30:2257-62.

77. Cedraschi C, Desmeules J, Rapiti E, Baumgartner E, Cohen P, Finckh A, et al. Fibromyalgia: a randomised, controlled trial of a treatment programme based on self management. Ann Rheum Dis 2004;63:290-6.

78. King SJ, Wessel J, Bhambhani Y, Sholter D, Maksymowych W. The effects of exercise and education, individually or combined, in women with fibromyalgia. J Rheumatol 2002;29:2620-7.

79. Nicassio PM, Radojevic V, Weisman MH, Schuman C, Kim J, Schoenfeld Smith K, et al. A comparison of behavioral and educational interventions for fibromyalgia. J Rheumatol 1997;24:2000-7.

80. Wigers SH, Stiles TC, Vogel PA. Effects of aerobic exercise versus stress management treatment in fibromyalgia, a 4,5 year prospective study. Scand J Rheumatol 1996(25):77-86.

81. Zijlstra TR, van de Laar MA, Bernelot Moens HJ, Taal E, Zakraoui L, Rasker JJ. Spa treatment for primary fibromyalgia syndrome: a combination of thalassotherapy, exercise and patient education improves symptoms and quality of life. Rheumatology Oxford, England 2005;44:539-46.

82. Keefe FJ, Rumble ME, Scipio CD, Giordano LA, Perri LM. Psychological aspects of persistent pain: current state of the science. J Pain 2004;5:195-211.

83. van der Werf SP, de Vree B, Alberts M, van der Meer JW, Bleijenberg G. Natural course and predicting self-reported improvement in patients with chronic fatigue syndrome with a relatively short illness duration. J Psychosom Res. 2002;53:749-53.

84. Hill J. Patient satisfaction in a nurse-led rheumatology clinic. J Adv Nurs 1997;25:347-354.

85. Hill J, Bird HA, Harmer R, Wright V, Lawton C. An evaluation of the effectiveness, safety and acceptability of a nurse practitioner in a rheumatology outpatient clinic. Brit J Rheumatol 1994;33:283-8.

86. Temmink D, Hutten JB, Francke AL, Rasker JJ, Abu Saad HH, van der Zee J. Rheumatology outpatient nurse clinics: a valuable addition? Arthritis Rheum 2001;45:280-6.

87. Tijhuis GJ, Zwinderman AH, Hazes JM, Breedveld FC, Vliet Vlieland PMT. Two year follow up of a randomized controlled trial of a clinical nurse specialist intervention, inpatient, and day patient team care in rheumatoid arthritis. J Adv Nurs 2003;41:34-43.

88. Tijhuis GJ, Zwinderman AH, Hazes JM, Van Den Hout WB, Breedveld FC, Vliet Vlieland TP, et al. A randomized comparison of care provided by a clinical nurse specialist, an inpatient team, and a day patient team in rheumatoid arthritis. Arthritis Rheum 2002;47:525-31.

89. Hill J, Thorpe R, Bird H. Outcomes for patients with RA: a rheumatology nurse practitioner clinic compared to standard outpatient care. Musculoskeletal care 2003;1:5-20.

90. Hill J. The outcome of OA patients from a nurse-led clinic. Ann Rheum Dis 2004;63(suppl):6.

91. Hill J. Rheumatology nurse specialists--do we need them? Rheumatology 2007;46:379-81.

92. Meadows A, Sheehan NJ. Prescribing and injecting: the expanding role of the rheumatology nurse. Musculoskeletal Care 2005;3:176-8.

93. Vrijhoef HJ, Spreeuwenberg C, Eijkelberg IM, Wolffenbuttel BH, van Merode GG. Adoption of disease management model for diabetes in region of Maastricht. BMJ 2001;323:983-5. 



\section{Chapter 2}

Specialized rheumatology nurses can substitute for rheumatologists in the diagnostic process of fibromyalgia

A randomized controlled trial

MEAL Kroese, GJC Schulpen, MCM Bessems, JL Severens, FJ Nijhuis, PP Geusens, RBM Landewé Arthritis Care \& Research 2008;59:1299-1305 


\section{Abstract}

\section{Objective}

To evaluate to what extent specialized rheumatology nurses (SRNs) can substitute for rheumatologists (RMTs) in diagnosing fibromyalgia (FM).

\section{Methods}

Referred patients with symptoms of FM ( $n=193)$ were randomized to a study group (SRN) $(n=97)$ or a control (RMT) group ( $n=96)$. The SRN patients were seen within 3 weeks by a SRN who took structured history and initiated routine lab tests. During a 5-minute supervision session, the RMT was informed by the SRN about medical history, performed a brief physical examination and confirmed or rejected the diagnosis of the SRN. The RMT patients were invited for a RMT visit after a regular waiting period of 3 months.

Outcome measures were initial agreement between SRN and RMT in SRN group, final diagnosis after 12-24 months follow-up, patient satisfaction, and diagnostic costs.

\section{Results}

The mean waiting time after randomization was 2.8 weeks in SRN group and 12.1 weeks in RMT group. Eight patients cancelled their appointment because of the waiting time (all RMT group). Excellent agreement ( $\mathrm{k}=0.91$ ) between RMT and SRN was found. After 12-24 months follow-up, none of the initial diagnoses was recalled in either group. Patients in the SRN group were significantly more satisfied than patients in the RMT group. Mean diagnostic costs were lower in the SRN group than in the RMT group (€219 vs. €281; 95\% UI €-103 to €-20).

\section{Conclusion}

Substituting SRNs for RMTs in the diagnostic process of FM is a trustworthy and successful approach, which saves waiting time, provides greater patient satisfaction and is cost-effective. 


\section{Introduction}

Fibromyalgia (FM) is a common benign musculoskeletal disorder characterized by widespread pain, stiffness, fatigue, depressed mood and disturbed sleep ${ }^{1}$. It occurs in $5 \%-6 \%$ of adults presenting at general medical and family practice clinics ${ }^{2,3}$. The cause of FM is still largely unknown. In a rheumatology outpatient clinic, FM is the diagnosis in $15 \%-30 \%$ of the new referrals ${ }^{3-6}$. The role of medical specialists (rheumatologists) in the care of patients with FM is limited; $90 \%$ of FM patients are referred back to their $\mathrm{GP}^{7}$. In light of the high number of patients with FM, the shortage of rheumatologists and the substantial time demands per patient, it is arguable whether the rheumatologist (RMT) should have the primary role in establishing a diagnosis of FM. Possibly, other trained health care workers, like the specialized rheumatology nurse (SRN), can contribute in the diagnostic process.

Over the last decade, the role of specialized nurses has evolved. Apart from their role in providing clinical care and education specialized nurses may also assist the physician in the care for patients with chronic but stable diseases ${ }^{8-17}$. In this study we have extended this task and investigated whether SRNs could assist in making a diagnosis of FM.

There are many potential advantages of appointing the SRN in such a new role: the waiting time to a first visit may be shortened and the RMT might dedicate more time to patients who need specialized medical care. Furthermore, a timely diagnosis of FM may help in reassuring the patient, in keeping him at work, in preventing loss of participation, and in limiting medical costs. Finally, referring to the SRN's specific competencies, the nurse may be able to provide better care to patients with FM than medical specialists.

To test these hypotheses, we have performed a randomized controlled trial in which the diagnostic visit performed by a SRN within 3 weeks after referral was compared with the diagnostic visit led by a RMT after a regular waiting period of approximately 3 months. Since important medical conditions may initially present with symptoms of $\mathrm{FM}$, and only become manifest after some time, all patients were followed for at least 1 year $^{18}$. In doing so, we evaluated the initial agreement between the SRN and the RMT in the SRN group, the final diagnosis after 12-24 months of follow-up, patient satisfaction, and costs.

\section{Patients and Methods}

\section{Subjects}

Patients who were referred by the GP to the rheumatology outpatient clinic of the Maastricht University Hospital, with a written referral letter expressing symptoms of FM as assessed by an uninvolved RMT, were recruited between December 2003 and November 2005. Participation was proposed to 264 consecutive patients. The inclusion criteria were: suspicion of FM, first referral to the rheumatology outpatient clinic, aged between 18 and 65 years, and the ability of reading and writing the Dutch 
language. Exclusion criteria were: severe co-morbidity and involvement in a legal procedure because of a disability pension.

The protocol was approved by the local ethics committee of the Maastricht University Hospital and University of Maastricht, and is registered under number ISRCTN77212411. Written informed consent was obtained from all participants.

\section{Study design}

Patients were randomized to a study group (SRN) or a control (RMT) group. The assignment was performed in blocks of 20 , split into SRN group $(n=10)$ or RMT group $(n=10)$. Randomisation was made by means of a computer generated random number table. An independent person who was not responsible for determining the participants eligibility provided sequentially numbered, sealed, and opaque envelops. The SRN patients were seen within 3 weeks by experienced SRNs $(n=2)$ who were trained in the diagnosis of FM. The SRN used a checklist in detecting symptoms of FM as well as conditions that should be excluded. The training included a brief explanation about the checklist and limited education about rheumatological conditions that may present with FM-like symptoms. An English translation of this checklist can be obtained via the first author. The SRN initiated a routine blood test to asses levels of haemoglobin, erythrocyte sedimentation rate, C-reactive protein, thyroid-stimulating hormone, serum alkaline phosphatase and serum creatinine. The content of this routine blood test was agreed upon by consensus in a panel of five RMTs before the start of the study. During a standardised 5-minute supervision session, immediately following the SRN consultation, a RMT who was involved in the study was informed by the SRN about the medical history. Furthermore, the RMT performed a brief and applied physical examination, and confirmed or rejected the diagnosis made by the SRN.

Patients in the control group were seen in a regular clinical visit by a RMT after a waiting period of about 3 months. This visit included extensive history taking, physical examination, and additional tests if considered necessary in the opinion of the RMT. In both groups FM was diagnosed according to the American College of Rheumatology criteria ${ }^{1}$.

\section{Assessments}

Outcome measures were the initial agreement between the SRN and RMT in the SRN group, the final diagnosis after 12-24 months follow-up, patient satisfaction, and diagnostic costs.

The judgements of SRN and RMT were measured by a questionnaire, completed after the diagnostic visit. The level of agreement was assessed by comparing these scores. The SRN as well as the RMT judged independently whether a diagnosis of FM was appropriate and how confident they were of their judgement on a $100 \mathrm{~mm}$ Visual Analogue Scale (VAS). The SRN also rated the need for supervision by the RMT on a $100 \mathrm{~mm}$ VAS. 
In order to investigate whether an important diagnosis was missed, the patients' medical files were investigated and the patients were asked about a change in diagnosis or additional diagnoses by telephone (MK) , 12-24 months after the first visit. In cases of inconsistencies between both approaches, the GP was contacted for further information.

Patient satisfaction was measured 1 week after the first consultation with questions derived from the QUOTE(Quality of Care Through the Patient's Eyes)-RheumaticPatients ${ }^{19}$. Quality of care from the perspective of patients was assessed in two phases. First, patients were asked to rate the relative importance (I) of the specific care aspects (e.g. 'the rheumatologist should know my problems very well') on a 4-item numerical rating scale, and second to rate the actual performance $(P)$ of the care provider on each care aspect (e.g. 'my rheumatologist knows my problems very well') on a 4-item numerical rating scale. The response categories were 'totally agree', 'agree', 'disagree', 'totally disagree'. 'Quality of health care from the patients' perspective' (Q) was operationalized as the product of importance (I) and (perceived) performance $(P)$, according to the formula: $Q=1 \times P^{19,20}$. The 1 categories were transformed and expressed as values between 0 and 10 . The $P$ response categories were dichotomized into percentages 'yes' and 'no'. P represents the proportion of respondents who were not satisfied with the care received. Q-values $\geq 1$ reflect care aspects that could be improved. $Q=1$ reflects a scenario with a mean I score of 6.5 , and $15 \%$ of the patients which reporting a negative experience ${ }^{21-23}$.

For the calculation of the diagnostic costs, we used the tariffs of the Dutch National Health Tariffs Authority (CTG) of 2006. The tariff for the SRN is $€ 60.80$ per hour and for the RMT $€ 147.00$ per hour. Overhead costs were not taken into consideration. The first visit led by the SRN as well as the second visit took approximately one hour each. The first visit led by the RMT took 45 minutes, a follow-up visit took 15 minutes, and a consultation by telephone was estimated at 10 minutes. Concerning the lab tests, fee and order tariffs were included. Regarding the function tests, fees were also included. Patients in the RMT group who cancelled their appointment were excluded from cost analysis.

\section{Sample size}

A pilot study has shown that patients rated the acceptability of a 3-month waiting time for a first visit led by a RMT on a numerical rating scale (NRS) from zero (unacceptable) to 10 (extremely acceptable) as 4.9 (2.2) (mean (SD)). In order to statistically support a difference of $20 \%$ ( 1 unit on a NRS) or more in favour of the SRN group (with significantly less waiting time) a sample size of 93 patients per group was required (two-sided $\alpha=0.05 ; \beta=0.10$ ).

\section{Statistical analysis}

Differences between both groups were analyzed by Chi-square test for categorical data and by $t$-test for continuous data. The Kappa statistic was used to test the agreement between the SRN and RMT. Associations were tested by Pearson 
correlation coefficients. Statistical significance for all analyses was set at $P<0.05$. Between-group difference in diagnostic costs was analyzed by non-parametric bootstrap simulations ${ }^{24}$. In a bootstrap simulation, a sample of cost pairs of equal size of the original sample is selected a 1000 times at random with replacement. From these data 95\% uncertainty intervals (UIs) for cost differences were calculated based on the $2.5^{\text {th }}$ and $97.5^{\text {th }}$ percentiles.

Statistical analysis was performed using SPSS version 11.5 (SPSS Inc., Chicago, IL).

\section{Results}

Figure 2.1 is the flow chart of the study. Seventy seven percent of the patients that were initially considered eligible to the trial were randomized. Reasons for ineligibility were no response $(n=23)$, language problems $(n=4)$ and refusal to participate $(n=29)$. Of the 193 randomized patients, 97 were allocated to the SRN group, and 96 to the RMT group. Of all patients included in the trial, $98.5 \%$ could be followed for final diagnosis after 12-24 months follow-up.



Figure 2.1 Flow chart of the study.

SRN = specialized rheumatology nurse; RMT = rheumatologist. 
Comparison of patient characteristics showed no meaningful differences between the SRN and the RMT group (Table 2.1). The majority of the patients were female. The mean (SD) age was 44.1 (11.1) and 44.7 (11.9) years in the SRN and RMT groups respectively. Half of the patients had a low educational level, most of the patients had a family with a partner and/or children, and $56 \%$ of the patients in the SRN group vs. $42 \%$ in the RMT group had a paid job. The mean (SD) duration of the complaints at presentation was 6.1 (7.2) years in the SRN group and 5.7 (6.8) years in the RMT group. Most patients ( $86 \%$ in the SRN and $79 \%$ in the RMT group) indicated additional health problems. Particularly musculoskeletal conditions ( $57 \%$ vs. $54 \%$ ), psychosocial ( $27 \%$ vs. $29 \%$ ), neurological ( $27 \%$ vs. $29 \%$ ) and pulmonary ( $26 \%$ vs. $23 \%$ ) complaints were reported.

There were no differences in socio-demographic characteristics at baseline between the patients lost to follow-up and those who completed the follow-up examination in either group.

Table 2.1 Characteristics of randomized patients $(n=193)^{*}$

\begin{tabular}{lcc}
\hline & SRN group $(\mathrm{n}=97)$ & RMT group $(\mathrm{n}=96)$ \\
\hline Age, mean \pm SD years & $44.1 \pm 11.1$ & $44.7 \pm 11.9$ \\
Female & $80(82.5)$ & $81(84.4)$ \\
Level of education & & $48(50.0)$ \\
Low & $58(59.2)$ & $33(34.4)$ \\
Middle & $32(32.7)$ & $15(17.6)$ \\
High & $8(8.1)$ & \\
Living situation & & $29(30)$ \\
Together with partner & $41(42)$ & $38(40)$ \\
Together with partner and children & $36(37)$ & $5(5)$ \\
Without partner, with children & $4(4)$ & $16(17)$ \\
Alone & $12(12)$ & $5(5)$ \\
Together with parents & $2(2)$ & $3(3)$ \\
Other & $2(2)$ & $40(42)$ \\
Paid job & $54(56)$ & $5.7 \pm 6.8$ \\
Duration of symptoms, mean \pm SD years & $6.1 \pm 7.2$ & $76(79)$ \\
Patient-reported comorbidity & $83(86)$ & \\
\hline
\end{tabular}

* Values are the numbers (percentage) unless otherwise indicated; SRN = specialized rheumatology nurse; RMT = rheumatologist.

The mean (SD) waiting time after randomization was $2.8(1.6)$ weeks in the SRN group and 12.1 (3.5) weeks in the RMT group $(P \leq 0.0001)$. In the RMT group, 8 patients cancelled their appointment because of the long waiting time. Six of them went to a rheumatology clinic in another hospital, one patient had no complaints anymore and one other patient was lost to follow-up.

In the SRN group, the initial agreement between the SRN and the RMT with regard to the diagnosis was 0.91 (95\% Cl: 0.78-1.00). The mean (SD) level of confidence with respect to the diagnosis was 74.1 (19.4) for the SRN and 84.8 (13.7) for the RMT. The mean (SD) level of perceived need for supervision as rated by the SRN was 60.5 (27.7). There was a positive association $(r=0.48 ; P<0.01)$ between the level of confidence of 
the SRN and the RMT and a negative association between the level of confidence of the SRN in the diagnosis and the perceived need for supervision $(r=-0.44 ; P<0.001)$.

FM was more frequently diagnosed in the SRN group $(P=0.001)$, while FM in conjunction with another musculoskeletal condition was more frequently diagnosed in the RMT group (Table 2.2). Five patients ( 1 in the SRN group and 4 in the RMT group) were diagnosed with an inflammatory rheumatological condition, and 12 patients ( 5 in the SRN group and 7 in the RMT group) were diagnosed with a nonrheumatological condition. After 12-24 months (median 18 months) follow-up, 6 initial diagnoses in 6 patients were changed: 3 patients (1 in SRN group with an initial diagnosis of low back pain and 2 in RMT group, one with an initial diagnosis of carpal tunnel syndrome and one with an initial diagnosis of periarthritis humeroscapularis) were finally diagnosed as having FM by a RMT. In 3 patients with FM (all in the SRN group), an additional musculoskeletal diagnosis was made: low back pain $(n=1)$, axial osteoarthritis $(n=1)$, and pseudoradicular syndrome $(n=1)$.

Table 2.2 Diagnosis at consultation*

\begin{tabular}{|c|c|c|c|c|}
\hline & \multicolumn{2}{|c|}{ SRN group $(n=97)$} & \multicolumn{2}{|c|}{ RMT group $(n=96)$} \\
\hline Fibromyalgia diagnoses & $89(92)$ & & $70(73)$ & \\
\hline Fibromyalgia alone & 75 & $(84)$ & 46 & (66) \\
\hline Fibromyalgia plus additional diagnosis & 14 & $(16)$ & 24 & (34) \\
\hline Rheumatological & & $11(79)$ & & $18(75)$ \\
\hline Inflammatory† & & 1 & & 1 \\
\hline Degenerative $\ddagger$ & & 4 & & 8 \\
\hline Other soft tissue disorders§ & & 6 & & 9 \\
\hline Non-rheumatological" & & $3(21)$ & & $6(25)$ \\
\hline Other diagnosis & $8(8)$ & & $25(26)$ & \\
\hline Rheumatological & 6 & $(75)$ & & (88) \\
\hline Inflammatory ${ }^{\dagger}$ & & 0 & & 3 \\
\hline Degenerative $\ddagger$ & & 1 & & 8 \\
\hline Other soft tissue disorders§ & & 5 & & 11 \\
\hline Non-rheumatologicalף & 2 & (25) & & (4) \\
\hline No complaints & 0 & (0) & 2 & (8) \\
\hline Unknown & $0(0)$ & & $1(1)$ & \\
\hline
\end{tabular}

* Values are the numbers (percentage); SRN = specialized rheumatology nurse; RMT = rheumatologist; $\dagger$ inflammatory diseases: case of undifferentiated arthritis with tenosynovitis $(n=1), \operatorname{RA}(n=1)$, spondylarthropathy $(n=1)$, psoriatic arthritis $(n=1)$, tophaceous gout $(n=1)$; $¥$ degenerative diseases: osteoarthritis of peripheral joints $(n=15)$, osteoarthritis and idiopathic carpal tunnel syndrome $(n=1)$; osteoarthritis of the hip $(n=1)$, axial osteoarthritis $(n=5)$; $\S$ other soft tissue disorders: periarthritis humeroscapularis $(n=5)$, chronic low back pain $(n=2)$, localised tendinopathy $(n=1)$, hypermobility syndrome $(n=6)$, bursitis $(n=1)$, retropatellar chondropathy $(n=1)$, Dupuytren's disease $(n=1)$, postural abnormality $(n=5)$, myalgia accompanying the use of statins $(n=1)$, undifferentiated articular pain $(n=1)$, localised pain $(n=1)$, non-specific myalgia $(n=1)$, athralgia $(n=4)$; ๆ non-rheumatological: hypothyroidism $(n=1), G^{\prime}$ raves' disease $(n=1)$, Sicca syndrome $(n=2)$, primary Raynaud's syndrome $(n=1)$, idiopathic carpal tunnel syndrome $(n=2)$, chronic fatigue syndrome $(n=1)$, depression $(n=1)$, high blood pressure $(n=1)$, hepatitis and psoriasis $(n=1)$. 
Table 2.3 shows the results of the QUOTE-based patient satisfaction questionnaire. In both groups, most indicators are rated relatively high (>8). Patients in the SRN group rated 'to be taken seriously' as most important, while patients in the RMT group rated 'hearing the findings at the end of the consultation' as most important. Patients rated a waiting time of 3 weeks for the SRN with 7.1, and a waiting time of 3 months for the RMT with $2.7(P<0.0001)$.

The actual performance of the SRN and RMT from the patient's perspective can be deduced from the ' $P$ ' columns. In general, the performance of the RMT was rated lower than the performance of the SRN. Patients especially missed 'usable advices' (62\% of the RMT group as compared with $20 \%$ of the SRN group $(P<0.0001)$ ) and 'attention of the health professional for the (psycho)social aspects of the illness' (39\% of the RMT group as compared with $8 \%$ of the SRN group $(P<0.0001))$. Approximately $70 \%$ of the patients in the RMT group considered 3 months waiting time for the RMT unacceptable.

Table 2.3 I scores, P scores and Q scores for the QUOTE-based questionnaire*

\begin{tabular}{|c|c|c|c|c|c|c|}
\hline & \multicolumn{3}{|c|}{ SRN group $(n=94)$} & \multicolumn{3}{|c|}{ RMT group $(n=85)$} \\
\hline & 1 & $\mathrm{P}$ & Q & 1 & $P$ & Q \\
\hline \multicolumn{7}{|l|}{ The SRN/RMT should } \\
\hline Take me seriously & 9.0 & 0.00 & 0.00 & 8.6 & 0.02 & 0.17 \\
\hline Know my problems very well & 8.1 & 0.20 & 1.62 & 8.3 & 0.23 & 1.90 \\
\hline Take enough time for me & 8.4 & 0.00 & 0.00 & 8.0 & 0.11 & $0.88^{\dagger}$ \\
\hline Take care that I can tell my story & 8.3 & 0.01 & 0.08 & 8.5 & 0.12 & $1.02+$ \\
\hline Tell his findings at the end of the consultation & 8.3 & 0.03 & 0.25 & 8.8 & 0.09 & 0.79 \\
\hline $\begin{array}{l}\text { Pay attention to the (psycho)social aspects of } \\
\text { my illness }\end{array}$ & 7.6 & 0.08 & 0.61 & 7.4 & 0.39 & $2.87 \ddagger$ \\
\hline Give clear information about my disorder & 8.6 & 0.03 & 0.26 & 8.4 & 0.18 & $1.51+$ \\
\hline Give usable advises & 8.4 & 0.20 & 1.68 & 8.2 & 0.62 & $5.08 \ddagger$ \\
\hline $\begin{array}{l}\text { A waiting time of } 3 \text { weeks for the SRN is } \\
\text { acceptable }\end{array}$ & 7.1 & 0.05 & 0.36 & & & \\
\hline $\begin{array}{l}\text { A waiting time of } 3 \text { months for the RMT is } \\
\text { acceptable }\end{array}$ & & & & 2.7 & 0.69 & $1.86 \ddagger$ \\
\hline
\end{tabular}

* $\mathrm{I}=$ importance (mean score on a scale ranging $0-10$ ); $\mathrm{P}=$ performance (proportion of respondents who did not perceive the item as being done by the SRN/RMT); $Q=$ quality impact (I x P); QUOTE = Quality of Care Through the Patient's Eyes; SRN = specialized rheumatology nurse; RMT = rheumatologist; $+P \leq 0.01 ; \ddagger P<0.0001$.

The relative impact of priorities and performances on quality of care can be deduced from the ' $Q$ ' columns. In the RMT group, the importance of 'giving usable advises' is valued $8.2 ; 62 \%$ of the patients reported that the RMT did not give usable advises. The quality impact is rather high $(Q=4.96)$ as a result of the product of a high importance score and a low performance score. Six of the nine indicators scored significantly better in the SRN group than in the RMT group.

Patients in the SRN group felt more reassured ( $P=0.003)$. In the RMT group, $78.3 \%$ of the patients indicated in retrospect, that they would have preferred a specialized 
nurse, if they would have had the option. In contrast, in the SRN group only $6.7 \%$ indicated that they would have preferred the RMT. The supervision of the rheumatologist was considered of additional value by $88 \%$ of the patients in the SRN group.

Table 2.4 shows the costs of the diagnostic process for both groups. The mean costs for the consultations with the RMT and/or the SRN were $€ 162$ in the SRN group and $€ 210$ in the RMT group ( $95 \% \mathrm{UI} €-75$ to $€-22$ ). Although the patients in the SRN group had fewer contacts with a RMT or SRN than patients in the RMT group (2.5 vs. 3.1 contacts (group means) respectively; $P=0.058$ ), the visits in the SRN group took more time than the visits in the RMT group (145 vs. 124 minutes (group means) respectively; $P=0.072$ ). Mainly because of the standard routine blood test in the SRN group, the mean costs of lab tests were higher in the SRN group (SRN group: €44; RMT group: $€ 23 ; 95 \% \mathrm{UI} € 12$ to $€ 30$ ). The mean costs of additional tests were in general low, but higher in the RMT group (€48 vs. $€ 14 ; 95 \%$ UI $€-54$ to $€-13$ ). Mean total costs were lower in the SRN group than in the RMT group (€219 per patient vs. €282 per patient; $95 \%$ UI $€-103$ to $€-20$ ). Similar analyses in terms of the amount of time, the number of contacts and costs limited to FM patients only showed identical results.

Table 2.4 Mean costs of the diagnostic process $(€)^{*}$

\begin{tabular}{lcccc}
\hline & $\begin{array}{c}\text { SRN group } \\
(\mathrm{n}=97)\end{array}$ & $\begin{array}{c}\text { RMT group } \\
(\mathrm{n}=88) \dagger\end{array}$ & $\begin{array}{c}\text { Mean } \\
\text { difference }\end{array}$ & 95\% UI \\
\hline Consultation with SNR and/or RMT & 162 & 210 & -48 & $-75,-22 \ddagger$ \\
Blood tests & 44 & 23 & 21 & $12,30 \ddagger$ \\
Function tests & 14 & 48 & -34 & $-54,-13 \ddagger$ \\
Total & 219 & 281 & -62 & $-103,-20 \ddagger$ \\
\hline
\end{tabular}

* SRN = specialized rheumatology nurse; RMT = rheumatologist; UI = uncertainty interval based on bootstrap replications; + eight patients cancelled the diagnostic consultation at the outpatient clinic; $¥$ significant difference.

\section{Discussion}

SRNs are effective, well received and cost-effective in the diagnosis and care of FM in patients referred to the RMT with generalised musculoskeletal complaints. The SRN approach saved waiting time for the patients, improved satisfaction of the patients and the rheumatologist, and was cheaper compared with a regular consultation, while there was no indication at follow-up that medically important diagnoses had been missed by the SRN.

SRNs are often deployed in processes that involve monitoring of patients with chronic diseases, or care processes. Their role in the diagnostic process is usually rather limited. For example, we have found a study showing that a trained headache nurse specialist can adequately diagnose tension-type headache and migraine, with a high agreement in diagnosis between the nurse and the doctor, in analogy with our study ${ }^{25}$. Two other studies found acceptable levels of agreement between a nurse and 
a RMT in recognising early arthritis (kappa: 0.79) and diagnosing musculoskeletal disorders of the upper limb (kappa: $0.66-1.00)^{26,27}$. Importantly, our study did not indicate that certain diagnoses were better recognised by the RMT than by the SRN, or that they were missed by the SRN: none of the diagnoses were changed during follow-up and only six additional (musculoskeletal) diagnoses were made.

The difference in the proportion of patients with a diagnosis of FM between the SRN and RMT group seems relevant. The proportion of patients with a diagnosis of FM was higher in the SRN group. One of the possibilities is that the RMT is more thorough in the diagnostic process. A second explanation is that the RMT tried to avoid making a diagnosis of FM. A third explanation could be that during the SRN approach the focus is on FM (yes or no) both with the SRN and with the supervising RMT, whereas the RMT during a regular visit may be more open to other diagnoses.

Before the study started, it was hypothesized that the 'unbiased approach' of the RMT might lead to a higher percentage of medically important diagnoses, such as inflammatory rheumatic diseases, in the RMT group. What we actually have found is that RMTs more often than SRNs rejected a diagnosis of FM, but not in favour of inflammatory or systemic rheumatic diseases, or unrelated but medically important diseases. They also did not choose the option of no diagnosis. They rather made a diagnosis of degenerative rheumatological condition or a condition belonging to the spectrum of soft-tissue disorders. This observation may reflect a better insight of the RMT in the entire spectrum of musculoskeletal problems as compared with the SRN, but does not necessarily reflect better patient care, since the impact of these diagnoses on general health is unknown.

Patients were very satisfied with this new diagnostic approach. The satisfaction scores overall were far better for the SRN group as they were for the RMT group. These findings are congruent with findings in the literature. Several studies have reported a higher level of patient satisfaction in favour of the specialized nurse $e^{8,9,28}$. However, a systematic review has concluded that patients are more satisfied with care provided by a nurse practitioner as compared with a doctor, whilst health outcomes were not different ${ }^{29}$. Although patients were very satisfied with the care of the SRN, it is fair to say that with respect to 'giving usable advices' and 'knowing problems very well' room for improvement exists.

Deploying SRNs in the diagnostic process was also more efficient in our study. A number of studies in the literature show the same trend. Venning et al. reported that in their study the clinical care and health service costs of nurse practitioners and GPs were similar, but nurse practitioners could be more cost-effective than GPs if they could reduce the number of visits or shorten the duration of the visits ${ }^{30}$. In the study by Van den Hout et al., the clinical nurse specialist was shown to provide equivalent effects on quality of life and utility, but at a lower cost ${ }^{31}$.

A number of limitations pertaining to design and interpretation of results should be recognised. First of all, the accuracy of the diagnosis made by the SRN and RMT could not be appropriately determined, There is still a possibility that the follow-up duration was too short. Further, at this moment we do not have information about the effects of the reduced waiting time and nurse-led diagnostic consultation on quality of life, 
disability, social participation and medical consumption. Concerning the generalizability of our results to other rheumatology outpatient clinics, it is expected that the added value of a SRN-led diagnostic consultation depends on the skills, competence and experience of both the SRN and RMT. Besides, the organisation of the outpatient clinic (e.g., duration of visits, overhead costs) determines the amount of cost and time that can be saved.

Further research has to reveal whether the SRN can also be deployed in the diagnostic process of other common musculoskeletal conditions, such as osteoarthritis. Such an approach will irrefutably imply a redefinition of professional competencies, applied training and a redistribution of clinical responsibilities.

In conclusion, the results of this study show that substitution of the RMT by a SRN in the diagnostic process of patients referred by the GP with signs and symptoms of FM is a feasible and successful alternative for the regular physician-led consultation. 


\section{References}

1. Wolfe F, Smythe HA, Yunus MB, Bennett RM, Bombardier C, Goldenberg DL, et al. The American College of Rheumatology 1990 Criteria for the Classification of Fibromyalgia. Report of the Multicenter Criteria Committee. Arthritis Rheum 1990;33:160-72.

2. Goldenberg DL, Simms RW, Geiger A, Komaroff AL. High frequency of fibromyalgia in patients with chronic fatigue seen in a primary care practice. Arthritis Rheum 1990;33:381-7.

3. Wolfe F, Ross K, Anderson J, Russell IJ, Hebert L. The prevalence and characteristics of fibromyalgia in the general population. Arthritis Rheum 1995;38:19-28.

4. Martin L, Nutting A, Maclntosh BR, Edworthy SM, Butterwick D, Cook J. An exercise program in the treatment of fibromyalgia. J Rheumatol 1996:1050-1053.

5. Vosse D. Referral patterns to the rheumatology outpatient department of the University Hospital Maastricht. Maastricht; 2007.

6. Vanhoof J, Declerck K, Geusens P. Prevalence of rheumatic diseases in a rheumatological outpatient practice. Ann Rheum Dis 2002;61:453-5.

7. Kroese ME, Schulpen GJ, Sonneveld HM, Vrijhoef HJ. Therapeutic approaches to fibromyalgia in the Netherlands: a comparison between 1998 and 2005. J Eval Clin Pract 2008;14:321-5.

8. Hill J. Patient satisfaction in a nurse-led rheumatology clinic. J Adv Nurs. 1997;25:347-354.

9. Hill J, Bird HA, Harmer R, Wright V, Lawton C. An evaluation of the effectiveness, safety and acceptability of a nurse practitioner in a rheumatology outpatient clinic. Br J Rheumatol 1994;33: 283-8.

10. Temmink D, Hutten JB, Francke AL, Rasker JJ, Abu Saad HH, van der Zee J. Rheumatology outpatient nurse clinics: a valuable addition? Arthritis Rheum 2001;45:280-6.

11. Tijhuis GJ, Zwinderman AH, Hazes JM, Breedveld FC, Vliet Vlieland PMT. Two year follow up of a randomized controlled trial of a clinical nurse specialist intervention, inpatient, and day patient team care in rheumatoid arthritis. J Adv Nurs. 2003;41:34-43.

12. Tijhuis GJ, Zwinderman AH, Hazes JM, Van Den Hout WB, Breedveld FC, Vliet Vlieland TP, et al. A randomized comparison of care provided by a clinical nurse specialist, an inpatient team, and a day patient team in rheumatoid arthritis. Arthritis Rheum 2002;47:525-31.

13. Hill J, Thorpe R, Bird H. Outcomes for patients with RA: a rheumatology nurse practitioner clinic compared to standard outpatient care. Musculoskeletal Care 2003;1:5-20.

14. Hill J. The outcome of OA patients from a nurse-led clinic. Ann Rheum Dis 2004;63(suppl):6.

15. Hill J. Rheumatology nurse specialists--do we need them? Rheumatology 2007;46:379-81.

16. Meadows A, Sheehan NJ. Prescribing and injecting: the expanding role of the rheumatology nurse. Musculoskeletal Care 2005;3:176-8.

17. Vrijhoef HJ, Spreeuwenberg C, Eijkelberg IM, Wolffenbuttel BH, van Merode GG. Adoption of disease management model for diabetes in region of Maastricht. British medical journal 2001;323:983-5.

18. Knottnerus JA, Dinant GJ. Medicine based evidence, a prerequisite for evidence based medicine. BMJ 1997;315:1109-10.

19. van Campen C, Sixma HJ, Kerssens JJ, Peters L, Rasker JJ. Assessing patients' priorities and perceptions of the quality of health care: the development of the QUOTE-Rheumatic-Patients instrument. $\mathrm{Br} J$ Rheumatol 1998;37:362-8.

20. Sixma HJ, van Campen C, Kerssens JJ, Peters L. Quality of care from the perspective of elderly people: the QUOTE-elderly instrument. Age Ageing 2000;29:173-8.

21. Sixma HJ, Kerssens JJ, van Campen C, Peters L. Quality of care from the patient's perspective: from theoretical concept to a new measuring instrument. Health Expect 1998;1:82-95.

22. Sixma HJ, van Campen C, Kerssens JJ, Peters L. De QUOTE-vragenlijsten. Kwaliteit van zorg vanuit patientenperspectief; vier nieuwe meetinstrumenten. Onderzoeksprogramma kwaliteit van zorg. Utrecht: NIVEL/ NWO /VWS; 1998.

23. Schouten G, Sixma HJ, Friele RD. Kwaliteit van zorg vanuit het perspectief van mensen met diabetes. Utrecht: NIVEL; 2000.

24. Briggs $\mathrm{AH}$, Wonderling DE, Mooney CZ. Pulling cost-effectiveness analysis up by its bootstraps: a nonparametric approach to confidence interval estimation. Health Econ 1997;6:327-40. 
25. Clarke CE, Edwards J, Nicholl DJ, Sivaguru A, Davies P, Wiskin C. Ability of a nurse specialist to diagnose simple headache disorders compared with consultant neurologists. I Neurol Neurosurg Psychiatry. 2005;76:1170-2.

26. Gormley GJ, Steele WK, Gilliland A, Leggett P, Wright GD, Bell AL, et al. Can diagnostic triage by general practitioners or rheumatology nurses improve the positive predictive value of referrals to early arthritis clinics? Rheumatology 2003;42:763-8.

27. Palmer K, Walker Bone K, Linaker C, Reading I, Kellingray S, Coggon D, et al. The Southampton examination schedule for the diagnosis of musculoskeletal disorders of the upper limb. Ann Rheum Dis 2000;59:5-11.

28. Vrijhoef HJ, Van Den Bergh JH, Diederiks JP, Weemhoff I, Spreeuwenberg C. Transfer of care for outpatients with stable chronic obstructive pulmonary disease from respiratory care physician to respiratory nurse--a randomized controlled study. Chronic illn 2007;3:130-44.

29. Horrocks S, Anderson E, Salisbury C. Systematic review of whether nurse practitioners working in primary care can provide equivalent care to doctors. BMJ 2002;324:819-23.

30. Venning P, Durie A, Roland M, Roberts C, Leese B. Randomised controlled trial comparing cost effectiveness of general practitioners and nurse practitioners in primary care. BMJ 2000;320:1048-53.

31. van den Hout WB, Tijhuis GJ, Hazes JM, Breedveld FC, Vliet Vlieland TP. Cost effectiveness and cost utility analysis of multidisciplinary care in patients with rheumatoid arthritis: a randomised comparison of clinical nurse specialist care, inpatient team care, and day patient team care. Ann Rheum Dis 2003;62:308-15. 


\section{Chapter 3}

\section{Specialized rheumatology nurse substitutes for rheumatologist in the diagnostic process of fibromyalgia}

A cost-consequence analysis alongside a randomized controlled trial

MEAL Kroese, JL Severens, GJC Schulpen, MCM Bessems, FJ Nijhuis, RBM Landewé The Journal of Rheumatology 2011;38:1413-22 


\section{Abstract}

\section{Objective}

To perform a cost-consequence analysis of substituting specialized rheumatology nurses (SRNs) for rheumatologists (RMTs) in the diagnostic process of fibromyalgia (FM), using both a health care and societal perspective and a 9 month time horizon.

\section{Methods}

Alongside a randomized controlled trial, we measured costs and consequences of a nurse-led diagnostic consult (SRN group, $n=97$ ) vs. a rheumatologist-led diagnostic consult (RMT group, $\mathrm{n}=96$ ). Patients were followed for 9 months. Every second month a questionnaire on medical consumption and social participation was filled out. Satisfaction was measured 1 week after the first consultation. During follow-up health status was measured by health related quality of life (EQ-5D), functional status (FIQ), fatigue (CIS-20) and self-efficacy (GSE).

\section{Results}

Patients in the SRN group were significantly more satisfied. Improvements in health status were similar in both groups after 9 months of follow-up. Total costs for health care consumption and patient and family costs were significantly lower in the SRN group (€1298 vs. €1644; difference $€ 346 ; 95 \%$ UI $€-746$ to $€-2$ ). Total societal costs were $€ 3853$ per patient for the SRN group and $€ 5293$ for the RMT group after 9 months of follow-up (difference €1440; $95 \%$ UI $€-3721$ to $€ 577)$.

\section{Conclusion}

From both a health care and societal perspective, the nurse-led diagnostic process is a recommendable approach. Patients in the SRN group were significantly more satisfied, improvements in health status were similar in both groups, and total societal costs were lower for the SRN group compared with the RMT group after 9 months follow-up. 


\section{Introduction}

Fibromyalgia (FM) is a chronic pain disorder characterized by generalised musculoskeletal pain and concomitant symptoms such as fatigue, sleep disturbances, cognitive dysfunction and depression. The prevalence has been estimated at $2 \%$ to $4 \%$ in the general population, comprising $10 \%$ to $20 \%$ of rheumatologic consultations and $5 \%$ to $8 \%$ of primary care consultations ${ }^{1,2}$.

Patients with FM rate their quality of life extremely low compared with other groups of patients ${ }^{3-6}$. FM has a negative impact on social and occupational functioning ${ }^{7}$. The economic burden of FM is considerable because of reduced productivity or ability to work and a high use of health care resources ${ }^{8-15}$.

Patients may repeatedly present to the general practitioner (GP) with various symptoms before a diagnosis of FM is made. This delay may result in repetitive drug prescriptions, multiple diagnostic tests and referrals to medical specialists and other health care providers ${ }^{16}$.

Little is known about the impact of labelling a patient with a diagnosis of FM. There are two schools of thought. A diagnosis of FM may lead to increased illness behaviour, dependence on health care providers, and increased health service $\operatorname{costs}^{17,18}$. A diagnosis of FM, however, may also reduce the number of referrals, use of health care providers, and costs ${ }^{16,19}$.

The importance of a prompt diagnosis in patients who are at risk of developing persistent pain and pain-related behaviour is increasingly recognised ${ }^{20}$. Early diagnosis and intervention may reassure the patient and reduce or prevent disability, which, in turn, will reduce societal and medical costs. Cost savings allowed by a diagnosis are estimated at $€ 126$ (year 2007 values) to $€ 200$ (year 2003 values) per patient per year $^{16,21}$.

Limitations in health care capacity and a high prevalence of FM may jeopardize an early approach. In Maastricht, in the southern part of The Netherlands, this problem was addressed by designing a nurse-led diagnostic process, in which trained specialized rheumatology nurses (SRNs) assist in the diagnostic process and simultaneously provide nursing care such as information, education and support to this group of patients.

Over the last decade, the role of specialized nurses has evolved in undertaking extended activities as patient assessments, formulating and carrying out a plan of disease management, and making referrals to other health professionals ${ }^{22,23}$.

In our previous study on the feasibility of substituting SRNs for rheumatologists (RMTs) in the diagnostic process of FM, we have shown that this approach is safe (no misclassifications), avoids waiting time, provides better patient satisfaction and is cheaper from a health service perspective ${ }^{24}$. However, insight in the full societal consequence of this nurse-led diagnostic process is important for healthprofessionals, health care management, health policy-decision-makers and third party payers. The present study investigates the impact of a timely diagnosis for FM by a SRN on health outcomes, social participation and costs from both a health care and societal perspective. 


\section{Patients and Methods}

\section{Patients}

Between December 2003 and November 2005, we performed a 9-month pragmatic prospective, randomized controlled trial with patients who were referred by their GP to the rheumatology outpatient clinic of the Maastricht University Hospital with a referral letter describing symptoms of FM. Inclusion criteria were suspicion of FM, first referral to the rheumatology outpatient clinic, age between 18 and 65 years, and the ability to read and write the Dutch language. Exclusion criteria were: severe comorbidity and involvement in a legal procedure because of a disability pension. The protocol was approved by the local ethics committee of the University Hospital and University of Maastricht and all participants gave written informed consent.

\section{Intervention}

The procedure of this RCT has been described in detail elsewhere ${ }^{24}$. In brief, patients were randomly assigned to either the nurse-led diagnostic consultation (SRN group) or to the regular physician-led diagnostic consultation (RMT group). The SRN patients were seen within 3 weeks by experienced SRNs $(n=2)$ who were trained in the diagnosis of FM. During the consultation, the SRN used a checklist in detecting symptoms of FM as well as conditions that should be excluded. Also a routine blood test was initiated. In a standardised 5-minute supervision session, immediately following the SRN consultation, a RMT who was involved in the study was informed by the SRN about the medical history. Furthermore, the RMT performed a brief and applied physical examination, and confirmed or rejected the diagnosis made by the SRN.

Patients in the RMT group were seen in a regular clinical visit by a RMT after a waiting period of about 3 months. This visit included extensive history taking, physical examination, and additional tests if considered necessary in the opinion of the RMT. In both groups FM was diagnosed according to the American College of Rheumatology criteria $^{25}$.

\section{Study design}

A prospective cost-consequence analysis ${ }^{26}$ was performed in order to be able to present an array of outcome measures alongside cost for the two procedures of diagnostic process. Such an analysis is opportune if it is not feasible or practical to value all costs and benefits in monetary terms ${ }^{27}$. In this situation available monetary values can be augmented by other measures of cost and benefit like waiting time and patient satisfaction ${ }^{27}$. Presenting the results of our economic evaluation in a disaggregated format allows readers and decision makers to select the information most relevant to their perspective, while the overview of all aspects reflects the societal perspective. 


\section{Health assessments}

Outcome measures recorded were patient satisfaction, health related quality of life (HRQoL), functional status, fatigue, self-efficacy, medical consumption and social participation. Patient satisfaction was measured 1 week after the first consultation. HRQoL and participation were assessed by two monthly questionnaires. Functional status, fatigue and self-efficacy were assessed at baseline (before randomization) and after 3 weeks, and at 3, 6 and 9 months of follow-up.

Patient satisfaction was measured with questions derived from the QUOTE (Quality of Care Through the Patient's Eyes)-Rheumatic-Patients ${ }^{28}$, where Q-values $\geq 1$ reflect care aspects that could be improved. Further details have been described elsewhere ${ }^{24}$.

HRQoL was measured by the EuroQol-5D (EQ-5D), a self-administered, generic instrument that incorporates descriptions and valuations of health states ${ }^{29}$. The EQ-5D was developed and validated in a number of European countries, including The Netherlands $^{30-32}$, and has been used several times in FM patients ${ }^{4,6}$. We used the British (for reasons of comparison to foreign studies) and the Dutch utility tariff, with results in possible utilities ranging from -0.59 and -0.33 respectively (worst imaginable health state) to 1 (best imaginable health state, equal to full health) ${ }^{31-34}$. The EQ-5D also includes a Visual Analogue Scale (VAS) on which patients rates their current health state with endpoints of 100 ('best imaginable health state') at the top and 0 ('worst imaginable health state') at the bottom. So, the EQ-5D utility is a reflection of how society values the patient's health state, and the EQ-VAS is a reflection of how patients value their own health state.

Social participation was assessed by questions on productivity as well as unpaid activities. A self-developed questionnaire measured paid labour (e.g. hours of paid employment, hours of sick leave). Time spent on unpaid tasks, chores, leisure- and social activities in the past two months was measured by an adapted activity questionnaire based on the Utrechtse Activiteiten Lijst ${ }^{35,36}$, a Dutch adaptation of the Craig Handicap Assessment Rating Technique ${ }^{37}$. The unpaid participation was divided in unpaid tasks and chores (hours per week spent on study, housekeeping, odd jobs around the house and voluntary work) and leisure and social activities (hours per week spent on sports, club life, social activities, and other leisure activities).

Functional status was measured with the Fibromyalgia Impact Questionnaire (FIQ), a self-administered 10-item instrument that measures physical functioning, number of days felt well, number of days unable to work because of FM symptoms, work difficulty, pain, fatigue, morning tiredness, stiffness, anxiety and depression ${ }^{38}$. All items of the FIQ were standardized on a scale ranging from 0 to 10 with 10 indicating greater impairment. The total FIQ score was calculated by adding up the 10 items (range 0-100) ${ }^{39}$.

Fatigue was assessed by the Checklist Individual Strength (CIS-20), a 20-item selfreport questionnaire ${ }^{40}$. Each item was scored on a 7-point Likert scale and a CIS total score is calculated by adding up the score of the 20 items (range 20-140). Higher scores indicate a higher degree of problems.

The Generalized Self-Efficacy Scale (GSE) is a 10-item scale designed to assess optimistic self-beliefs to cope with a variety of difficult demands in life ${ }^{41}$. Responses 
are made on a 4-point scale and are summed up to yield the final score, ranging from 10 to 40 , with 10 indicating lower self-efficacy.

\section{Cost assessment}

Costs during the 9 months follow-up period were assessed from the societal perspective, including health care consumption, patient and family costs, and productivity costs. Two monthly cost-diaries ( $t_{1}$ (before randomization) - $t_{6}$ ) completed by the patients were used to estimate health care costs (e.g. consultations, medication, home care) and non-health care costs (e.g. home help, informal care, medical aids, health activities, and productivity costs). Table 3.1 shows the cost items defined and the price value used. Prices were generally obtained from Dutch standard prices that were defined to reflect societal costs and to standardize economic evaluations ${ }^{42}$. The calculation of the costs of the diagnostic process has been described in detail elsewhere ${ }^{24}$. In short, for the calculation of the diagnostic costs, we used the tariffs of the Dutch National Health Tariffs Authority of 2006. Overhead costs were not taken into consideration.

All costs were presented in 2007 prices and inflated where appropriate, using the general Dutch consumer price index rate (www.cbs.nl). The costs of the diagnostic process were published in 2006 prices $^{24}$ and were also indexed. For eight patients in the RMT group, costs for the diagnostic process could not be calculated because they cancelled their appointment. Therefore, the mean costs of the diagnostic process of the remaining 88 patients were used.

Productivity costs were calculated by using the human capital limited approach (HClim). The human capital approach estimates the value of all potentially lost production in contrast with the friction cost method in which productivity costs are only counted as long as it takes to replace someone ${ }^{43,44}$. The difference between the $\mathrm{HClim}$ and the $\mathrm{HC}$ extended approach (HCext) is that in HClim disease-related work disability at baseline is not taken into account, while in HCext work disability at baseline is included in the estimation of productivity costs ${ }^{45}$. We chose for HClim because FM leads to disease-related work disability for a substantial part of the patients. In the cost-diary, patients reported their official working hours per week and the number of days and hours of absenteeism. Because FM is highly prevalent in middle-aged women, paid work was valued at age- and sex-dependent standard hourly costs, ranging from $€ 17$ to $€ 41$ per hour (including $80 \%$ production elasticity) ${ }^{42}$. Costs associated with paid labour were calculated for each patient as the difference between the official working hours reported and the number of hours actually worked, valued at the patient's value per hour. 
Table 3.1 Costs per unit by categories, and sources of cost estimates*

\begin{tabular}{|c|c|c|}
\hline Cost categories & Source of estimate & $\begin{array}{c}\text { Cost per unit , } € \\
(2007)\end{array}$ \\
\hline \multicolumn{3}{|l|}{ Hospital } \\
\hline Diagnostic process of fibromyalgia & Dutch National Health Tariffs Authority (CTG) ${ }^{24}$ & Various \\
\hline Outpatient & Cost manual of Oostenbrink et al. ${ }^{42}$ & 110.83/visit ${ }^{\dagger}$ \\
\hline Specialized nurse & Cost manual of Oostenbrink et al. ${ }^{42}$ & 84.38/visit ${ }^{\dagger}$ \\
\hline \multicolumn{3}{|l|}{ General practitioner } \\
\hline Practice & Cost manual of Oostenbrink et al. ${ }^{42}$ & 21.98/contact $¥$ \\
\hline Home & Cost manual of Oostenbrink et al. ${ }^{42}$ & 42.75/contact \\
\hline Telephone & Cost manual of Oostenbrink et al. ${ }^{42}$ & $10.69 /$ contact \\
\hline Out-of-hours services (practice) & Dutch National Health Tariffs Authority (CTG) & $65.02 /$ contact $^{\mathrm{a}}$ \\
\hline Out-of-hours services (telephone) & Dutch National Health Tariffs Authority (CTG) & $25.00 /$ contact \\
\hline \multicolumn{3}{|l|}{ Health care professionals } \\
\hline Physiotherapist & Cost manual of Oostenbrink et al. ${ }^{42}$ & $24.68 /$ contact $\ddagger$ \\
\hline Mensendieck and Cesar therapy & Cost manual of Oostenbrink et al. ${ }^{42}$ & 24.95/contact $¥$ \\
\hline Occupational therapist & Cost manual of Oostenbrink et al. ${ }^{42}$ & $24.95 /$ contact $¥$ \\
\hline Psychologist & Cost manual of Oostenbrink et al. ${ }^{42}$ & 76.31/contact $¥$ \\
\hline Social worker & Dutch National Health Tariffs Authority (CTG) & $55.61 /$ contact $\ddagger$ \\
\hline Activity therapy & Dutch National Health Tariffs Authority (CTG) & $55.61 /$ contact $\ddagger$ \\
\hline Dietician & Cost manual of Oostenbrink et al. ${ }^{42}$ & $27.06 /$ contact $\ddagger$ \\
\hline Alternative medicine & Patient-reported costs & Various $\ddagger$ \\
\hline \multicolumn{3}{|l|}{ Medication } \\
\hline Prescribed drugs & Pharmacotherapeutic Compass $2007^{63}$ & Various/DDD \\
\hline OTC drugs & Patient-reported costs & Various \\
\hline Day care & Cost manual of Oostenbrink et al. ${ }^{42}$ & $128.03 / \mathrm{d}$ \\
\hline Professional domestic care & Cost manual of Oostenbrink et al. ${ }^{42}$ & $22.96 / \mathrm{h}$ \\
\hline \multicolumn{3}{|l|}{ Informal care } \\
\hline Various & Cost manual of Oostenbrink et al. ${ }^{42}$ & $8.78 / \mathrm{h}$ \\
\hline Paid housekeeper & Cost manual of Oostenbrink et al. ${ }^{42}$ & $8.78 / \mathrm{h}$ \\
\hline Meal service & Estimated market price & $7.00 / d$ \\
\hline Expenses for health activities & Patient-reported costs & Various \\
\hline Expenses for medical aids & $\begin{array}{l}\text { Patient-reported costs or estimated market } \\
\text { price } \S\end{array}$ & Various \\
\hline \multirow[t]{12}{*}{ Productivity costs } & Cost manual of Oostenbrink et al. ${ }^{42}$ & man \\
\hline & Standard hourly wage per age for man and & $15-24$ yrs: $€ 20.49$ \\
\hline & woman & 25-34yrs: €32.74 \\
\hline & & 35-44yrs: €40.86 \\
\hline & & 45-54yrs: €45.37 \\
\hline & & 55-65yrs: €47.82 \\
\hline & & woman \\
\hline & & 15-24yrs: €20.07 \\
\hline & & 25-34yrs: €29.88 \\
\hline & & 35-44yrs: €33.60 \\
\hline & & 45-54yrs: €34.21 \\
\hline & & 55-65yrs: €36.41 \\
\hline
\end{tabular}

* OTC = over the counter; DDD = daily defined dose; + Including $€ 5.02$ travel expenses (mean distance to hospital $7 \mathrm{~km}$ ): $14^{*} 0,17 / \mathrm{km}+€ 2,65$ (parking) ${ }^{42} ; \ddagger$ Including $€ 0.61$ travel expenses (mean distance to GP/PT $1.8 \mathrm{~km}$ ): 3.6*0.17/km; § via various websites, e.g. http://www.thuiszorgwinkel, http://www.medireva.nl. 


\section{Sample size}

In summary, the power calculation was based upon the acceptability of a 3-month waiting time for a first visit led by a rheumatologist and is described in detail elsewhere $^{24}$.

\section{Statistical analysis}

All analyses were conducted on the basis of intention-to-treat. Descriptive statistics were used for demographic and clinical variables and included percentages, means, and standard deviations.

Due to the rather large number of missing values in the cost and social participation data at $t_{3}-t_{5}$ (31\%-42\%), we used a non-parametric multiple imputation method, which replaces each missing value with a set of $\mathrm{m}$ plausible values, to generate five replacement values $(m=5)$ for each of the missing cells in these datasets, using multiple linear regression models. Means presented for cost and social participation are an average of the means from the 5 datasets created.

Average total costs were calculated for patients in each group. Given that cost data are often positively skewed, a non-parametric bootstrap method was used to obtain uncertainty intervals (UIs) for the mean differences in costs ${ }^{46}$.

Because of the random assignment, differences in health outcome at inflow in the study were considered to occur by chance ${ }^{47}$. For consistency, health outcome data at 9 months of follow-up were treated in the same way as the cost data: a multiple imputation method was used to generate 5 replacement values for each of the missing cells and the non-parametric bootstrap was applied to calculate Uls .

Statistical analysis was performed using SPSS 17.0 (SPSS Inc., Chicago, IL). Bootstrapping was performed using Excel.

\section{Results}

\section{Patient characteristics}

A total of 193 patients were randomized, 97 were allocated to the SRN group, and 96 to the RMT group. Comparison of patient characteristics showed no meaningful differences between the SRN and the RMT group. The majority of the patients were women. The mean (SD) age was 44.1 (11.1) and 44.7 (11.9) years in the SRN and RMT groups respectively. The mean (SD) duration of complaints at presentation was 6.1 (7.2) years in the SRN group and 5.7 (6.8) years in the RMT group. Most patients (86\% in the SRN and 79\% in the RMT group) indicated additional health problems.

Resource use 2 months prior to randomization is described in Table 3.2. The RMT group reported more GP contacts (3.3 vs. 2.5 ), but less physiotherapy consultations (1.8 vs. 2.9). A majority of the patients declared to use prescribed medications $(58.8 \%$ in the SRN and $52.1 \%$ in the RMT group). Mean costs for prescribed medications were $€ 34.10$ in the SRN group and $€ 25.50$ in the RMT group. Usage of over the counter 
(OTC) medications was higher in the SRN group (47.4\% vs. $39.6 \%)$. Costs for (paid and unpaid) help and medical aids were higher in the RMT group (help: $€ 62.00$ vs. $€ 34.00$; medical aids: $€ 25.00$ vs. $€ 3.60$ ). In the SRN group, more money was spent on health activities (€20.70 vs. €10.40).

More patients in the SRN group had a job (47.4\% vs. $36.8 \%)$, especially a full-time job $(22.7 \%$ vs. $11.7 \%)$ and less patients received a disablement insurance benefit $(22.7 \%$ vs. $34.7 \%$ ). The percentage patients with sick pay was $21.6 \%$ in the SRN group and $25.0 \%$ in the RMT group. The SRN group had more contractual hours (15.1 vs. 11.7 per week), worked a higher number of hours (12.2 vs. 8.2 per week), and reported a lower number of sick leave hours during the 2 months prior to randomization (25.4 vs. 35.2).

Table 3.2 Average resource use per patient 2 months before baseline and during 9 months follow-up (means) and difference in resource use during 9 months follow-up between RMT group and SRN group*

\begin{tabular}{|c|c|c|c|c|c|}
\hline \multirow[t]{2}{*}{ Cost components } & \multicolumn{2}{|c|}{$\begin{array}{l}\text { RMT group } \\
(n=96)\end{array}$} & \multicolumn{2}{|c|}{$\begin{array}{l}\text { SRN group } \\
(n=97)\end{array}$} & \multirow{2}{*}{$\begin{array}{c}\begin{array}{c}\text { Difference } \\
(95 \% \text { UI)* }\end{array} \\
\text { Resource used } \\
\text { during } 9 \text { months } \\
\text { follow-up }\end{array}$} \\
\hline & $\begin{array}{l}2 \text { months } \\
\text { before } \\
\text { baseline }\end{array}$ & $\begin{array}{l}\text { During } \\
9 \text { months } \\
\text { follow-up }\end{array}$ & $\begin{array}{l}2 \text { months } \\
\text { before } \\
\text { baseline }\end{array}$ & $\begin{array}{l}\text { During } \\
9 \text { months } \\
\text { follow-up }\end{array}$ & \\
\hline \multicolumn{6}{|l|}{ Health care consumption } \\
\hline Total GP contacts & 3.3 & 6.1 & 2.5 & 4.6 & $-1.5(-2.6,-0.2)^{\dagger}$ \\
\hline $\begin{array}{l}\text { Outpatient specialist care contacts } \\
\text { (except contacts mentioned in } \\
\text { table } 3.2 \text { ) }\end{array}$ & 0.6 & 0.8 & 0.3 & 0.5 & $-0.3(-0.6,0.0)^{\dagger}$ \\
\hline Physiotherapy contacts & 1.8 & 9.8 & 2.9 & 8.0 & $-1.8(-4.6,1.4)$ \\
\hline Psychological therapy contacts & 0.4 & 1.8 & 0.4 & 1.7 & $-0.1(-1.1,1.0)$ \\
\hline Other therapy contacts & 0.5 & 3.4 & 0.3 & 1.9 & $-1.5(-2.9,-0.3) \dagger$ \\
\hline $\begin{array}{l}\text { Multidisciplinary day-care ( } \mathrm{nr} \text { of } \\
\text { contacts) }\end{array}$ & 0.0 & 0.9 & 0.0 & 0.6 & $-0.3(-1.4,0.6)$ \\
\hline Home help (hrs a week) & 0.1 & 0.7 & 0.1 & 0.8 & $0.1(-0.5,0.7)$ \\
\hline \multicolumn{6}{|l|}{ Patient and family costs } \\
\hline $\begin{array}{l}\text { Paid housekeeping help (hrs a } \\
\text { week) }\end{array}$ & 0.3 & 2.7 & 0.2 & 1.5 & $-1.2(-2.5,-0.1)^{\dagger}$ \\
\hline $\begin{array}{l}\text { Unpaid help from family/friends } \\
\text { (hrs a week) }\end{array}$ & 0.2 & 4.2 & 0.0 & 2.5 & $-1.7(-4.1,0.4)$ \\
\hline Meal provision (nr of meals) & 0.0 & 0.5 & 0.3 & 1.7 & $1.2(-0.1,3.3)$ \\
\hline
\end{tabular}

* $\mathrm{RMT}=$ rheumatologist; SRN = specialized rheumatology nurses; $\mathrm{UI}=$ uncertainty interval based on bootstrap replications; GP = general practitioner; † significant difference.

\section{Health outcomes}

Table 3.3 shows the results on waiting time and patient satisfaction of the two approaches, which have also been previously published elsewhere ${ }^{24}$. The mean waiting time after randomization was 2.8 weeks in the SRN group and 12.1 weeks in the RMT group $(P \leq 0.0001)$. In the RMT group, 8 patients cancelled their appointment 
because of a too long waiting time. Patients in the SRN group were significantly more satisfied than patients in the RMT group with regard to nearly all items.

Table 3.3 Cost-consequence of diagnostic procedure (means): comparison between RMT group and SRN group*

\begin{tabular}{|c|c|c|c|c|c|}
\hline \multirow[t]{2}{*}{ Cost components } & \multicolumn{2}{|c|}{$\begin{array}{l}\text { RMT group } \\
(n=96)^{\dagger}\end{array}$} & \multicolumn{2}{|c|}{$\begin{array}{c}\text { SRN group } \\
(\mathrm{n}=97)\end{array}$} & \multirow[t]{2}{*}{$\begin{array}{l}\text { Difference } \\
(95 \% \text { UI) }\end{array}$} \\
\hline & Units & Costs $(€)$ & Units & Costs $(€)$ & \\
\hline Waiting time (wks) & 12.1 & & 2.8 & & $-9.3(-10.0,-8.4) \S$ \\
\hline Number of 'no shows' & 8 & & 0 & & -8 \\
\hline \multirow[t]{3}{*}{ Number of FM (\%) } & $66(75)$ & $\mathrm{n}=88$ & $89(92)$ & & $23(17)$ \\
\hline & $70(73)$ & $n=96$ & & & 19 (19) \\
\hline & $\mathrm{n}=88$ & & & & \\
\hline Total consultations (RMT and/or SRN) & 3.1 & & 2.5 & & $-0.6(-1.1,0.0) \S$ \\
\hline $\begin{array}{l}\text { Total length of consultations } \\
\text { (minutes) }\end{array}$ & 124 & & 144 & & $21(-2,42)$ \\
\hline $\begin{array}{l}\text { Costs consultations RMT and/or SRN } \\
(€)\end{array}$ & & 210 & & 162 & $-48(-75,-22) \S$ \\
\hline Costs blood tests $(€)$ & & 23 & & 44 & $21(12,30) \S$ \\
\hline Costs function tests $(€)$ & & 48 & & 14 & $-34(-54,-13) \S$ \\
\hline Total costs $(€)$ & & 281 & & 219 & $-62(-103,-20) \S$ \\
\hline Patient satisfaction $\ddagger$ & $\mathrm{n}=85$ & & $\mathrm{n}=94$ & & \\
\hline Take seriously & 0.17 & & 0.00 & & $-0.17(-0.47,0.00) \S$ \\
\hline Know problems very well & 1.86 & & 1.58 & & $-0.28(-1.29,0.71)$ \\
\hline Take enough time for me & 0.74 & & 0.00 & & $-0.74(-1.26,-0.33) \S$ \\
\hline Take care that I can tell story & 0.95 & & 0.11 & & $-0.84(-1.52,-0.29) \S$ \\
\hline $\begin{array}{l}\text { Tell findings at the end of } \\
\text { consultation }\end{array}$ & 0.85 & & 0.25 & & $-0.60(-1.30,0.01)$ \\
\hline $\begin{array}{l}\text { Pay attention to (psycho)social } \\
\text { aspects of illness }\end{array}$ & 2.42 & & 0.48 & & $-1.94(-2.71,-1.19) \S$ \\
\hline $\begin{array}{l}\text { Give clear information about } \\
\text { disorder }\end{array}$ & 1.47 & & 0.24 & & $-1.23(-1.99,-0.49) \S$ \\
\hline Give usable advises & 4.96 & & 1.59 & & $-3.37(-4.53,-2.23) \S$ \\
\hline Acceptable waiting time & 1.54 & & 0.20 & & $-1.34(-1.74,-0.95) \S$ \\
\hline
\end{tabular}

* $\mathrm{RMT}=$ rheumatologist; SRN = specialized rheumatology nurses; $\mathrm{UI}=$ uncertainty interval based on bootstrap replications; +8 patients cancelled the diagnostic consultation at the outpatient clinic; $\ddagger$ measured by QUOTE(Quality of Care Through the Patient's Eyes)-based questionnaire. Higher values indicate less satisfaction. Values $\geq 1$ reflect care aspects that could be improved; $§$ significant difference. 
The changes in health status during the 9 months follow-up are presented in Table 3.4. The RMT group scored lower than the SRN group at baseline and at 9 months of follow-up on nearly all health outcomes. It can be seen that the improvements are fairly similar across the two groups.

Table 3.4 Health outcome measurements after 9 months follow-up per patient*

\begin{tabular}{lcccccc}
\hline & \multicolumn{3}{c}{ RMT group ( $\mathrm{n=96)}$} & \multicolumn{3}{c}{ SRN group (n=97) } \\
\cline { 2 - 7 } Outcome measure & $\begin{array}{l}\text { baseline } \\
\text { 9 months } \\
\text { follow-up }\end{array}$ & Delta (95\% UI) & baseline & $\begin{array}{c}9 \text { months } \\
\text { follow-up }\end{array}$ & Delta (95\% UI) \\
\hline EQ-5D UK tariff & 0.35 & 0.43 & $0.08(-0.01,0.16)$ & 0.43 & 0.49 & $0.06(-0.03,0.14)$ \\
EQ-5D Dutch tariff & 0.43 & 0.47 & $0.04(-0.05,0.13)$ & 0.51 & 0.54 & $0.03(-0.05,0.11)$ \\
EQ-VAS & 47.7 & 47.4 & $-0.3(-5.0,4.4)$ & 49.2 & 49.8 & $0.6(-4.6,5.6)$ \\
FIQ - total & 59.9 & 58.4 & $-1.5(-5.9,3.0)$ & 57.0 & 56.1 & $-0.9(-5.4,3.4)$ \\
CIS 20 - total & 99.0 & 93.9 & $-5.1(-11.1,1.4)$ & 90.4 & 90.7 & $0.3(-6.5,7.1)$ \\
CIS-20 - fatigue severity & 47.3 & 42.5 & $-4.8(-7.0,-2.4)^{\dagger}$ & 44.4 & 41.9 & $-2.5(-5.4,0.2)$ \\
Self-efficacy & 26.5 & 26.2 & $-0.3(-1.6,1.0)$ & 27.4 & 26.7 & $-0.7(-2.1,0.8)$ \\
\hline
\end{tabular}

* $\mathrm{RMT}=$ rheumatologist; SRN = specialized rheumatology nurses; $\mathrm{UI}=$ uncertainty interval based on bootstrap replications; EQ-VAS = EuroQol Visual Analogue Scale; FIQ = Fibromyalgia Impact Questionnaire; CIS-20 = Checklist Individual Strength; + significant difference.

\section{Health care and productivity costs}

The costs of the diagnostic process have been published elsewhere ${ }^{24}$ and are presented in Table 3.3. Mean total costs of the diagnostic process were lower in the SRN group than in the RMT group (€219 per patient vs. €282 per patient; 95\% UI $€-103$ to $€-20)$.

The use of health care resources during the 9 months of follow-up is summarized in Table 3.2. The resource use is generally higher in the RMT group. The RMT group reported significantly more contacts with GPs, medical specialists, and other paramedical professionals and significantly more hours of paid housekeeping help.

Table 3.5 shows a comparison of paid and unpaid activities between the SRN group and the RMT group. After 9 months of follow-up, a slight decrease of contractual hours and a small increase of actually worked hours is seen in both groups. Also, a substantial decrease in sick leave is observed, especially in the RMT group. The decrease of absenteeism in the RMT group occurred just in the last month of followup, resulting in higher costs for absenteeism in this group (€-1109; 95\% UI €-3581 to $€ 1094)$.

Concerning unpaid activities, the RMT group spent, in contrast to the SRN group, slightly more hours on unpaid tasks and chores and leisure and social activities.

Table 3.6 presents the mean health care and societal costs per patient during 9 months of follow-up. Cost differences were nearly all in favour of the SRN group. Costs of the diagnostic process and GP contacts were significantly lower in the SRN group compared with the RMT group. Expenses for health activities, conversely, were higher in the SRN group compared with the RMT group. Total costs excluding absenteeism were significantly lower in the SRN group (€1298 vs. €1644; 95\% UI €- 
746 to $€-2$ ). Mean total costs from a societal perspective were $€ 3853$ per patient for the SRN group and $€ 5293$ for the RMT group after 9 months of follow-up. Productivity costs accounted for two-thirds of the total societal costs and had a high impact on the incremental costs. The mean cost difference was $€ 1440$ per patient ( $95 \%$ UI $€-3721$ to $€ 577)$ in favour of the SRN group.

Table 3.5 Amount of paid and unpaid participation per patient (mean hours per week): comparison between RMT group and SRN group*

\begin{tabular}{|c|c|c|c|c|c|c|}
\hline \multirow[b]{2}{*}{ Outcome measure } & \multicolumn{3}{|c|}{ RMT group ( $n=96$ ) } & \multicolumn{3}{|c|}{ SRN group $(n=97)$} \\
\hline & baseline & $\begin{array}{l}9 \text { months } \\
\text { follow-up }\end{array}$ & $\begin{array}{c}\text { Delta } \\
(95 \% \text { UI) }\end{array}$ & baseline & $\begin{array}{l}9 \text { months } \\
\text { follow-up }\end{array}$ & $\begin{array}{c}\text { Delta } \\
(95 \% \text { UI) }\end{array}$ \\
\hline Official working hours & 11.9 & 10.4 & $\begin{array}{c}-1.5 \\
(-5.4,2.6)\end{array}$ & 15.2 & 14.3 & $\begin{array}{c}-0.9 \\
(-5.1,3.3)\end{array}$ \\
\hline Actually worked hours & 8.3 & 10.4 & $\begin{array}{c}2.1 \\
(-1.3,5.8)\end{array}$ & 12.2 & 13.3 & $\begin{array}{c}1.1 \\
(-3.0,5.2)\end{array}$ \\
\hline $\begin{array}{l}\text { Absent hours (mean last } \\
2 \text { months) }\end{array}$ & 36.6 & 9.4 & $\begin{array}{c}-27.2 \\
(-44.6,-11.6)^{\dagger}\end{array}$ & 26.1 & 13.7 & $\begin{array}{c}12.4 \\
(-26.8,1.0)\end{array}$ \\
\hline $\begin{array}{l}\text { Absent hours (HClim; sum } 9 \\
\text { months follow-up) }\end{array}$ & & 99.5 & & & 76.1 & $\begin{array}{c}-23.4 \\
(-86.6,32.2)\end{array}$ \\
\hline $\begin{array}{l}\text { Costs of absenteeism from } \\
\text { work }(\mathrm{HClim})(€)\end{array}$ & & 3674 & & & 2565 & $\begin{array}{c}-1109 \\
(-3581,1094)\end{array}$ \\
\hline \multicolumn{7}{|l|}{ Unpaid participation } \\
\hline Education & 1.6 & 2.3 & $\begin{array}{c}0.7 \\
(-1.1,2.4)\end{array}$ & 1.0 & 1.8 & $\begin{array}{c}0.8 \\
(-0.4,2.1)\end{array}$ \\
\hline Housekeeping & 23.4 & 22.2 & $\begin{array}{c}-1.2 \\
(-7.4,4.5)\end{array}$ & 23.0 & 20.5 & $\begin{array}{c}-2.5 \\
(-8.1,2.9)\end{array}$ \\
\hline $\begin{array}{l}\text { Odd jobs around the } \\
\text { house }\end{array}$ & 2.6 & 3.2 & $\begin{array}{c}0.6 \\
(-0.7,1.9)\end{array}$ & 3.1 & 4.0 & $\begin{array}{c}0.9 \\
(-0.5,2.3)\end{array}$ \\
\hline Volunteer work & 1.0 & 1.6 & $\begin{array}{c}0.6 \\
(-0.4,1.6)\end{array}$ & 0.5 & 1.0 & $\begin{array}{c}0.5 \\
(0.0,1.0)^{\dagger}\end{array}$ \\
\hline Sport & 1.5 & 2.2 & $\begin{array}{c}0.7 \\
(-0.1,1.3)\end{array}$ & 1.7 & 2.4 & $\begin{array}{c}0.7 \\
(0.0,1.5)^{\dagger}\end{array}$ \\
\hline Club life & 0.4 & 0.9 & $\begin{array}{c}0.5 \\
(0.1,0.9) \dagger\end{array}$ & 0.7 & 0.9 & $\begin{array}{c}0.2 \\
(-0.3,0.6)\end{array}$ \\
\hline Leisure time & 7.0 & 7.0 & $\begin{array}{c}0.0 \\
(-2.3,2.1)\end{array}$ & 7.3 & 5.7 & $\begin{array}{c}-1.6 \\
(-3.2,0.2)\end{array}$ \\
\hline Social activities & 2.9 & 3.6 & $\begin{array}{c}0.7 \\
(-0.1,1.7)\end{array}$ & 3.5 & 4.0 & $\begin{array}{c}0.5 \\
(-0.4,1.4)\end{array}$ \\
\hline Other activities & 0.2 & 1.0 & $\begin{array}{c}0.8 \\
(0.0,2.1)^{\dagger}\end{array}$ & 0.2 & 0.4 & $\begin{array}{c}0.2 \\
(-0.1,0.6)\end{array}$ \\
\hline Unpaid tasks and chores & 28.7 & 29.2 & $\begin{array}{c}0.5 \\
(-5.5,6.8)\end{array}$ & 27.7 & 27.3 & $\begin{array}{c}-0.4 \\
(-5.8,5.0)\end{array}$ \\
\hline Leisure and social activities & 11.9 & 13.8 & $\begin{array}{c}1.9 \\
(-0.9,4.6)\end{array}$ & 13.2 & 13.1 & $\begin{array}{c}-0.1 \\
(-2.4,2.2)\end{array}$ \\
\hline
\end{tabular}

* $\mathrm{RMT}$ = rheumatologist; SRN = specialized rheumatology nurses; $\mathrm{UI}=$ uncertainty interval based on bootstrap replications; $\mathrm{HClim}=$ human capital limited approach; ${ }^{\dagger}$ significant difference. 
Table 3.6 Mean costs of health care consumption during 9 months follow-up per patient $(€)^{*}$

\begin{tabular}{|c|c|c|c|}
\hline Cost components & $\begin{array}{l}\text { RMT group } \\
(n=96)\end{array}$ & $\begin{array}{l}\text { SRN group } \\
(n=97)\end{array}$ & $\begin{array}{l}\text { Difference } \\
(95 \% \text { UI) }\end{array}$ \\
\hline \multicolumn{4}{|l|}{ Health care consumption } \\
\hline Total costs diagnostic process & 287 & 223 & $-64(-103,-26) \ddagger$ \\
\hline Total GP contacts & 123 & 83 & $-40(-76,-1) \ddagger$ \\
\hline $\begin{array}{l}\text { Outpatient specialist care contacts (except } \\
\text { contacts in Table 3.2) }\end{array}$ & 103 & 63 & $-40(-79,0) \ddagger$ \\
\hline Therapist contacts & 436 & 355 & $-81(-224,70)$ \\
\hline Prescribed medications & 148 & 115 & $-33(-80,7)$ \\
\hline OTC medications & 30 & 24 & $-6(-20,8)$ \\
\hline Multidisciplinary day-care & 98 & 62 & $-36(-169,82)$ \\
\hline \multicolumn{4}{|l|}{ Patient and family costs } \\
\hline Home help (paid/unpaid) & 295 & 216 & $-79(-276,109)$ \\
\hline Meal provision & 15 & 16 & $1(-12,20)$ \\
\hline Expenses for health activities & 82 & 118 & $36(-6,86)$ \\
\hline Expenses for medical aids & 19 & 19 & $0(-20,23)$ \\
\hline Total costs (excl absenteeism from work) & $1644+$ & $1298+$ & $-346(-746,-2) \ddagger$ \\
\hline Absenteeism from work (HClim) & 3674 & 2565 & $-1109(-3581,1094)$ \\
\hline Total societal costs & $5293+$ & $3853+$ & $-1440(-3721,577)$ \\
\hline
\end{tabular}

\section{Discussion}

This study investigated the health and economic consequences of substituting SRNs for RMTs in the diagnostic process of FM. Patients in the SRN group were significantly more satisfied, but differences in health status between the two groups during 9 months of follow-up were small and insignificant. Mean total costs from societal perspective (including absenteeism) were $€ 1440$ per patient lower in the SRN group than in the RMT group after 9 months of follow-up (95\% UI €-3721 - €577).

We could not prove that a timely diagnosis had a positive effect on health outcomes and social participation in terms of hours spent. However, medical and productivity costs were significantly lower in the SRN group. Since the time horizon of our analysis is only 9 months, a longer follow-up may be necessary to confirm these effects.

Our results suggest that health care use in terms of contacts with GPs, medical specialists, and physical and psychological therapists and in medication costs was similar in both groups before and after diagnosis. The literature is not equivocal in the effects of making a diagnosis on health care utilization. Annemans et al. suggest that making a diagnosis leads to a decrease of resource use and costs, which is confirmed by other studies ${ }^{16,48,49}$. However, Hughes et al. found that following diagnosis, visits for most symptoms and health care use markers declined, but within 2-3 years most 
visits rose to levels at or higher than those at diagnosis ${ }^{21}$. On the other hand, Maugars et al. described a decrease in referrals and tests after diagnosis, and an increase in drug use and GP visits for the first two years after diagnosis ${ }^{48}$. White et al. finally illustrated that health care costs rose immediately after diagnosis ${ }^{50}$. In our study we saw an increase after diagnosis of contacts with other therapists, paid housekeeping help, informal care, multidisciplinary day-care and expenses for health activities.

Notwithstanding a considerable decrease of sick leave hours in both intervention groups, productivity costs based on absenteeism accounted for two-thirds of the total societal costs in our study. This is much higher than described in previous studies in which approximately $20 \%-33 \%$ of the total societal costs of FM are related to productivity costs ${ }^{10,14,51-53}$. This could be due to the way productivity costs were calculated. Huscher et al. showed that indirect costs differ by a factor of 3 , based on whether the human capital approach or the friction costs approach is used ${ }^{54}$.

The percentage indirect costs $(74 \%$ and $77 \%$ of the total societal costs for the SRN group and the RMT group respectively) is in line with other studies ${ }^{10}$. In the study of Boonen et al. $^{51}$, also based on patient diaries, the annual direct medical costs were $€ 1311$ (year 2002 values), which is rather in line with our results converted to total annual costs ( $€ 1233$ and $€ 1633$ in the SRN and the RMT group respectively).

Also, the total annual costs per patient are comparable: $€ 7813$ (year 2002 values) in the study of Boonen et al. ${ }^{51}, € 5137$ (converted to annual costs) in the SRN group and $€ 7057$ in the RMT group (converted to annual costs). Although Annemans et al. ${ }^{16}$ shows that the total costs for FM, reported by Boonen et al. and 12 other studies, are quite similar, a direct comparison of Dutch data with data from other countries should be done cautiously ${ }^{55}$.

Our study has several difficulties. First, the choice for a cost-consequence analysis has disadvantages. Ideally, all outcomes should be integrated into one overall index of benefit. This is important when comparing different interventions or comparing the results of a study with other studies or other diseases in all facets. A cost-minimisation analysis was not relevant in our study, as it assumes outcomes to be equivalent which was not the case. In a cost-effectiveness analysis consequences of programmes are measured in the most appropriate natural effects or physical units, while in a costutility analysis the consequences of interventions are adjusted by health state preference or utility weights. In our situation with utility as one of the consequences and outcomes, we found no difference between improvement in quality of life in the intervention groups. Besides, these analyses from societal perspective includes all costs irrespective of who bears them. A cost-benefit analysis measures costs as well as consequences of an intervention in monetary terms which was not feasible for mostly all our consequences and therefore not an useful option.

In our study the outcomes are difficult to be integrated into one overall measure of benefit, since they concern both consequences at the patient level (e.g. satisfaction, health status) and at the health care system level (e.g. waiting time, number of noshows). A cost-consequence analysis overcomes this problem by presenting information on both costs and outcomes in a disaggregated form, allowing decisionmakers to make the necessary value judgements (implicitly weighing the relative importance of the outcomes) and trade-offs that are relevant from their particular 
perspective. However, in our study costs from both health care and societal perspectives as well as consequences seem to point in the same direction so we can formulate one overall conclusion and related recommendation.

Second, notwithstanding randomization, we found baseline differences for the EQ-5D index score, CIS-20, percentage of employed patients and hours of absenteeism. Concerning the between-group differences in work situation at baseline, costs of absenteeism at baseline were calculated and the difference was not found to be statistically significant. We have the opinion that adjustment for cost differences at baseline is not necessary in this situation as the cost differences at baseline for other than productivity costs are very small and go in both directions. Besides, the recommendation of Van Asselt et al. for dealing with cost differences at baseline concerns baseline differences in total costs and not baseline differences in components of $\operatorname{costs}^{56}$. However, the finding that productivity costs were $€ 1109$ lower in the SRN group should be interpreted cautiously. Using the most conservative adjustment, this amount should be reduced with the difference in productivity costs at baseline (€445). Third, our study suffered importantly from missing data. We have carefully checked if these missing values were at random. Patients with lower scores at baseline were generally more likely to be missing at some time point. Since FM patients seems to have lower scores than non-FM patients and the SRN group contained more FM patients, the HRQL scores of the SRN group could be an underestimation. Therefore, the incremental difference between the RMT group and the SRN group could also be a conservative difference. Although we also found more missing values in non-FM patients and therefore in the RMT group, we assume the effect on the scores is limited because of the small number of missing non-FM patients on the total of the group. Fourth, an unknown number of patients in the RMT group have undergone a medical consultation in another hospital due to waiting time. The visits to RMT and SRN are, as far as reported, included in the costs of outpatient specialist care contacts, but we have no data of performed diagnostic tests and therefore these costs could not be included, what could have caused an underestimation of the medical consumption in the RMT group. This is closely connected with the next point. Nearly all cost data are based on cost diaries, which may not necessarily reflect actual patterns of use because of problems with patient recall. However, patient reported health care consumption data are considered to be relatively reliable regarding formal care ${ }^{57}$ and if biased, we do not expect systematic reporting differences between the groups in our study. In addition, the estimated productivity costs did not include costs associated with reduced productivity on the job (presenteeism) or with replacement costs ${ }^{58,59}$. In a future study, it is worth to take into account these costs because one of the consequences of FM is work loss and those patients who do not lose their jobs still obviously experience difficulties in their working life as a direct result of $\mathrm{FM}^{60,61}$. Next, in our study we could not assess a possible difference in placebo effect of the nurse-led diagnostic process vs. usual care. Within a cost-consequence analysis however the aim is to assess a difference in effectiveness, including a possible placebo-effect instead of clinical efficacy as in clinical trials. 
An important disadvantage of the nurse-led diagnostic process was the fact that more than $8 \%$ of the SRN-patients refused to participate because they indicated that they would only accept a rheumatologist consultation. However, given our analytic approach based upon intention-to-treat, this issue is incorporated in our findings and conclusion. This is a study based upon Dutch data, and the generalizability of our conclusion, and especially the issue of compliance to consultation by a nurse specialist, should be carefully considered, for instance by explicit assessment of transferability issues ${ }^{62}$.

Finally, given the incremental approach of our analysis we did not consider overhead costs of hospital facilities; those were considered to be sunk costs. When a FM clinic is to be initiated, it is important to be aware that such costs might be relevant. One should note as well that our results were obtained in a trial setting and possibly can differ from real life data as it is commonly the case in a protocolized trial. Therefore, we advice to monitor the outcomes after the implementation of such a nurse-led diagnostic process.

In conclusion, the nurse-led diagnostic process is a recommendable approach from both a health care and societal perspective. Patients in the SRN group were significantly more satisfied, and no differential changes in health status were observed between the two groups during 9 months of follow-up. Total health care consumption costs and patient and family costs were significantly lower in the SRN group. Also, costs from a societal perspective (including absenteeism) were lower in the SRN group compared with the RMT group. 


\section{References}

1. Wolfe F, Ross K, Anderson J, Russell IJ, Hebert L. The prevalence and characteristics of fibromyalgia in the general population. Arthritis Rheum 1995;38:19-28.

2. Vanhoof J, Declerck K, Geusens P. Prevalence of rheumatic diseases in a rheumatological outpatient practice. Ann Rheum Dis 2002;61:453-5.

3. Bernard AL, Prince A, Edsall P. Quality of life issues for fibromyalgia patients. Arthritis Care Res 2000;13:42-50.

4. Picavet HS, Hoeymans N. Health related quality of life in multiple musculoskeletal diseases: SF-36 and EQ-5D in the DMC3 study. Ann Rheum Dis 2004;63:723-9.

5. Verbunt JA, Pernot DH, Smeets RJ. Disability and quality of life in patients with fibromyalgia. Health Qual Life Outcomes 2008;6:8.

6. Wolfe F, Hawley DJ. Measurement of the quality of life in rheumatic disorders using the EuroQol. Br J Rheumatol 1997;36:786-93.

7. Arnold LM, Crofford LJ, Mease PJ, Burgess SM, Palmer SC, Abetz L, et al. Patient perspectives on the impact of fibromyalgia. Patient Educ Couns 2008;73:114-20.

8. Berger A, Dukes E, Martin S, Edelsberg J, Oster G. Characteristics and healthcare costs of patients with fibromyalgia syndrome. Int J Clin Pract 2007;61:1498-508.

9. Penrod JR, Bernatsky S, Adam V, Baron M, Dayan N, Dobkin PL. Health services costs and their determinants in women with fibromyalgia. J Rheumatol 2004;31:1391-8.

10. Robinson RL, Birnbaum HG, Morley MA, Sisitsky T, Greenberg PE, Claxton AJ. Economic cost and epidemiological characteristics of patients with fibromyalgia claims. J Rheumatol 2003;30:1318-25.

11. Sicras-Mainar A, Rejas J, Navarro R, Blanca M, Morcillo A, Larios R, et al. Treating patients with fibromyalgia in primary care settings under routine medical practice: a claim database cost and burden of illness study. Arthritis Res Ther 2009;11:R54.

12. Silverman S, Dukes EM, Johnston SS, Brandenburg NA, Sadosky A, Huse DM. The economic burden of fibromyalgia: comparative analysis with rheumatoid arthritis. Curr Med Res Opin 2009;25:829-40.

13. White KP, Speechley M, Harth M, Ostbye T. The London Fibromyalgia Epidemiology Study: direct health care costs of fibromyalgia syndrome in London, Canada. J Rheumatol 1999;26:885-9.

14. White LA, Birnbaum HG, Kaltenboeck A, Tang J, Mallett D, Robinson RL. Employees with fibromyalgia: medical comorbidity, healthcare costs, and work loss. J Occup Environ Med 2008;50:13-24.

15. Wolfe F, Anderson J, Harkness D, Bennett RM, Caro XJ, Goldenberg DL, et al. A prospective, longitudinal, multicenter study of service utilization and costs in fibromyalgia. Arthritis Rheum 1997;40:1560-70.

16. Annemans L, Wessely S, Spaepen E, Caekelbergh K, Caubere JP, Le Lay K, et al. Health economic consequences related to the diagnosis of fibromyalgia syndrome. Arthritis Rheum 2008;58:895-902.

17. Ehrlich GE. Pain is real; fibromyalgia isn't. J Rheumatol 2003;30:1666-7.

18. Hadler NM. "Fibromyalgia" and the medicalization of misery. J Rheumatol 2003;30:1668-70.

19. White KP, Nielson WR, Harth M, Ostbye T, Speechley M. Does the label "fibromyalgia" alter health status, function, and health service utilization? A prospective, within-group comparison in a community cohort of adults with chronic widespread pain. Arthritis Rheum 2002;47:260-5.

20. Keefe FJ, Rumble ME, Scipio CD, Giordano LA, Perri LM. Psychological aspects of persistent pain: current state of the science. J Pain 2004;5:195-211.

21. Hughes G, Martinez C, Myon E, Taieb C, Wessely S. The impact of a diagnosis of fibromyalgia on health care resource use by primary care patients in the UK: an observational study based on clinical practice. Arthritis Rheum 2006;54:177-83.

22. Goh L, Samanta J, Samanta A. Rheumatology nurse practitioners' perceptions of their role. Musculoskeletal Care 2006;4:88-100.

23. Hill J. Rheumatology nurse specialists--do we need them? Rheumatology (Oxford) 2007;46:379-81.

24. Kroese MEAL, Schulpen GJC, Bessems MCM, Severens JL, Nijhuis FJ, Geusens PP, et al. Substitution of specialized rheumatology nurses for rheumatologists in the diagnostic process of fibromyalgia: a randomized controlled trial. Arthritis Care \& Research 2008;59:1299-1305. 
25. Wolfe F, Smythe HA, Yunus MB, Bennett RM, Bombardier C, Goldenberg DL, et al. The American College of Rheumatology 1990 Criteria for the Classification of Fibromyalgia. Report of the Multicenter Criteria Committee. Arthritis Rheum 1990;33:160-72.

26. Mauskopf JA, Paul JE, Grant DM, Stergachis A. The role of cost-consequence analysis in healthcare decision-making. Pharmacoeconomics 1998;13:277-88.

27. McIntosh E, Donaldson C, Ryan M. Recent advances in the methods of cost-benefit analysis in healthcare. Matching the art to the science. Pharmacoeconomics 1999;15:357-67.

28. van Campen C, Sixma HJ, Kerssens JJ, Peters L, Rasker JJ. Assessing patients' priorities and perceptions of the quality of health care: the development of the QUOTE-Rheumatic-Patients instrument. $\mathrm{Br} J$ Rheumatol 1998;37:362-8.

29. The EuroQol Group. EuroQol--a new facility for the measurement of health-related quality of life. . Health Policy 1990;16:199-208.

30. Brooks R. EuroQol: the current state of play. Health Policy 1996;37:53-72.

31. Lamers LM, McDonnell J, Stalmeier PF, Krabbe PF, Busschbach JJ. The Dutch tariff: results and arguments for an effective design for national EQ-5D valuation studies. Health Econ 2006;15:1121-32.

32. Lamers LM, Stalmeier PF, McDonnell J, Krabbe PF, van Busschbach JJ. Kwaliteit van leven meten in economische evaluaties: het Nederlands EQ-5D-tarief [Measuring the quality of life in economic evaluations: the Dutch EQ-5D tariff]. Ned Tijdschr Geneeskd 2005;149:1574-8.

33. Dolan P. Modeling valuations for EuroQol health states. Medical care 1997;35:1095-108.

34. Weinstein MC, Torrance G, McGuire A. QALYs: the basics. Value Health 2009;12 Suppl 1:S5-9.

35. Post M. Resultaatmeting in de dwarslaesierevalidatie In: van Asbeck FWA, editor. Handboek Dwarslaesierevalidatie. Houten Bohn Stafleu van Lochum; 2007:365-376.

36. Schonherr MC, Groothoff JW, Mulder GA, Eisma WH, Schonherr MC, Groothoff JW, et al. Participation and satisfaction after spinal cord injury: results of a vocational and leisure outcome study. Spinal Cord 2005;43:241-8.

37. Whiteneck GG, Charlifue SW, Gerhart KA, Overholser JD, Richardson GN. Quantifying handicap: a new measure of long-term rehabilitation outcomes. Arch Phys Med Rehabil 1992;73:519-26.

38. Burckhardt CS, Clark SR, Bennett RM. The fibromyalgia impact questionnaire: development and validation. J Rheumatol 1991;18:728-33.

39. Bennett R. The Fibromyalgia Impact Questionnaire (FIQ): a review of its development, current version, operating characteristics and uses. Clin Exp Rheumatol 2005;23(5 Suppl 39):S154-62.

40. Vercoulen JHHM, Alberts M, Bleijenberg G. De Checklist Individual Strength (CIS). Gedragstherapie 1999;32:131-136.

41. Schwarzer R, Jerusalem M. Generalized Self-Efficacy Scale. In: Weinman J, Wright S, Johnston M, editors. Measures in health psychology: A user's portfolio. Causal and control beliefs. Windsor, UK: NFER-NELSON; 1995:35-37.

42. Oostenbrink JB, Bouwmans CAM, Koopmanschap MA, Rutten FFH. Handleiding voor kostenonderzoek. Methoden en standaard kostprijzen voor economische evaluaties in de gezondheidszorg. Rotterdam: Instituut voor Medical Technology Assessment, Erasmus MC in opdracht voor College voor zorgverzekeringen; 2004.

43. Koopmanschap MA, Rutten FF, van Ineveld BM, van Roijen L. The friction cost method for measuring indirect costs of disease. J Health Econ 1995;14:171-89.

44. Rice DP, Cooper BS. The economic value of human life. American Journal of Public Health and the Nation's Health 1967;57:1954-1966.

45. van Asselt AD, Dirksen CD, Arntz A, Severens JL. Difficulties in Calculating Productivity Costs: Work Disability Associated with Borderline Personality Disorder. Value in Health 2008;11:637-644.

46. Thompson SG, Barber JA. How should cost data in pragmatic randomised trials be analysed? BMJ 2000;320:1197-200.

47. Altman DG, Dore CJ. Randomisation and baseline comparisons in clinical trials. Lancet 1990;335: 149-53.

48. Maugars Y, Annemans L, Roué-Le lay K, André E, Caubere JP, Taieb C. Fibromyalgia: the avoided cost of the non-diagnosed patient in France. Ann Rheum Dis 2008;67(Suppl II):258.

49. Taieb C, Lamotte M, Maugars Y, Le Lay K. Health economic comparison of outpatient management of fibromyalgia before and after diagnosis in five European countries. Ann Rheum Dis 2009;68 (Suppl 3):690. 
50. White LA, Robinson RL, Yu AP, Kaltenboeck A, Samuels S, Mallett D, et al. Comparison of health care use and costs in newly diagnosed and established patients with fibromyalgia. J Pain 2009;10:976-83.

51. Boonen A, van den Heuvel R, van Tubergen A, Goossens M, Severens JL, van der Heijde D, et al. Large differences in cost of illness and wellbeing between patients with fibromyalgia, chronic low back pain, or ankylosing spondylitis. Ann Rheum Dis 2005;64:396-402.

52. Robinson RL, Birnbaum HG, Morley MA, Sisitsky T, Greenberg PE, Wolfe F. Depression and fibromyalgia: treatment and cost when diagnosed separately or concurrently. J Rheumatol 2004;31:1621-9.

53. Zijlstra TR, Braakman-Jansen LMA, Taal E, Rasker JJ, van de Laar MAFJ. Cost-effectiveness of Spa treatment for fibromyalgia: general health improvement is not for free. Rheumatology 2007;46: 1454-9.

54. Huscher D, Merkesdal S, Thiele K, Zeidler H, Schneider M, Zink A. Cost of illness in rheumatoid arthritis, ankylosing spondylitis, psoriatic arthritis and systemic lupus erythematosus in Germany. Ann Rheum Dis 2006;65:1175-83.

55. Knies S, Severens JL, Ament AJHA, Evers SMAA. Using cost-effectiveness results from abroad for local policy decisisions. European Journal of Hospital Pharmacy Practice 2008;14:51-54.

56. van Asselt $A D$, van Mastrigt GA, Dirksen CD, Arntz A, Severens JL, Kessels AG. How to deal with cost differences at baseline. Pharmacoeconomics 2009;27:519-28.

57. van den Brink M, van den Hout WB, Stiggelbout AM, van de Velde CJ, Kievit J. Cost measurement in economic evaluations of health care: whom to ask? Med Care 2004;42:740-6.

58. Koopmanschap M, Burdorf A, Jacob K, Meerding WJ, Brouwer W, Severens H. Measuring productivity changes in economic evaluation: setting the research agenda. Pharmacoeconomics 2005;23:47-54.

59. Severens JL, Laheij RJF, Jansen JBMJ, van der Lisdonk EH, Verbeek ALM. Estimating the cost of lost productivity in dyspepsia. Aliment Pharmacol Ther 1998;12:919-923.

60. Annemans L, Le Lay K, Taieb C. Societal and patient burden of fibromyalgia syndrome. Pharmacoeconomics 2009;27:547-59.

61. Bennett RM, Jones J, Turk DC, Russell IJ, Matallana L. An internet survey of 2,596 people with fibromyalgia. BMC Musculoskelet Disord 2007;8:27.

62. Knies S, Ament AJ, Evers SM, Severens JL. The Transferability of Economic Evaluations: Testing the Model of Welte. Value Health 2009.

63. Dutch Health Care Insurance Board. Pharmacotherapeutic Compass; 2007. 



\section{Chapter 4}

\section{Diagnosis of fibromyalgia is associated with impaired health outcomes and substantial health care costs after 9 months of follow-up}

MEAL Kroese, RBM Landewé, GJC Schulpen, MCM Bessems, JL Severens 


\section{Abstract}

\section{Objective}

To investigate in patients referred with symptoms suggestive of fibromyalgia (FM) whether a) patients in whom a diagnosis of (FM) was actually made differ in prognosis from patients in which another diagnosis (non-FM) was made with respect to health outcomes and health care costs after 9 months of follow-up, and b) an early diagnosis of FM has a favourable effect on these outcomes after 9 months of follow-up in comparison to a regular (delayed) diagnosis.

\section{Methods}

All patients were participants in a randomized clinical trial (RCT) $(n=193)$ on the feasibility of substitution of specialized rheumatology nurses (SRNs) for rheumatologists in making a diagnosis of FM. Patients had to have symptoms suggestive of FM, with which they were referred to the outpatient clinic of rheumatology. Patients were allocated to an early diagnosis group, and seen by a supervised SRN, or to a delayed diagnosis group, put on a waiting list, and seen by a regular rheumatologist. Health outcomes, measured at baseline and after 9 months of follow-up, were health related quality of life (HRQoL), functional status, fatigue, pain-related anxiety, pain catastrophizing, positive and negative affect and self-efficacy. Costs were measured by 2-monthly questionnaires on medical consumption and productivity. This post-hoc analysis compared health outcomes of patients in whom a diagnosis of FM was made with patients in whom another diagnosis was made (non-FM) and investigated the effects of early versus delayed diagnosis.

\section{Results}

Of all patients, $82.4 \%$ ( $n=159)$ met the American College of Rheumatology criteria for FM, in 33 patients $(17.1 \%)$ another diagnosis (non-FM) was made and of 1 patient the diagnosis remained unknown. FM patients had a longer duration of complaints (6.3 yrs vs. $4.2 \mathrm{yrs} ; P=0.029$ ) and indicated more additional health problems $(85.5 \%$ vs. $66.7 \%$; $P=0.01)$ than non-FM patients. Before the diagnosis was made, FM patients also scored consistently worse than non-FM patients. The timing of diagnosis (early vs. delayed) did not influence these results. During nine months of follow-up, FM patients showed a stable course in almost all health outcomes, while non-FM patients improved in almost all these outcomes. FM patients created slightly more health care costs than non-FM patients ( $€ 1498$ vs. $€ 1315$; difference $€-183,95 \%$ uncertainty interval (UI) €-613 to €255), but costs related to absenteeism from work were slightly higher in the non-FM patients ( $€ 3031$ vs. $€ 3732$; difference $€ 701,95 \%$ UI $€-2474$ to $€ 5226$ ). An early diagnosis, however, importantly saved costs in patients with a non-FM diagnosis both from a health care and a societal perspective (total societal costs early vs. delayed diagnosis: $€ 700$ vs. $€ 6425$; difference $€ 5725$, 95\% UI €1985 to $€ 10.988$ ).

\section{Conclusion}

A diagnosis of FM is associated with worse health outcomes such as functional status and HRQoL than another diagnosis in patients referred to the outpatient clinic of rheumatology with symptoms suggestive of FM. 


\section{Introduction}

Fibromyalgia (FM) is a chronic musculoskeletal disorder characterized by widespread pain, fatigue, depressed mood and disturbed sleep ${ }^{1}$. Many patients with FM suffer significantly from disability and reduced quality of life ${ }^{2}$.

Before a diagnosis of FM is made, patients may repeatedly present to their general practitioner (GP) with various symptoms. However, little is known about the impact and prognosis after establishing the diagnosis. Generally speaking, there are two schools of thought about the diagnostic process ${ }^{3}$. According to the first theory, it is possible that acquiring an 'FM-label' may lead to increased illness behaviour, dependence on health care providers, and increased health service costs ${ }^{4,5}$. According to the second theory, a timely and definite diagnosis may reduce the number of referrals, use of multiple health care providers, and costs ${ }^{6}$.

Recently, there has been growing recognition of the importance of early identification resulting in early intervention of patients who are at risk of chronic pain ${ }^{7}$. Intervening early in the course of a pain condition may help preventing the long-term physical and psychological suffering. It has the potential to reduce or prevent disability in patients with chronic pain, which, in turn, will reduce societal and medical costs ${ }^{8}$.

The fact that timing in diagnosis is important has been one of the reasons for conducting a randomized controlled trial (RCT) on referred patients with musculoskeletal symptoms suggestive of $\mathrm{FM}$, in which diagnostic visits performed by a specialized rheumatology nurse (SRN) within 3 weeks ('early diagnosis') after referral were compared with diagnostic visits performed by a rheumatologist (RMT) after a regular waiting period of approximately 3 months ('delayed diagnosis') ${ }^{9}$. We concluded from the results of that trial that substituting SRNs for RMTs in the diagnostic process of FM is a trustworthy and successful approach that not only saves waiting time but also provides greater patient satisfaction, and cost-savings ${ }^{9,10}$. After 9 months, however, we could not find differences in patient's health status between the two approaches.

In the analysis of the RCT it was not distinguished whether a diagnosis of FM or of another condition was made. In order to further investigate the impact of a diagnosis of FM in comparison to another diagnosis, we performed a post-hoc analysis of these trial data, comparing the patients in whom a diagnosis of FM was made with those in whom another condition was diagnosed. Further, we investigated the impact of an early diagnosis via the SRN in comparison with a delayed diagnosis by the RMT.

\section{Patients and Methods}

\section{Patients}

Subjects were 193 patients of a RCT in which the diagnostic process performed by a SRN within 3 weeks after referral (early diagnosis group; $n=97$ ) was compared with the diagnostic process performed by a RMT after a regular waiting period of 
approximately 3 months (delayed diagnosis group; $n=96)^{9}$. The patients were referred by the GP to the rheumatology outpatient clinic of the Maastricht University Medical Centre, with a written referral letter expressing symptoms of widespread pain suggestive of FM. After the diagnostic process, 159 (82.4\%)patients could be classified as having FM according to the American College of Rheumatology criteria ${ }^{1}$. In 33 (17.1\%) patients another diagnosis was made and of 1 patient the diagnosis remained unknown (Table 4.1).

Table 4.1 Final diagnosis of 193 patients referred for musculoskeletal symptoms suggestive of fibromyalgia in whom a diagnosis was made within 3 weeks after referral (early diagnosis) or after a regular 3-month waiting time (delayed diagnosis)*

\begin{tabular}{|c|c|c|c|c|}
\hline & \multicolumn{2}{|c|}{$\begin{array}{l}\text { Early diagnosis group } \\
\qquad(\mathrm{n}=97)\end{array}$} & \multicolumn{2}{|c|}{$\begin{array}{l}\text { Delayed diagnosis group } \\
\qquad(\mathrm{n}=96)\end{array}$} \\
\hline Fibromyalgia diagnoses & $89(92)$ & & $70(73)$ & \\
\hline Fibromyalgia alone & 75 & (84) & 46 & (66) \\
\hline Fibromyalgia plus additional diagnosis & 14 & (16) & 24 & (34) \\
\hline Rheumatological & & $11(79)$ & & $18(75)$ \\
\hline Inflammatory ${ }^{\dagger}$ & & 1 & & 1 \\
\hline Degenerative & & 4 & & 8 \\
\hline Other soft tissue disorders§ & & 6 & & 9 \\
\hline Non-rheumatological" & & $3(21)$ & & $6(25)$ \\
\hline Other diagnosis & $8(8)$ & & $25(26)$ & \\
\hline Rheumatological & 6 & (75) & 22 & (88) \\
\hline Inflammatory ${ }^{\dagger}$ & & 0 & & 3 \\
\hline Degenerative $\ddagger$ & & 1 & & 8 \\
\hline Other soft tissue disorders§ & & 5 & & 11 \\
\hline Non-rheumatologicalq & 2 & $(25)$ & & (4) \\
\hline No complaints & 0 & (0) & 2 & (8) \\
\hline Unknown & $0(0)$ & & $1(1)$ & \\
\hline
\end{tabular}

* Values are the numbers (percentage); SRN = specialized rheumatology nurse; RMT = rheumatologist; $\dagger$ inflammatory diseases: case of undifferentiated arthritis with tenosynovitis $(n=1), \operatorname{RA}(n=1)$, spondylarthropathy $(n=1)$, psoriatic arthritis $(n=1)$, tophaceous gout $(n=1)$; $\ddagger$ degenerative diseases: osteoarthritis of peripheral joints $(n=15)$, osteoarthritis and idiopathic carpal tunnel syndrome $(n=1)$; osteoarthritis of the hip $(n=1)$, axial osteoarthritis $(n=5)$; $\S$ other soft tissue disorders: periarthritis humeroscapularis $(n=5)$, chronic low back pain $(n=2)$, localised tendinopathy $(n=1)$, hypermobility syndrome $(n=6)$, bursitis $(n=1)$, retropatellar chondropathy $(n=1)$, Dupuytren's disease $(n=1)$, postural abnormality $(n=5)$, myalgia accompanying the use of statins $(n=1)$, undifferentiated articular pain $(n=1)$, localised pain $(n=1)$, non-specific myalgia $(n=1)$, athralgia $(n=4)$; ๆ non-rheumatological: hypothyroidism $(n=1), G^{\prime}$ raves' disease $(n=1)$, Sicca syndrome $(n=2)$, primary Raynaud's syndrome $(n=1)$, idiopathic carpal tunnel syndrome $(n=2)$, chronic fatigue syndrome $(n=1)$, depression $(n=1)$, high blood pressure $(n=1)$, hepatitis and psoriasis $(n=1)$. 


\section{Study design}

For the purpose of this article, we investigated health outcomes and health related costs in patients with a diagnosis of FM versus those with another diagnosis (non-FM), both at baseline (i.e. before randomization and diagnosis) and after 9 months, as well as the potential impact of an early vs. a delayed diagnosis.

\section{Health assessments}

Health outcomes were health related quality of life (HRQoL) (EuroQol-5D UK tariff (EQ-5D) and EQ-VAS) ${ }^{11,12}$, functional status (Fibromyalgia Impact Questionnaire $(F I Q))^{13,14}$, fatigue (Checklist Individual Strength $\left.(C I S-20)\right)^{15}$, pain-related anxiety (shortened version of the Pain Anxiety Symptom Scale (PASS-20)) ${ }^{16}$, pain catastrophizing (Pain Catastrophizing Scale $(P C S))^{17}$, positive and negative affect (Positive and Negative Affect Schedule (PANAS)) ${ }^{18}$ and self-efficacy (General SelfEfficacy Scale $(G S E))^{19}$.

The EQ-5D index score is valued between -0.59 (worst possible state) and 1 (best possible state) (UK tariff).The EQ-VAS is an instrument for self-rating current health and ranges from 0 (worst possible health) to 100 (best possible health).

The FIQ consists of 10 items, measuring self-reported function. Each item was standardised on a 0-10 scale with higher scores indicating greater impairment. Besides this, a total FIQ score was calculated by adding up the 10 items (range 0-100).

Higher scores of the CIS-20 (range 20-140), PASS-20 (range 0-100), PCS (range 0-52), PANAS (range 10-50 for the positive as well as the negative effect), and the GSE (range 10-40) indicate respectively higher levels of fatigue, pain-related anxiety, pain catastrophizing, positive and negative effect and self-efficacy.

Health outcomes were assessed at baseline (before randomization) and after 3 weeks, 3, 6 and 9 months of follow-up. Cronbach's alphas of the different health outcomes were minimal 0.88 in the present study.

\section{Cost assessment}

Costs during the 9 months follow-up period were assessed from the societal perspective, including health care, patient, and productivity costs. Two monthly costdiaries ( $t_{1}$ (before randomization) - $t_{6}$ ) completed by the patients were used to estimate medical consumption, health care costs (e.g. consultations, medication, home care) and non-health care costs (e.g. home help, informal care, medical aids, health activities, and productivity costs). The calculation of the costs and the price values used are described elsewhere ${ }^{9,10}$. Productivity costs were calculated for each patient as the difference between the official working hours reported and the number of hours actually worked, valued at the patient's value per hour, using the human capital limited approach $(\mathrm{HClim})^{20}$. All costs were presented in 2007 prices and inflated where appropriate, using the general Dutch consumer price index rate (www.cbs.nl). 


\section{Statistical analysis}

Demographic characteristics and health outcomes were analysed by $t$-test for continuous data and by Chi-square test for categorical data. Pearson's correlation coefficients were calculated to explore the relationship between diagnosis and HRQoL, functional status, fatigue, pain-related anxiety, pain catastrophizing, positive and negative affect, and self-efficacy.

A logistic regression analysis was performed on the missing data occurring in the study. Based on this analysis we considered the missing data fulfilling the criteria for 'missing at random (MAR)'.

A linear mixed model analysis was used to assess changes in health outcomes over time and between subjects. An advantage of this method is its handling of missing data; in the mixed model analysis all available data are used to estimate marginal means and its standard error (SE).

In order to complete missing cost data, a non-parametric multiple imputation method was used, which created five new datasets. Means calculated for costs are an average of the means from these datasets created. Mean incremental costs per patients were calculated as well as mean differences in costs and 95\% uncertainty intervals (UIs) using a non-parametric double-sided bootstrap method.

Data were analysed using SPSS 17.0 (SPSS Inc., Chicago, IL).

\section{Results}

In the RCT, 159 patients (82\%) met the American College of Rheumatology criteria for FM. In 33 patients (18\%) another diagnosis (non-FM) was made (Table 4.1). The early diagnosis group was seen within 3 weeks after randomization while the regular diagnosis group had a rheumatological consultation after a regular waiting period of approximately 3 months. The demographic characteristics of the FM and non-FM patients are summarized in Table 4.2, subdivided into patients with an early (SRN) and a delayed (RMT) diagnosis. There were no clear differences between FM patients and non-FM patients before diagnosis, but FM patients had a significantly longer duration of complaints than non-FM patients (6.3 \pm 7.4 yrs vs. $4.2 \pm 4.1 \mathrm{yrs} ; P=0.029)$, considered their complaints more frequently as severe ( $86 \%$ vs. $67 \% ; P=0.012$ ), and indicated more additional health problems than non-FM patients ( $86 \%$ vs. $67 \%$; $P=0.01$ ). Before making a diagnosis, the early diagnosed FM patients and those with a delayed diagnosis differed with respect to the percentage of patients with a paid job (59\% vs. 41\%; $P=0.034)$. The early diagnosed non-FM patients differed from the delayed diagnosed non-FM patients with respect to the level of education (low education: $87.5 \%$ vs. $36.0 \%$ respectively; $P=0.044)$. 
Table 4.2 Characteristics of 192 patients referred for musculoskeletal complaints suggestive of fibromyalgia in whom a diagnosis was made within 3 weeks after referral (early diagnosis) or after a regular 3-month waiting time (delayed diagnosis)*

\begin{tabular}{|c|c|c|c|c|}
\hline & \multicolumn{2}{|c|}{$\begin{array}{l}\text { Patients with a } \\
\text { diagnosis of FM } \\
(n=159)\end{array}$} & \multicolumn{2}{|c|}{$\begin{array}{l}\text { Patients with another } \\
\text { diagnosis, non-FM } \\
(n=33)\end{array}$} \\
\hline & $\begin{array}{l}\text { Early diagnosis } \\
\qquad(\mathrm{n}=89)\end{array}$ & $\begin{array}{c}\text { Delayed } \\
\text { diagnosis } \\
(n=70)\end{array}$ & $\begin{array}{l}\text { Early diagnosis } \\
\qquad(n=8)\end{array}$ & $\begin{array}{c}\text { Delayed } \\
\text { diagnosis } \\
(n=25)\end{array}$ \\
\hline Age, mean \pm SD years & $43.5 \pm 10.9$ & $46.3 \pm 11.9$ & $50.1 \pm 12.2$ & $40.3 \pm 11.5^{\dagger}$ \\
\hline Female & $75(84.3)$ & $59(84.3)$ & $5(62.5)$ & $21(84.0)$ \\
\hline \multicolumn{5}{|l|}{ Level of education } \\
\hline Low & $50(56.2)$ & $38(54.3)$ & 7 (87.5) & $9(36.0) \dagger$ \\
\hline Middle & $32(35.9)$ & $21(30.0)$ & $0(0.0)$ & $12(48.0)$ \\
\hline High & $7(7.8)$ & $11(15.8)$ & $1(12.5)$ & $4(16.0)$ \\
\hline \multicolumn{5}{|l|}{ Living situation } \\
\hline Together with partner & $36(40.4)$ & 23 (32.9) & $5(62.5)$ & $6(24.0)$ \\
\hline Together with partner and children & $34(38.2)$ & $24(34.3)$ & $2(25.0)$ & $14(56.0)$ \\
\hline Without partner, with children & $4(4.5)$ & $5(7.1)$ & $0(0.0)$ & $0(0.0)$ \\
\hline Alone & $11(12.4)$ & $11(15.7)$ & $1(12.5)$ & $4(16.0)$ \\
\hline Together with parents & $2(2.2)$ & $5(7.1)$ & $0(0.0)$ & $0(0.0)$ \\
\hline Other & $2(2.2)$ & $2(2.9)$ & $0(0.0)$ & $1(4.0)$ \\
\hline Paid job & $52(58.4)$ & $29(41.4)^{\dagger}$ & $4(50.0)$ & $13(52.0)$ \\
\hline Duration of complaints, mean \pm SD years & $6.3 \pm 7.4$ & $3.9 \pm 3.7$ & $6.3 \pm 7.6$ & $4.3 \pm 4.2$ \\
\hline Patient-reported severity of complaints & $73(82.0)$ & $62(88.6)$ & $7(87.5)$ & $15(60.0)$ \\
\hline Patient-reported anxiety about complaints & $72(80.9)$ & $54(77.1)$ & $5(62.5)$ & $19(76.0)$ \\
\hline Patient-reported comorbidity & $77(86.5)$ & $59(84.3)$ & $6(75.0)$ & $16(64.0)$ \\
\hline
\end{tabular}

* Diagnosis of $\mathrm{n}=1$ unknown; values are the numbers (percentage) unless otherwise indicated; $+P<0.05$.

Health outcomes before diagnosis are summarised in Table 4.3. It is important to note that FM-patients had consistently worse values than non-FM patients, both in the early diagnosis group as well as in the delayed diagnosis group. Overall, at baseline, FM patients reported a significantly lower HRQoL (EQ-5D: $0.37 \pm 0.33$ vs. $0.53 \pm 0.31$, $P=0.013$; EQ-VAS: $46.7 \pm 17.8$ vs. $57.1 \pm 16.8, P=0.003$ ), a significantly lower level of physical function (FIQ physical function: $4.2 \pm 2.4$ vs. $3.3 \pm 2.4 ; P=0.05$ ), a significantly higher level of disability (FIQ total: $59.7 \pm 15.3$ vs. $51.9 \pm 15.6 ; P=0.09$ ), fatigue (FIQ fatigue: $7.7 \pm 2.1$ vs. $6.0 \pm 2.6 ; P=0.001$ ), and pain-related anxiety (PASS-20 total: $39.2 \pm 21.8$ vs. $32.1 \pm 15.9 ; P=0.047)$ than non-FM patients. Before establishing the diagnosis, statistically significant differences between the early diagnosed FM patients and those with a delayed diagnosis were found for CIS-20 total, PASS-20 total and Positive Effect (PANAS). The early and the normally diagnosed non-FM patients varied concerning FIQ fatigue and CIS-20 total. 
Table 4.3 Baseline values (mean (SD)) for several health outcomes in 192 patients referred for musculoskeletal complaints suggestive of fibromyalgia in whom a diagnosis was made within 3 weeks after referral (early diagnosis) or after a regular 3-month waiting time (delayed diagnosis). Results are stratified for patients with a diagnosis of fibromyalgia (FM) and patients with another diagnosis (non-FM)*

\begin{tabular}{|c|c|c|c|c|}
\hline & \multicolumn{2}{|c|}{$\begin{array}{l}\text { Patients with a diagnosis of FM } \\
\qquad(n=159)\end{array}$} & \multicolumn{2}{|c|}{$\begin{array}{l}\text { Patients with another diagnosis, } \\
\qquad \begin{array}{l}\text { non-FM } \\
(\mathrm{n}=33)\end{array}\end{array}$} \\
\hline & $\begin{array}{c}\text { Early } \\
\text { diagnosis } \\
(\mathrm{n}=89) \\
\end{array}$ & $\begin{array}{c}\text { Delayed } \\
\text { diagnosis }(n=70)\end{array}$ & $\begin{array}{c}\text { Early } \\
\text { diagnosis } \\
(n=8)\end{array}$ & $\begin{array}{c}\text { Delayed } \\
\text { diagnosis }(n=25)\end{array}$ \\
\hline EQ-5D (UK tariff) (-0.59-1) & $0.42(0.31)$ & $0.32(0.34)$ & $0.62(0.30)$ & $0.50(0.31)$ \\
\hline EQ-VAS (0-100) & $48.1(17.8)$ & $44.9(17.7)$ & $62.4(17.6)$ & $55.6(16.6)$ \\
\hline \multicolumn{5}{|l|}{ FIQ-subscales (0-10) } \\
\hline Physical function & $4.2(2.3)$ & $4.2(2.5)$ & $1.9(2.2)$ & $3.7(2.4)$ \\
\hline Days feel good & $5.9(2.4)$ & $6.2(2.4)$ & $5.7(3.4)$ & $5.9(2.4)$ \\
\hline Days missed work & $2.2(3.2)$ & $3.4(4.1)$ & $1.8(3.9)$ & $1.0(2.4)$ \\
\hline Job ability & $7.0(2.4)$ & $6.7(2.9)$ & $4.6(2.4)$ & $6.4(3.0)$ \\
\hline Pain & $6.1(2.0)$ & $6.5(1.8)$ & $5.4(2.3)$ & $5.9(1.9)$ \\
\hline Fatigue & $7.5(2.2)$ & $7.9(2.0)$ & $4.3(2.3)$ & $6.5(2.4)^{\dagger}$ \\
\hline Unrefreshed sleep & $7.4(2.3)$ & $7.7(2.4)$ & $6.4(3.0)$ & $7.6(2.1)$ \\
\hline Stiffness & $7.1(1.9)$ & $7.3(2.4)$ & $5.7(3.1)$ & $7.0(2.2)$ \\
\hline Anxiety & $4.7(2.8)$ & $5.2(2.9)$ & $3.8(3.1)$ & $4.6(2.9)$ \\
\hline Depression & $4.5(2.9)$ & $4.7(3.0)$ & $3.0(2.7)$ & $4.0(2.8)$ \\
\hline Total & $58.3(14.3)$ & $61.4(16.6)$ & $44.5(16.3)$ & 54.3 (14.9) \\
\hline CIS-20 total (20-140) & $92.8(22.9)$ & $100.6(22.5)^{\dagger}$ & $71.1(25.2)$ & $94.1(22.9) \dagger$ \\
\hline PASS-20 total (0-100) & $36.1(19.4)$ & $43.0(24.1)$ & $23.0(15.2)$ & $34.5(15.4)$ \\
\hline PCS total (0-52) & $22.4(12.1)$ & $23.9(13.9)$ & $20.4(10.8)$ & $19.0(9.2)$ \\
\hline \multicolumn{5}{|l|}{ PANAS (10-50) } \\
\hline Positive & $27.5(8.5)$ & $24.7(7.7)^{\dagger}$ & $27.6(5.2)$ & $22.8(6.7)$ \\
\hline Negative & $24.6(9.1)$ & $25.7(8.8)$ & $21.0(9.8)$ & $23.9(7.7)$ \\
\hline GSE (10-40) & $27.2(5.2)$ & $26.4(4.8)$ & $28.9(6.0)$ & $27.2(3.1)$ \\
\hline
\end{tabular}

*Diagnosis of $\mathrm{n}=1$ unknown; $\mathrm{FIQ}=$ Fibromyalgia Impact Questionnaire; CIS-20 = Checklist Individual Strength; PASS-20 = shortened version of the Pain Anxiety Symptom Scale; PCS = Pain Catastrophizing Scale; PANAS $=$ Positive and Negative Affect Schedule; GSE $=$ General Self-Efficacy Scale; $+P<0.05$.

We formally tested whether the timing of diagnosis (early vs. delayed) had a different impact on health outcomes in FM patients than in non-FM patients, using interaction analysis. The time of diagnosis (early vs. delayed) did not modify the relationships between the diagnosis (FM vs. non-FM) and several health outcomes (results not shown), so that we ignored the original group-allocation (early vs. regular) in the subsequent analyses.

Figures 1-5 summarize changes in health outcomes during 9 months of follow-up between FM- and non-FM patients. With respect to HRQoL, patients with a diagnosis of FM did not change at all over time, while patients in whom another diagnosis was 
made showed improvement during the 9 months of follow-up $(P \leq 0.0001)$. The same effect was seen with respect to almost all separate items of the FIQ, as well as to the FIQ total score $(P$-values $\leq 0.005)$. Fatigue, pain-related anxiety and pain catastrophizing all showed similar effects.

Patients with a diagnosis of FM incurred slightly more health care costs than non-FM patients (€1498 vs. €1315), but this difference was not statistically significant (difference $€-183,95 \%$ UI $€-613$ to $€ 255$ ). Costs concerning absenteeism from work were somewhat higher in the non-FM patients ( $€ 3031$ vs. $€ 3732$; difference $€ 701$, $95 \%$ UI $€-2474$ to $€ 5226)$. An early diagnosis generated lower costs both from health care and societal perspective, especially for non-FM patients (total societal costs FM patients: early vs. delayed diagnosis, €4190 vs. €5014; difference €824, 95\% UI €-1579 to $€ 3402$ ); total societal costs non-FM patients: early vs. delayed diagnosis, $€ 700$ vs. $€ 6425$; difference $€ 5725$, 95\% UI €1985 to €10.988).
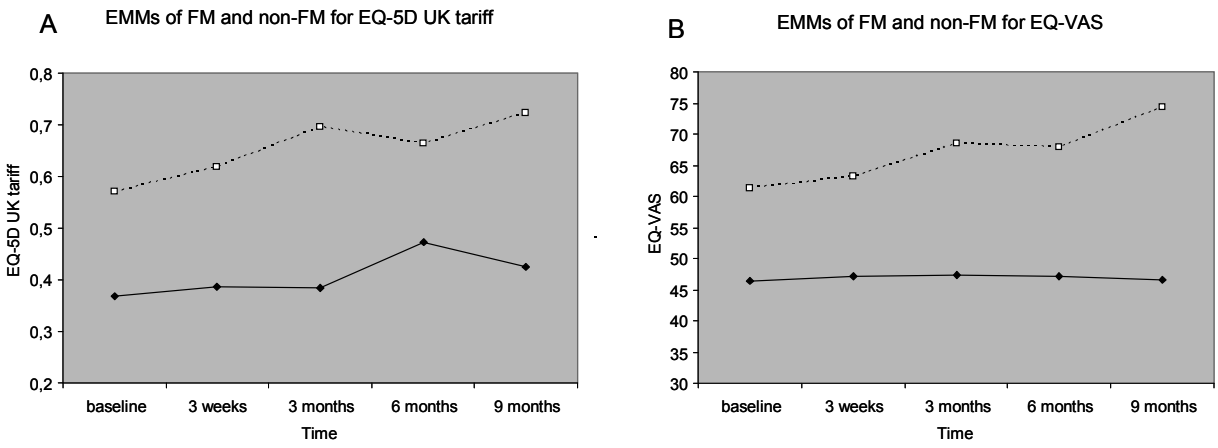

C EMMs of FM and non-FM for FIQ physical function



D EMMS of FM and non-FM for FIQ feel good

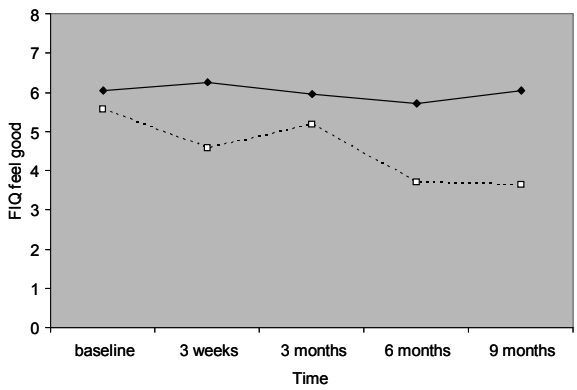

Figure 4.1. Estimated marginal means for EQ-5D UK tariff (Fig 4.1a), EQ-5D VAS (Fig 4.1b), FIQ 'physical function' (Fig 4.1c) and FIQ 'days feeling good' (Fig 4.1d) stratified for patients with a diagnosis of fibromyalgia (FM) and patients with another diagnosis (non-FM). 

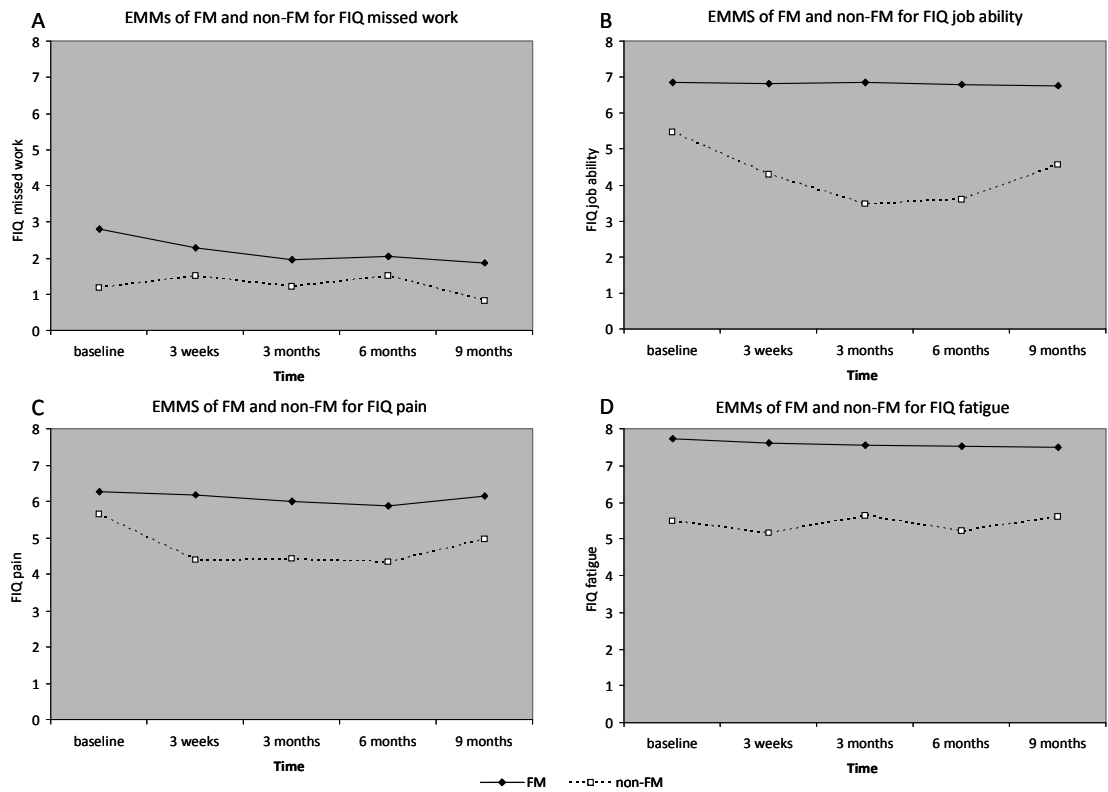

Figure 4.2 Estimated marginal means for FIQ 'days missed work' (Fig 4.2a), FIQ 'job ability' (Fig 4.2b), FIQ 'pain' (Fig 4.2c) and FIQ 'fatigue' (Fig 4.2d) stratified for patients with a diagnosis of fibromyalgia (FM) and patients with another diagnosis (non-FM).

A EMMs of early and regularly diagnosed FM and non-

FM patients for morning tiredness

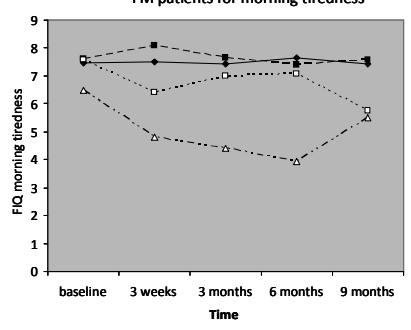

C EMMs of FM and non-FM for FIQ anxiety



B EMMs of FM and non-FM for FIQ stiffness

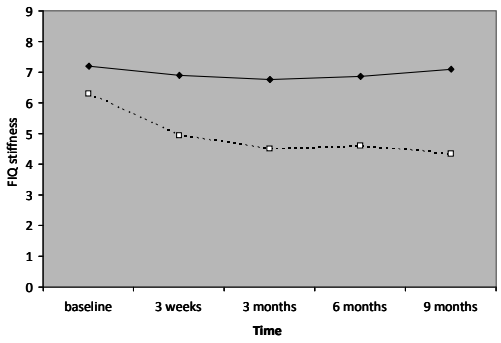

D EMMs for FM and non-FM for FIQ depression



Figure 4.3 Estimated marginal means for FIQ 'morning tiredness'(Fig 4.3a), FIQ 'stiffness' (Fig 4.3b), FIQ 'anxiety' (Fig 4.3c) and FIQ 'depression' (Fig 4.3d) stratified for patients with a diagnosis of fibromyalgia (FM) and patients with another diagnosis (non-FM). 

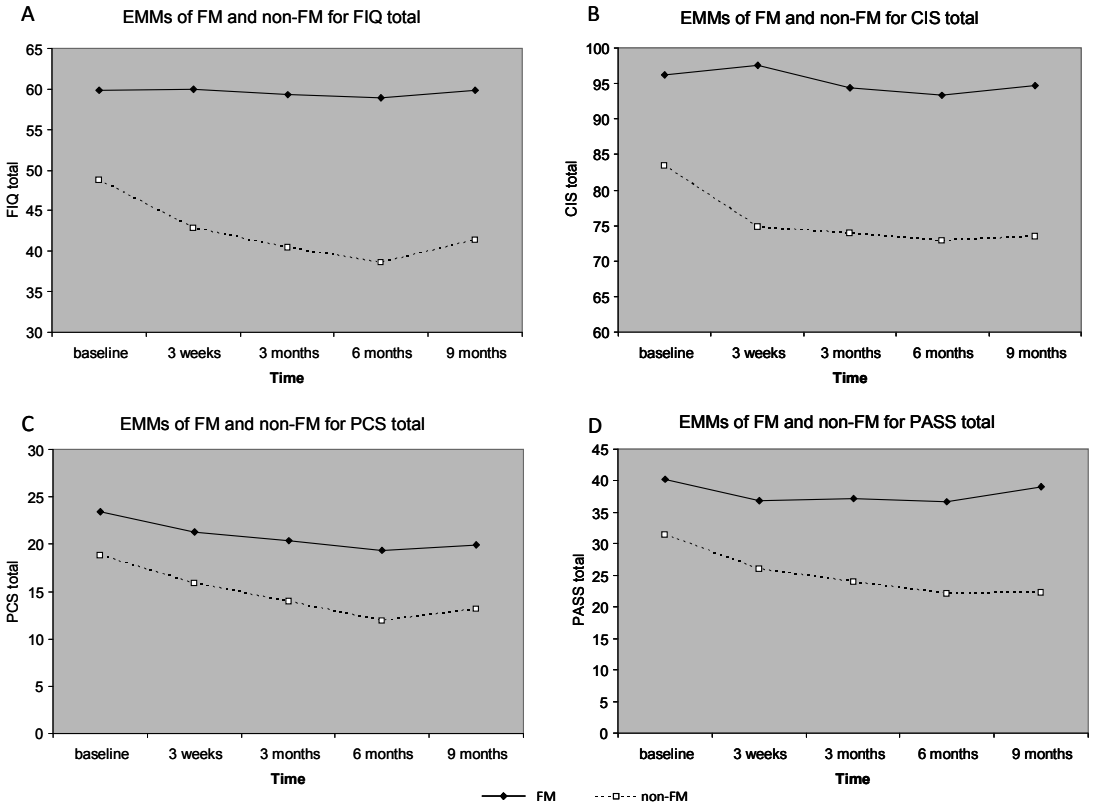

Figure 4.4 Estimated marginal means for FIQ 'total' (Fig 4.4a), CIS-20 'total' (Fig 4.4b), PCS 'total' (Fig 4.4c) and PASS-20 'total' (Fig 4.4d) stratified for patients with a diagnosis of fibromyalgia (FM) and patients with another diagnosis (non-FM).
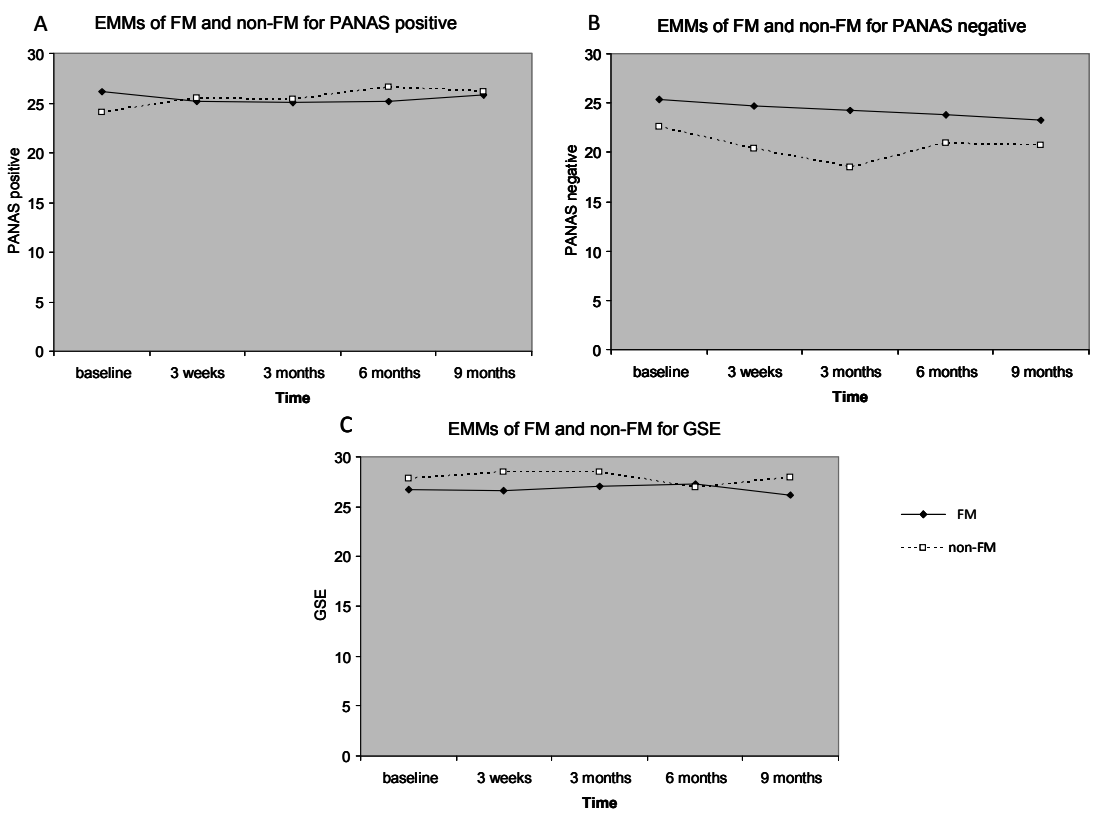

Figure 4.5 Estimated marginal means for PANAS 'positive' (Fig 4.5a), PANAS 'negative' (Fig 4.5b) and GSE (Fig $4.5 \mathrm{c}$ ) stratified for patients with a diagnosis of fibromyalgia (FM) and patients with another diagnosis (non-FM). 


\section{Discussion}

The main conclusion of this post-hoc analysis of an RCT with patients referred to the outpatient clinic of the department of rheumatology with symptoms suggestive of FM (e.g. widespread pain) is that patients in whom such a diagnosis of FM was confirmed reported far worse scores for almost all measured health outcomes in comparison with patients diagnosed with any other condition. An important finding is that these differences were already existent at baseline, before the actual diagnosis was made and communicated to the patient. Another important finding is that patients with a 'confirmed' and 'communicated' diagnosis of FM fared a stable -but far worse- course than patients in whom another diagnosis was made and communicated (or in whom a diagnosis of FM was rejected). In fact, health outcomes tended to improve in this latter group in the entire broad array of measured outcomes. A timing of diagnosis did not have any impact on health outcomes, neither at baseline nor after follow-up. An early diagnosis, however, saved costs, especially in patients with a non-FM diagnosis.

The primary goal of this post-hoc analysis was to find support for one of the two prevailing schools ${ }^{3}$ regarding the importance of the recognition of FM as an entity and of a timely diagnosis: one school disregards FM as an entity for reasons of 'stigmatisation' and justification for inappropriate illness behaviour ${ }^{4,5}$; the other school emphasizes a clear vignette and a timely diagnosis as a means to prevent anxiety and uncertainty about the future, and thus as a means to save direct and indirect health care costs ${ }^{6}$.

The results of our post hoc analysis do not give resolution with respect to any of both schools. In fact, our results do not support any of both.

It is unlikely that the unfavourable course of the patients with a diagnosis of FM is due to 'stigmatisation' since these patients were reporting bad outcomes in all aspects of health already before the confirmation of the diagnosis. The positive changes in health seen in the non-FM patients over time indicate that the assessment tools that were used are sufficiently sensitive to change to pick up improvements in health over a 9-month time course, which indirectly suggests that FM is indeed a 'bad fate'.

It is also unlikely that a clear and timely label of FM prevents anxiety, uncertainty, and inappropriate illness behaviour. This study showed that patients diagnosed with FM were remarkably stable over time, not only with respect to signs and symptoms of fibromyalgia such as pain, stiffness and fatigue, but also with respect to pain-related anxiety (PASS-20), pain catastrophizing (PCS) and HRQoL (EQ-5D). The timing of the diagnosis did not have any impact on these. We have previously reported from this trial that patients that were diagnosed early had a higher level of satisfaction and incurred lower medical costs. The higher patient satisfaction, though, was likely due to perceived differences in the content of the diagnostic procedure (SRN versus a formal medical specialist consultation) rather than to 'timing'. Lower medical costs in the early diagnosis group appeared to be due to significantly greater expenditures for the more frequently occurring alternative diagnoses in the delayed diagnosis group. In 
other words: the rheumatologists were in doubt about a diagnosis of FM more frequently than the nurses, and did significantly more diagnostic tests in patients in whom they suspected another diagnosis than FM.

An important question in this context is why patients diagnosed with FM have such bad health outcomes, while the pathophysiological substrate for that suffering is so ill defined.

Beyond any doubt, the patients assessed in this study suffer a lot, which has an important impact on their quality of life and costs for society ${ }^{21}$. From that perspective, it is irrelevant whether a patient is diagnosed with FM or with some other diagnosis, as long as the health care provider realises that the patient has a serious and important problem that interferes with quality of life. Health care interventions in such patients should aim at exploring complaints, difficulties and limitations in the individual patient, rather than at making a diagnosis. More importantly, they should not loose interest or cast doubt on the 'reality' of the diagnosis if that diagnosis is FM.

Another important observation is that the bad health status of patients diagnosed with FM extends to all kinds of health outcomes: high scores were found for pain, stiffness and fatigue, but also for anxiety and to some extent for depression. Apart from that, these patients report consistently they suffer from more co-morbidities, and they consistently grade the severity of their condition as higher than patients with other 'non-FM conditions'. These findings are confirmed in the literature, as FM patients rate their quality of life extremely low compared with other groups of patients, like rheumatoid arthritis (RA), and osteoarthritis (OA ${ }^{22-24}$. The FM patients in our study have higher scores for 'pain catastrophizing' and experience more negative affects than patients with other diagnoses. The scores for the PCS as well as the PASS20 are comparable to the scores found in FM patients by Roelofs et al. ${ }^{25}$ and in contrast to higher scores found other studies in FM patients ${ }^{26,27}$ as well as in other diagnosis like chronic whiplash ${ }^{28}$ and diabetic neuropathy ${ }^{29}$.

Two theories as to why patients with a disorder, which -if recognised as 'real' at all- do so badly in terms of health, should briefly be discussed here:

The first theory, which has a 'medical' basis, starts with the assumption that FM is a condition of still unexplained widespread musculoskeletal pain with such an impact on a patient's life that it leads to function loss, anxiety and depression. It is this chain of symptoms that is implicitly recognised by the diagnosing health care provider as being specific for FM, and since it takes some time to fully develop, the label of FM is reserved for the 'bad cases'. This may explain why patients with a diagnosis of FM report such bad health outcomes over the entire spectrum.

The second theory assumes that FM is a behavioural rather than a 'medical' disorder. In this theory, in which fear and anxiety play a dominant role, potentially superimposed on a state of 'hypersensitivity', that has been reported consistently in many patients with FM, innocuous and objectively mild pain stimuli that are 
interpreted by the patient as dangerous and harmful elicit feelings of anxiety and fear, and ultimately depression ${ }^{30,31}$. Also according to this theory, patients report very bad health outcomes over a broad spectrum of health, but scores are importantly coloured here by the perception of the patient, and reflect an aggravated situation, that in the absence of valid objective measures can never be validated. An important argument pointing to the validity of this theory is that we and others have found high scores for 'pain-catastrophizing' (ruminating, magnification, helplessness) and for experiencing 'negative affects' ${ }^{27,32}$. Indeed, FM patients tended to 'magnify' the severity of their condition at baseline, and reported significantly more co-morbidities (that were not checked).

It should be noted that this post-hoc analysis suffers from many methodological shortcomings that limit its interpretability.

First, the comparison of health outcomes between 'FM-patients' and 'non-FMpatients' is fallible because these subgroups have been created artificially, after randomization. Differences in health states, for example, can be due to true differences, but also to selection by diagnosing health care providers that limit the diagnosis of FM to the worst patients (channelling).

Second, many of the reported health outcomes are measured by a 'FM-specific' questionnaire, such as the FIQ and its subscales. However, several studies comparing FM patients to patients with other conditions like RA, SLE, migraine and major depressive disorder have found that FM patients have higher FIQ scores than the nonFM patients ${ }^{13,33-35}$.

Third, patients in this analysis reflect patients entered in a clinical trial that probably do not resemble patients in common clinical practice.

Fourth, the number of patients in the 'non-FM subgroup' was relatively small and very heterogeneous, so that the improvements seen in health status in this artificial subgroup cannot be assigned to specific diagnoses. Further, these changes may lack robustness.

Fifth, the relationship between a diagnosis of FM and bad health outcomes invites to semi-causal speculation (which we have also done here), but the design of this study does not allow any conclusion about a causal relationship at all. This study can and should only serve to describe associations between a diagnosis of FM and health outcomes.

In summary, this post-hoc analysis of an RCT in patients with a suspicion of FM, in which an approach with an early diagnostic visit was compared with a regular, and thus delayed, diagnostic trajectory, revealed that patients who got a label of FM had far worse health outcomes at baseline and after 9 months of follow-up than patients in whom another diagnosis was made. Patients with a diagnosis of FM, in contrast to others, do not seem to improve their health status over time, which points to the persistence of this ill-defined condition. Timing of the diagnosis (early vs. delayed) appeared to be of trivial importance.

Regardless of the validity of the concept of FM and its presumed causes, these results point towards the impact that FM may have on the quality of life for individual 
patients, and -in light of its prevalence- on the economic consequences for society: it is to be expected that patients that report such huge health problems over such a broad health spectrum may be at serious risk of incurring huge medical costs and loosing their jobs. It is a challenge for the medical and rheumatological community to appropriately cope with ill-defined conditions such as FM, in order to improve the individual's quality of life and to limit direct and indirect costs for society. 


\section{References}

1. Wolfe F, Smythe HA, Yunus MB, Bennett RM, Bombardier C, Goldenberg DL, et al. The American College of Rheumatology 1990 Criteria for the Classification of Fibromyalgia. Report of the Multicenter Criteria Committee. Arthritis Rheum 1990;33:160-172.

2. Mease P. Fibromyalgia syndrome: review of clinical presentation, pathogenesis, outcome measures, and treatment. J Rheumatol 2005;75:6-21.

3. Annemans L, Wessely S, Spaepen E, Caekelbergh K, Caubere JP, Le Lay K, et al. Health economic consequences related to the diagnosis of fibromyalgia syndrome. Arthritis Rheum 2008;58:895-902.

4. Ehrlich GE. Pain is real; fibromyalgia isn't. J Rheumatol 2003;30:1666-1667.

5. Hadler NM. "Fibromyalgia" and the medicalization of misery. J Rheumatol 2003;30:1668-1670.

6. White KP, Nielson WR, Harth M, Ostbye T, Speechley M. Does the label "fibromyalgia" alter health status, function, and health service utilization? A prospective, within-group comparison in a community cohort of adults with chronic widespread pain. Arthritis Rheum 2002;47:260-265.

7. Keefe FJ, Rumble ME, Scipio CD, Giordano LA, Perri LM. Psychological aspects of persistent pain: current state of the science. J Pain 2004;5:195-211.

8. van Koulil S, Effting M, Kraaimaat FW, van Lankveld W, van Helmond $T$, Cats $H$, et al. Cognitivebehavioural therapies and exercise programmes for patients with fibromyalgia: state of the art and future directions. Ann Rheum Dis 2007;66:571-581.

9. Kroese MEAL, Schulpen GJC, Bessems MCM, Severens JL, Nijhuis FJ, Geusens PP, et al. Substitution of specialized rheumatology nurses for rheumatologists in the diagnostic process of fibromyalgia: a randomized controlled trial. Arthritis Care \& Research 2008;59:1299-1305.

10. Kroese ME, Severens JL, Schulpen GJ, Bessems MC, Nijhuis FJ, Landewe RB. Specialized Rheumatology Nurse Substitutes for Rheumatologists in the Diagnostic Process of Fibromyalgia: A Cost-Consequence Analysis and a Randomized Controlled Trial. J Rheumatol 2011;38:1413-1422.

11. The EuroQol Group. EuroQol--a new facility for the measurement of health-related quality of life. Health Policy 1990;16:199-208.

12. Dolan P. Modeling valuations for EuroQol health states. Med Care 1997;35:1095-1108.

13. Bennett R. The Fibromyalgia Impact Questionnaire (FIQ): a review of its development, current version, operating characteristics and uses. Clinical and experimental rheumatology 2005;23(5 Suppl 39):S154-162.

14. Burckhardt CS, Clark SR, Bennett RM. The fibromyalgia impact questionnaire: development and validation. J Rheumatol 1991;18:728-733.

15. Vercoulen JHHM, Alberts M, Bleijenberg G. De Checklist Individual Strength (CIS). Gedragstherapie 1999;32:131-136.

16. McCracken LM, Dhingra L. A short version of the Pain Anxiety Symptoms Scale (PASS-20): preliminary development and validity. Pain Res Manag 2002;7:45-50.

17. Sullivan MJL, Bishop SR, Pivik J. The pain catastrophizing scale: development and validation. Psychological Assessment 1995;7:524-532.

18. Watson D. Development and validation of brief measures of positive and negative affect: the panas scales. J Pers Soc Psychol 1988;54:1063-1070.

19. Schwarzer R, Jerusalem M. Generalized Self-Efficacy Scale. In: Weinman J, Wright S, Johnston M, editors. Measures in health psychology: A user's portfolio. Causal and control beliefs. Windsor, UK: NFER-NELSON; 1995:35-37.

20. van Asselt AD, Dirksen CD, Arntz A, Severens JL. Difficulties in Calculating Productivity Costs: Work Disability Associated with Borderline Personality Disorder. Value in Health 2008;11:637-644.

21. Annemans L, Le Lay K, Taieb C. Societal and patient burden of fibromyalgia syndrome. Pharmacoeconomics 2009;27:547-59.

22. Burckhardt CS, Clark SR, Bennett RM. Fibromyalgia and quality of life: a comparative analysis. J Rheumatol 1993;20:475-9.

23. Verbunt JA, Pernot DH, Smeets RJ. Disability and quality of life in patients with fibromyalgia. Health Qual Life Outcomes 2008;6:8.

24. Wolfe F, Hawley DJ. Measurement of the quality of life in rheumatic disorders using the EuroQol. Br J Rheumatol 1997;36:786-93. 
25. Roelofs J, McCracken L, Peters ML, Crombez G, van Breukelen G, Vlaeyen JW. Psychometric evaluation of the Pain Anxiety Symptoms Scale (PASS) in chronic pain patients. J Behav Med 2004;27:167-83.

26. Alda M, Luciano JV, Andres E, Serrano-Blanco A, Rodero B, Del Hoyo YL, et al. Effectiveness of cognitive behaviour therapy for the treatment of catastrophisation in patients with fibromyalgia: a randomised controlled trial. Arthritis Res Ther 2011;13:R173.

27. Martinez MP, Sanchez Al, Miro E, Medina A, Lami MJ. The relationship between the fear-avoidance model of pain and personality traits in fibromyalgia patients. J Clin Psychol Med Settings 2011;18: 380-91.

28. Adams H, Ellis T, Stanish WD, Sullivan MJ. Psychosocial factors related to return to work following rehabilitation of whiplash injuries. J Occup Rehabil 2007;17:305-15.

29. Sullivan MJ, Lynch ME, Clark AJ. Dimensions of catastrophic thinking associated with pain experience and disability in patients with neuropathic pain conditions. Pain 2005;113:310-5.

30. Leeuw M, Goossens ME, Linton SJ, Crombez G, Boersma K, Vlaeyen JW. The fear-avoidance model of musculoskeletal pain: current state of scientific evidence. J Behav Med 2007;30:77-94.

31. Sommer C, Hauser W, Gerhold K, Joraschky P, Petzke F, Tolle T, et al. [Etiology and pathophysiology of fibromyalgia syndrome and chronic widespread pain]. Schmerz 2008;22:267-82.

32. Hassett AL, Cone JD, Patella SJ, Sigal LH. The role of catastrophizing in the pain and depression of women with fibromyalgia syndrome. Arthritis Rheum 2000;43:2493-500.

33. Bennett RM, Friend R, Jones KD, Ward R, Han BK, Ross RL. The Revised Fibromyalgia Impact Questionnaire (FIQR): validation and psychometric properties. Arthritis Res Ther 2009;11:R120.

34. Martinez JE, Ferraz MB, Sato El, Atra E. Fibromyalgia versus rheumatoid arthritis: a longitudinal comparison of the quality of life. J Rheumatol 1995;22:270-4.

35. White KP, Speechley M, Harth M, Ostbye T. Comparing self-reported function and work disability in 100 community cases of fibromyalgia syndrome versus controls in London, Ontario: the London Fibromyalgia Epidemiology Study. Arthritis Rheum 1999;42:76-83. 



\section{Chapter 5}

\section{Therapeutic approaches to fibromyalgia in the Netherlands}

A comparison between 1998 and 2005

MEAL Kroese, GJC Schulpen, HM Sonneveld, HJM Vrijhoef Journal of Evaluation in Clinical Practice 2008;14:321-5 


\section{Abstract}

\section{Objective}

To gather information from 5 disciplines on their usual management methods of fibromyalgia (FM) in order to assess whether treatment regimens have changed in the Netherlands during a period of 6 years. In addition, insight was gained into the therapeutic motives of the professionals.

\section{Methods}

A questionnaire was sent to a sample of 150 persons per discipline: general practitioners (GPs), rheumatologists (RMTs), rehabilitation specialists (RSs), physiotherapists (PTs), and psychologists.

\section{Results}

The overall response rate was $40.4 \%$. The referral behaviour changed (significantly), especially between GPs and RMTs. An increased choice for aerobic exercise (RSs: $P=0.023$ ) and multidisciplinary therapy (RMT: $P=0.046$ ) was found. RMTs and RSs showed decreased medication prescribing (RMT: $P=0.024$ ). Preferences of treatment for $F M$ differ per discipline. The choice is principally made on the basis of subjective, profession group-bound factors. Particularly for GPs, dynamic patient factors are an important motive in the management of FM.

\section{Conclusions}

Despite the fact that most changes found are in conformity with the literature, the absolute application percentages of recommended therapies are still very low. The differences in practice between the several disciplines seem explicable on the basis of the factors that have a prominent role in the choice of a therapy for FM. This study underlines the need for further research into methods and processes of the management of FM, and their clinical effectiveness. An effective way of dissemination, especially of guidelines, is essential. 


\section{Introduction}

In medical science, no syndrome exists with more discussion and controversy than fibromyalgia (FM). It takes a large claim on health services. FM occurs in 5\%-6\% of adult patients presenting at general medical and family practice clinics and in $10 \%-20 \%$ of adult patients presenting to rheumatologists (RMTs) ${ }^{1-3}$. In a review of referral patterns to a community-based rheumatology clinic, FM was responsible for more than $15 \%$ of new referrals ${ }^{4}$. Although hard, consistent data about the medical cost are lacking, it is clear that the costs for the community are high and that this syndrome is socially relevant ${ }^{5}$. Although FM is a controversial disorder, FM patients do have pain and are entitled to good care.

A survey conducted in 1998 among five different disciplines involved in the treatment of FM showed that a wide variety of therapies are used to manage pain and other symptoms in FM patients in the Netherlands ${ }^{6}$. However relatively few treatments had been rigorously tested ${ }^{6,7}$. Since the 1998 survey, several systematic reviews have been published, which concluded that the most empirical support exists for nonpharmacological approaches in FM, primarily, graded physical aerobic exercise ${ }^{8-11}$. Concerning pharmacotherapeutic agents, the available evidence supports the use of tricyclic antidepressants and/or selective serotonin re-uptake inhibitors ${ }^{12-14}$. Furthermore, studies that used a combination approach showed greater improvements than those comparing a single intervention. It would seem therefore, that FM is better managed by a multimodal approach, incorporating aerobic exercise, education and, if necessary, pharmacologic therapies, to address physical, functional and psychological aspects of $\mathrm{FM}^{15,16}$.

To investigate whether the management of FM has changed in the last 6 years as a result of insights from recently published systematic reviews, the inventory of 1998 was repeated ${ }^{6,8-11}$. Information was gathered from the same five disciplines in the Netherlands on their usual methods of common treatment and management of patients with FM. In addition, insight was gained into the motives of the professionals to answer the questions: to what degree did the common treatment and management of FM change and, if so, for what reasons?

In addition to information on the perceived influence of several factors on the common treatment and management of FM in the Netherlands between 1998 and 2005 , this study might also be seen as an illustration on how to conduct such a survey in another country.

\section{Methods}

The data were collected by means of an anonymous, postal, self-administered questionnaire containing closed questions on all possible applied treatments for FM. The questionnaire was sent to a representative sample of 150 persons from the following disciplines: general practitioners (GPs), rheumatologists (RMTs), rehabilitation specialists, physiotherapists (PTs), and psychologists. The samples were selected from the Dutch Medical Directory ${ }^{17}$ or from their respective professional 
associations. For the disciplines in which less than 150 practitioners were working, all professionals were included. A reminder was sent after two weeks.

The questionnaire of 1998, which was based upon a review of the literature on FM and on discussions with practitioners from the several disciplines, was updated ${ }^{6}$. The frequency of referrals to other professionals and treatment application were both measured on a 5-point Likert scale: never, sometimes, regularly, often, always.

In 2005, an extra question was added to find out which factors possibly influence the professional management of FM. The factors were taken from a report of the Dutch Council for Public Health and Health Care, which describes the influences of changes on the practice of professionals from four perspectives: the consumer/patient, the community/government, the institutions/organizations, and the professions ${ }^{18}$. In this paper, only the perspectives of the patient/consumer and the professions are reported, because the other two are only valid in the Netherlands.

\section{Data analysis}

Frequency counts were calculated per discipline and for each possible answer category. To quantify these, percentages were calculated and reported in categories, namely $<1 \%, 1 \%-25 \%, 26 \%-74 \%, 75 \%-99 \%$, $>99 \%$. In this paper, only the categories 'regularly', 'often' and 'always' are reported, as we are interested in common management. The categories 'often' and 'always' have been combined.

The difference scores of 2005 versus 1998 were computed and the non-parametric Kruskal-Wallis test was used to check whether the differences were statistically significant. Because of absence of correlation between the variables, correction for multiple testing was not applied. Statistical significance was set at $P \leq 0.05$. For the analysis of the data, SPSS version 11.5 was used (SPSS Inc., Chicago, IL, USA).

\section{Results}

The overall response rate was 42\% in 1998 and $40 \%$ in 2005 (Table 5.1). In both years, PSY had the lowest response. The discipline with the highest response was RS (57\%) in 1998 and RMT (59\%) in 2005.

Table 5.1 Initial samples and respondents*

\begin{tabular}{lcccc}
\hline & \multicolumn{2}{c}{1998} & \multicolumn{2}{c}{2005} \\
\cline { 2 - 5 } Discipline & \multicolumn{1}{c}{ Initial sample } & Response & Initial sample & Response \\
$\mathrm{n}$ & $150(\mathrm{MD})$ & $59(39)$ & $150(\mathrm{MD})$ & $52(35)$ \\
\hline General practitioner & $114(\mathrm{MD})$ & $63(55)$ & $150(\mathrm{PA})$ & $89(59)$ \\
Rheumatologist & $150(\mathrm{PA})$ & $71(47)$ & $150(\mathrm{MD})$ & $54(36)$ \\
Physiotherapist & $150(\mathrm{PA})$ & $41(27)$ & $150(\mathrm{PA})$ & $39(26)$ \\
Psychologist & $151(\mathrm{MD})$ & $86(57)$ & $150(\mathrm{PA})$ & $69(46)$ \\
Rehabilitation specialist & 715 & $320(42)$ & 750 & $303(40)$ \\
Total & & & & $\mathrm{n})$ \\
\hline
\end{tabular}

* $\mathrm{MD}=$ Medical Directory; $\mathrm{PA}=$ professional association 
Table 5.2 indicates how often the several disciplines refer to each other. An overall increase of the referral behaviour is observed, although the referrals of GPs and rehabilitation specialists to PTs had slightly decreased since 1998. GPs are making significantly more referrals to RMTs $(P=0.002)$. On the other hand, RMTs nearly always refer FM patients back to GPs (89.5\%).

Table 5.2 Referrals by the several disciplines in 2005 and compared with 1998 (in \%)*

\begin{tabular}{|c|c|c|c|c|c|c|c|c|c|c|}
\hline \multirow[b]{3}{*}{ Referrer } & \multicolumn{10}{|l|}{ Refer to } \\
\hline & \multicolumn{2}{|c|}{$\begin{array}{c}\text { General } \\
\text { practitioner }\end{array}$} & \multicolumn{2}{|c|}{ Rheumatologist } & \multicolumn{2}{|c|}{$\begin{array}{l}\text { Rehabilitation } \\
\text { specialist }\end{array}$} & \multicolumn{2}{|c|}{ Physiotherapist } & \multicolumn{2}{|c|}{ Psychologist } \\
\hline & $\begin{array}{c}\text { regularl } \\
y\end{array}$ & $\begin{array}{l}\text { often- } \\
\text { always }\end{array}$ & regularly & $\begin{array}{l}\text { often- } \\
\text { always }\end{array}$ & regularly & $\begin{array}{l}\text { often- } \\
\text { always }\end{array}$ & regularly & $\begin{array}{l}\text { often- } \\
\text { always }\end{array}$ & regularly & $\begin{array}{l}\text { often- } \\
\text { always }\end{array}$ \\
\hline General & $\times$ & $x$ & 46.9 & 28.5 & 38.8 & 4.1 & 38.8 & 22.4 & 20.4 & 12.2 \\
\hline practitioner & & & $(+20.6)^{\dagger}$ & $(+14.5)^{\dagger}$ & $(+26.5)$ & $(-1.2)$ & $(-1.6)$ & $(-0.5)$ & $(+11.6)$ & $(+10.4)$ \\
\hline \multirow[t]{2}{*}{ Rheumatologist } & 4.7 & 89.5 & $\times$ & $\times$ & 25.6 & 7.0 & 20.9 & 16.3 & 9.5 & 6.0 \\
\hline & $(-3.4)$ & $(+4.0)$ & & & $(+15.9)$ & $(-2.7)$ & $(-11.4)$ & $(+5.0)$ & $(+3.0)$ & $(+2.8)$ \\
\hline \multirow{2}{*}{$\begin{array}{l}\text { Rehabilitation } \\
\text { specialist }\end{array}$} & 31.5 & 33.4 & 14.0 & 5.3 & $\times$ & $\times$ & 30.4 & 7.1 & 17.9 & 16.1 \\
\hline & $(-0.4)$ & $(+11.1)$ & $(+2.9)$ & $(-1.7)$ & & & $(+5.4)$ & $(-5.4)$ & $(-7.1)$ & $(+0.8)$ \\
\hline Physiotherapist & $\times$ & $\times$ & $\times$ & $x$ & $x$ & $x$ & $\times$ & $\times$ & $\times$ & $\times$ \\
\hline Psychologist & $\times$ & $x$ & $x$ & $\times$ & $\times$ & $x$ & $\times$ & $\times$ & $\times$ & $\times$ \\
\hline
\end{tabular}

*Values in parentheses represent difference with $1998 ;+$ significant difference $(P \leq 0.01)$.

In Table 5.3, the treatments used prominently in 2005 and the differences (delta scores) between 2005 and 1998 are shown. Giving information and giving emotional support are the main activities of the several disciplines, but the preferences seem to differ per discipline. The second choice of GPs are analgesics, while it is aerobic exercise for RMTs and rehabilitation specialists. If a GP chooses exercise therapy, he or she refers to the PT rather than to aerobics exercise. Unlike to other doctors, rehabilitation specialists choose sooner antidepressants first before analgesics when prescribing medication.

A multidisciplinary therapy is the last choice of GPs, whereas rehabilitation specialists prefer this to psychologists and to medication. Prescribing of medication by GPs increased (both for analgesics and antidepressants), while prescribing of medication by rehabilitation specialists and especially by RMTs $(P=0.024)$ decreased. All doctors recommended much more aerobic exercise, but rehabilitation specialists prescribed aerobic exercise significantly more often $(P=0.023)$. The choice for a multidisciplinary therapy had substantial increased the last 6 years, particularly for RMTs $(P=0.046)$ and rehabilitation specialists.

From Table 5.4, it can be seen that the practitioners are led more by the 'professional group' than by the 'patient/consumer' in the choice of a treatment for FM. Concerning the professional group, it is notable that subjective factors, for instance, own experiences, seem to be more important for RMTs and rehabilitation specialists than for GPs. The GP is mostly guided by objective factors, such as publications and research results, but not to the same extent as the other two medical disciplines. 
Regarding the patient/consumer as influencing factor, dynamic aspects, for instance, the expectations of the patient, are much more significant than static characteristics, such as the social class of the patient. Especially for GPs, dynamic factors are very important motives for their treatment choices.

Table 5.3 The application of common treatments by the several disciplines in 2005 and compared with 1998 (in \%)*

\begin{tabular}{|c|c|c|c|c|c|c|}
\hline \multirow[b]{3}{*}{ Treatment } & \multicolumn{6}{|l|}{ Discipline } \\
\hline & \multicolumn{2}{|c|}{$\begin{array}{c}\text { General } \\
\text { practitioner }\end{array}$} & \multicolumn{2}{|c|}{ Rheumatologist } & \multicolumn{2}{|c|}{$\begin{array}{l}\text { Rehabilitation } \\
\text { specialist }\end{array}$} \\
\hline & regularly & $\begin{array}{l}\text { often- } \\
\text { always }\end{array}$ & regularly & $\begin{array}{l}\text { often- } \\
\text { always }\end{array}$ & regularly & $\begin{array}{l}\text { often- } \\
\text { always }\end{array}$ \\
\hline \multirow[t]{2}{*}{ Analgesics } & 34.0 & 38.3 & 32.9 & 21.1 & 1.9 & 5.6 \\
\hline & $(-6.4)$ & $(+8.4)$ & $(-9.7)^{\dagger}$ & $(-10.1)^{\dagger}$ & $(-8.8)$ & $(+3.8)$ \\
\hline \multirow[t]{2}{*}{ Antidepressants } & 38.3 & 6.4 & 24.4 & 17.4 & 12.3 & 12.3 \\
\hline & $(+6.7)$ & $(+0.3)$ & $(-1.8)$ & $(-7.2)$ & $(-10.9)$ & $(-7.3)$ \\
\hline \multirow{2}{*}{$\begin{array}{l}\text { Information/education/ } \\
\text { advice }\end{array}$} & 24.5 & 65.3 & 3.5 & 95.4 & 8.8 & 87.7 \\
\hline & $(+3.4)$ & $(+2.2)$ & $(+0.3)$ & $(+0.2)$ & $(-5.1)$ & $(+8.6)$ \\
\hline \multirow{2}{*}{$\begin{array}{l}\text { Emotional support/ } \\
\text { coaching }\end{array}$} & 20.4 & 55.1 & 20.9 & 51.1 & 35.1 & 56.2 \\
\hline & $(-11.2)$ & $(+6.0)$ & $(+3.2)$ & $(-8.6)$ & $(+1.8)$ & $(+4.8)$ \\
\hline \multirow[t]{2}{*}{ Psychologist } & 20.4 & 12.2 & 9.5 & 6.0 & 17.9 & 16.1 \\
\hline & $(+11.6)$ & $(+10.4)$ & $(+3.0)$ & $(+2.8)$ & $(-7.1)$ & $(-0.6)$ \\
\hline \multirow[t]{2}{*}{ Aerobics exercise/fitness } & 30.6 & 20.4 & 28.2 & 49.4 & 35.1 & 47.4 \\
\hline & $(+4.3)$ & $(+6.4)$ & $(+4.0)$ & $(+10.7)$ & $(-5.2)^{\dagger}$ & $(+18.2)^{\dagger}$ \\
\hline \multirow[t]{2}{*}{ Physiotherapist } & 38.8 & 22.4 & 20.9 & 16.3 & 30.4 & 7.1 \\
\hline & $(-1.6)$ & $(-0.5)$ & $(-11.4)$ & $(+5.0)$ & $(+5.4)$ & $(-5.4)$ \\
\hline \multirow[t]{2}{*}{ Multidisciplinary therapy } & 20.4 & 0.0 & 9.5 & 8.3 & 36.8 & 26.4 \\
\hline & $(+13.4)$ & $(0.0)$ & $(+9.5)+$ & $(+3.5)^{\dagger}$ & $(+32.6)$ & $(+23.6)$ \\
\hline
\end{tabular}

* Values in parentheses represent difference with 1998; † significant difference $(P \leq 0.05)$.

Table 5.4 Factors that influence the choice of a treatment for fibromyalgia by practitioners (in \%)*

\begin{tabular}{|c|c|c|c|}
\hline & GP & RMT & RS \\
\hline \multicolumn{4}{|l|}{ Patient/consumer as influencing factor } \\
\hline \multicolumn{4}{|l|}{ Static } \\
\hline Religious persuasions of the patient & 25.5 & 8.4 & 8.9 \\
\hline Social class of the patient & 59.6 & 51.8 & 43.6 \\
\hline Family situation of the patient & 76.6 & 74.7 & 74.5 \\
\hline \multicolumn{4}{|l|}{ Dynamic } \\
\hline Suggestion of a treatment by the patient & 91.3 & 79.3 & 76.8 \\
\hline Expectation/preferences of the patient & 91.5 & 75.9 & 94.5 \\
\hline Critical attitude of the patient & 87.2 & 66.3 & 70.9 \\
\hline \multicolumn{4}{|l|}{ Professional group as influencing factor } \\
\hline \multicolumn{4}{|l|}{ Objective } \\
\hline $\begin{array}{l}\text { (New) publications and research results (evidence- } \\
\text { based medicine) }\end{array}$ & 80.9 & 92.7 & 94.6 \\
\hline Protocols developed by professional group & 89.1 & 87.7 & 96.4 \\
\hline Refresher course & 95.7 & 97.5 & 92.9 \\
\hline \multicolumn{4}{|l|}{ Subjective } \\
\hline Own experiences & 93.6 & 96.3 & 100.0 \\
\hline Experiences of colleagues & 78.7 & 93.9 & 96.4 \\
\hline
\end{tabular}

* GP = general practitioner; RMT = rheumatologist; RS = rehabilitation specialist. 


\section{Discussion}

This study provides an overview of the current management of FM among several Dutch disciplines. Until 2005 there had been no unequivocal approach in the treatment of FM in the Netherlands. The international recommended therapies are not commonly applied and there is a variety of differences between the care providers. Furthermore, FM patients are often referred by and to the several disciplines involved in the management of this syndrome. The choice of a treatment for FM is principally made on the basis of subjective, professional group-bound factors such as own experiences. It is therefore remarkable that dynamic patient factors such as expectations or preferences are also an important motive in the management of FM, particularly among GPs.

How do we judge the current situation? Since the survey of 1998, several systematic reviews have been published, and therefore more distinctiveness in the management of FM conforming to the literature is expected ${ }^{6,8-11}$. Nevertheless, none of the treatments stands out. Moreover, we found an increase in the referral behaviour of doctors, especially between each other. The recommended treatments could all be initiated or managed within primary care. The high referral profile indicates that other motives are prevailing. One could speculate whether this is due to (a) the GP's lack of awareness of the recommended treatments; (b) the fact that GPs are mostly influenced by patient expectations or (c) the fact that the most preferred therapy (combined, multidisciplinary) is not available to GPs.

Arguments for speculation (a) are, for instance, the preference of GPs for PT to aerobics exercise and the fact that GPs prescribe much more analgesics than antidepressants, while in the literature the available evidence supports aerobic exercise and the use of antidepressants ${ }^{8-14}$. The GP's lack of awareness can possibly be caused by the fact that he or she has not systematically studied the literature or that he of she does not comply with the recommendations in the literature, as can be seen in the diagnosis of $\mathrm{FM}^{19}$. Speculation (b) is borne out of the data as presented in Table 5.4. For the GP, the expectations and preferences of the patient are much more important than evidence-based medicine. Speculation (c) is nothing less than a fact in the Netherlands, because in some regions multidisciplinary programmes do not exist or the GP is not acquainted with this form of therapy, or this therapy is not accessible in primary care.

Among the limitations of the present study are the suboptimal response rates of both surveys. It is remarkable that the response rate in 2005 was even slightly lower than in 1998, despite the mailing of a reminder. Possible causes include increased pressure from work and the enormous amount of mailings that several health care professionals have to deal with. Nevertheless, the samples were randomly selected, coming from all parts of the Netherlands, and the mean response rate was above the borderline of $25 \%$. Therefore, we state that the results of this survey give a robust indication of the current management of FM in the Netherlands and the reasons for this. 
On the basis of this survey, it can be concluded that the management of FM in the Netherlands between 1998 and 2005 has remained unchanged. The societal problem is not reduced, but rather made more serious by the moving of patients back and forth between doctors. Despite the published systematic reviews in the last 6 years $^{8-11}$, only a few items in the therapeutic approach have been changed, some in conformity with the literature, others not. We found a significant increase in the application of some of the international recommended treatments, however the absolute percentages are still very low. The increase is a trend which hopefully will persist. The differences in practice between the several disciplines seem explicable on the basis of the factors that have a prominent role in the choice of a therapy for FM. These findings underline the need for further research into the methods and processes of the management of FM by the several disciplines. Building on the existing evidence is essential. Furthermore, our results emphasize that research outcomes require an effective way of dissemination and implementation. The high prevalence and high medical cost of FM justify the development of guidelines. Finally, this study may provide the basis for a more detailed examination of the rational for clinical decision making in this area of practice. 


\section{References}

1. Goldenberg, DL, Simms RW, Geiger A, Komaroff AL. High frequency of fibromyalgia in patients with chronic fatigue seen in a primary care practice. Arthritis Rheum 1999;33:381-387.

2. Kennedy M, Felson DT. A prospective long-term study of fibromyalgia syndrome. Arthritis Rheum 1996;39:682-685.

3. Wolfe F, Ross K, Anderson J, Russell IJ, Hebert L. The prevalence and characteristics of fibromyalgia in the general population. Arthritis Rheum 1995; 38:19-28.

4. Martin L, Nutting A, Maclntosh BR, Edworthy SM, Butterwick D, Cook J. An exercise program in the treatment of fibromyalgia. J Rheumatol 1996;23:1050-1053.

5. Hughes G, Martinez C, Myon E, Taïeb C, Wessely S. The impact of diagnosis of fibromyalgia on health care resources use by primary care patients in the UK. Arthritis Rheum 2006;54:177-183.

6. Kroese $M$, De Vet $H$, Scholten R. An inventory of the need for research to the effectiveness of treatment of a number of chronic benign pain syndroms. Part I: Inventory of frequently applied treatments [Een inventarisatie van de behoefte aan onderzoek naar de effectviteit van behandelingen voor een aantal chronisch benigne pijnsyndromen. Deel I: Inventarisatie van regelmatig toegepaste behandelingen]. Maastricht: University Maastricht, 1999.

7. Kroese $M$, De Vet $H$, Scholten R. An inventory of the need for research to the effectiveness of treatment of a number of chronic benign pain syndroms. Part II: Inventory of systematic reviews and effectiveness trials [Een inventarisatie van de behoefte aan onderzoek naar de effectiviteit van behandelingen voor een aantal chronisch benigne pijnsyndromen. Deel II: Inventarisatie van systematische reviews en effectonderzoek]. Maastricht: University Maastricht, 1999.

8. Busch A, Schachter CL, Peloso PM, Bombardier C. Exercise for treating fibromyalgia syndrome. Cochrane Database Systematic Review 2002;3:Cd003786.

9. Hadhazy VA, Ezzo J, Creamer P, Berman BM. Mind-body therapies for the treatment of fibromyalgia. A systematic review. J Rheumatol 2000;27: 2911-2918.

10. Rossy LA, Buckelew SP, Dorr N, Hagglund KJ, Thayer JF, Mclntosh MJ, et al. A meta-analysis of fibromyalgia treatment interventions. Ann Behav Med 1999;21:180-191.

11. Sim J, Adams N. Systematic review of randomized controlled trials of nonpharmacological interventions for fibromyalgia. Clin J Pain 2002;18: 324-336.

12. Arnold LM, Keck PE jr, Welge JA. Antidepressant treatment of fibromyalgia. A meta-analysis and review. Psychosomatics 2000; 41:104-113.

13. O'Malley PG, Balden E, Tomkins G, Santoro J, Kroenke K, Jackson JL. Treatment of fibromyalgia with antidepressants: A meta-analysis. J Gen Intern Med 2000;15: 659-666.

14. Rao, SG, Bennett RM. Pharmacological therapies in fibromyalgia. Best Pract Res Clin Rheumatol 2003;17: 611-627.

15. Mease, PJ, Clauw DJ, Arnold LM, Goldenberg DL, Witter J, Williams DA, et al. Fibromyalgia syndrome. J Rheumatol 2005;32: 2270-2277.

16. Sim J, Adams N. Therapeutic approaches to fibromyalgia syndrome in the United Kingdom: A survey of occupational therapists and physical therapists. Eur J Pain 2003; 7:173-180.

17. Medical Directory the Netherlands 2005-2006 [Geneeskundig Adresboek Nederland 2005-2006]. Houten: Bohn Stafleu van Loghum, 2005.

18. Dutch Council for Public Health and Health Care. Professionals in health care-advise to the Minister of Health, Wellbeing and Sports. [Raad voor de Volksgezondheid. Professionals in de gezondheidszorg advies uitgebracht door de Raad voor de Volkgezondheid en Zorg aan de Minister van Volksgezondheid, Welzijn en Sport] Zoetermeer, 2000.

19. Fitzcharles M-A, Boulos P. Inaccuracy in the diagnosis of fibromyalgia syndrome: analysis of referrals. Rheumatology 2003;42:263-267. 



\section{Chapter 6}

The feasibility and efficacy of a multidisciplinary intervention with aftercare meetings for fibromyalgia

MEAL Kroese, GJC Schulpen, MCM Bessems, FJ Nijhuis, JL Severens, RBM Landewé Clinical Rheumatology 2009;28:923-9 


\section{Abstract}

\section{Objective}

To examine the feasibility and long-term results of a 12 -week multidisciplinary part-time daycare intervention with 5 aftercare meetings in fibromyalgia (FM) patients.

\section{Methods}

One hundred and five patients diagnosed with FM started with a multidisciplinary intervention and were assessed for feasibility, functional status (Fibromyalgia Impact Questionnaire (FIQ)) and health related quality of life (EuroQol-5D (EQ-5D)) until 9 months after completion. The programme consisted of sociotherapy, physiotherapy, psychotherapy and creative arts therapy.

\section{Results}

Drop-out rate was $4.8 \%$. The attendance rate of 100 patients who completed the 12 -week programme and 5 aftercare meetings was high (97.4\%), just like patient and therapist satisfaction ( 8.2 on a 10 points scale). After the 12-week programme, statistically significant improvement was seen in both FIQ and EQ-5D. This improvement maintained after 9 months of follow-up. On average, moderate improvements were observed.

\section{Conclusions}

Our 12-week multidisciplinary part-time day-care intervention with 5 aftercare meetings for FM patients is feasible and it is indicated that it can lead to sustained improvement in functional status and health related quality of life. 


\section{Introduction}

Fibromyalgia (FM) is a common chronic pain condition, characterized by generalized pain, stiffness, fatigue, disturbed sleep, psychological distress and impaired cognitive function $^{1,2}$. The cause of and pathologic mechanisms underlying FM are unknown, but FM may lead to disability and a reduced quality of life ${ }^{3}$.

Increasingly, FM is considered as a combination of physical, psychological and social disabilities, the biopsychosocial model ${ }^{4,5}$. In this model, physical treatment is combined with psychological, behavioural and/or educational interventions ${ }^{6}$. The studies that have systematically compared monotherapies with treatment combinations that include both physical and psychosocial components, have fairly consistently shown that for chronic pain combined treatments result in better outcomes than single therapies ${ }^{7}$. Rossy et al. concluded in their meta-analysis that the optimal intervention for FM would include exercise and cognitive-behavioural therapy $(C B T)^{8}$. A number of studies have investigated the effect of multimodal or multidisciplinary therapy for FM, but the systematic reviews performed in this area concluded that the evidence is scarce because of few studies, the low quality of the studies, and the varying elements of the therapy ${ }^{9-11}$. Besides, the drop-out rates in the studies are generally high ${ }^{12-17}$, suggesting that the treatment was not individualised. Another concern is that the majority of the studies did not include long-term followup assessments and if they did, that positive outcomes largely disappear in the longterm $^{11}$.

Notwithstanding these weaknesses in evidence, multidisciplinary interventions are increasingly applied in the care for patients with FM, even though the costs of the programmes are substantial. So, methodologically rigorous studies focused on the needs of the patients and the maintenance of the treatment effects in the longer term are needed.

We developed a multidisciplinary intervention which is, especially through the aftercare meetings, aiming at internalisation of the learned skills and maintenance of the expected treatment effects. The programme tries to link up with the individual needs of the patients. Before the effectiveness and cost-effectiveness of this multidisciplinary intervention with aftercare meetings could be examined in a randomized controlled trial (RCT), the present study was performed to get an impression about the feasibility of the multidisciplinary intervention in terms of attendance and drop-out rates, as well as about the level of efficacy and sustainability that could be expected.

\section{Methods}

\section{Data Collection}

Subjects were patients with a diagnosis of FM from the Maastricht University Hospital and recruited between January 2002 and June 2003. After diagnosis, the 
rheumatologist referred them to a specialized rheumatology nurse. The nurse informed the patients about the multidisciplinary programme and asked for motivation to participate and change. Patients had to be between 18 and 65 years of age. Exclusion criteria were illiteracy, pregnancy, involvement in any litigation concerning disability income, specific medical disorders and diseases making immediate medical treatment necessary or preventing subjects performing physical exercise, and severe psychopathology that would make the patient unable to participate in a group format.

Subjects were assessed 9 times: at the start of the programme, 1 and 2 months after the start, immediately upon completion of the 12-week programme, and 1, 2, 3, 5 and 9 months after completion.

\section{Intervention}

The patients followed a 12-week multidisciplinary intervention, which took place in a part-time day-care setting, so that patients could continue their daily activities such as working, studying or caring for their children. The programme included 3 mornings a week, 2 sessions of $1 \frac{1}{2}$ hour per morning and took place in groups of 8-9 patients. During 9 months of follow-up, the participants took part in 5 aftercare meetings which took place in decreasing frequency: the first one was scheduled 4 weeks after the 12-programme, the following ones 6, 8, 10 and 12 weeks later.

To anticipate the seeking of extra support in the traditional medical care and to link up with the personal needs, individual treatment options were included in the programme (an individual course of maximal 7 hours with one of the different therapists). No physician was involved in the programme to prevent the medicalization of FM.

During the 12 weeks, a multidisciplinary team offered a programme of sociotherapy, physiotherapy, psychotherapy, and creative arts therapy. Sociotherapy (twice a week) was aiming at education (based on transactional analysis ${ }^{18-20}$ ), formulating and evaluating learning goals, training social skills and making contact with fellowpatients. Physiotherapy (twice a week) was focussed on improving physical condition (based on graded activity and time-contingent in stead of pain-contingent) by fitness exercises and at learning to enjoy exercise. Besides, different forms of relaxation and exercises focusing on alternative patterns of movement were practised in order to improve awareness and reduce muscle tone during daily activities, and ergonomical advises were given. During the psychotherapy sessions (once a week), general information was presented about FM and the influence of stress on the development and maintenance of the complaints. In these sessions, methods of core qualities ${ }^{21}$, rational emotive therapy ${ }^{22-25}$, and transactional analysis ${ }^{18-20}$ were used. Creative arts therapy (once a week) was used to support the consciousness-raising process.

The intervention was aiming at teaching patients skills necessary to deal with pain and disability, and building confidence so that they could successfully use these skills in their daily lives. The trained skills include social and coping skills, problem solving strategies, behavioural goal setting, adjustment of activities of daily living, keeping a 
balance between activity and rest. In the programme, self management was explicitly promoted. Patients were encouraged to bear responsibility for their lives and not to victimize themselves. During the treatment, patients were confronted with their pain experience, and were focused on their own (problematic) situations. Because of that, they may become more aware of personal difficulties and complaints for which they required counselling. The strength and uniqueness of our intervention is the integration of the general principles in the 4 therapy methods and the unremitting inter-relationship between these therapy methods.

It is also unique that during the entire programme, it was tried to make links with home- and job situations in an attempt to stimulate behavioural changes. The 5 aftercare meetings which were aiming at internalizing learned skills were introduced as a relapse prevention,. Furthermore, efforts were made to encourage patients to continue to exercise together, e.g. to visit a fitness centre at the end of the programme. Besides efforts aiming at internalisation, explicit attention was paid to motivate the participants to attend the programme.

\section{Outcome measures}

Feasibility. Feasibility was assessed using the following parameters: drop-out rate (\%), attendance rate (\%), patient and therapist satisfaction (report marks on a 10 points scale).

Functional status. The Fibromyalgia Impact Questionnaire (FIQ), a 10-item selfadministered instrument, was used to assess the functional status ${ }^{26}$. The first item focuses primarily on the patient's ability to do large muscle tasks. The next 2 items represents the number of days in the past week patients felt good and the number of days they missed work. The last 7 items - ability to do work, pain, fatigue, unrefreshed sleep, stiffness, anxiety, and depression - are all measured by a visual analogue scale (VAS) ${ }^{26}$. All items of the FIQ were standardized on a scale ranging from 0 to 10 with 10 indicating greater impairment ${ }^{26}$. Besides this, a total FIQ score was calculated by adding up the first en the last seven items (range 0-80) ${ }^{27}$.

Health related quality of life (HRQoL). The EuroQol-5D (EQ-5D) is a self-administered, generic instrument that incorporates descriptions and valuations of health states ${ }^{28}$. It consists of five items measuring mobility, self-care, usual activities, pain/discomfort, and anxiety/depression. Each dimension has three levels of severity, generating a total of 243 theoretically possible health states. The different combinations of responses to the five items are weighted to produce a single index. Following the original work based on a UK-population ${ }^{29}$, health states were converted to an EQ-5D index score with weights derived from time trade off (TTO) measurements based on a representative sample of the general population from the Netherlands ${ }^{30}$. The possible states are valued between -0.33 (worst possible state) and 1 (best possible state) ${ }^{30}$. Another part of the EQ is a VAS, on which the patient rates his current health state with endpoints of 100 ('best imaginable health state') at the top and 0 ('worst imaginable health state') at the bottom ${ }^{28}$. 


\section{Statistical analysis}

Feasibility. Percentages and standard deviations were computed for attendance- and drop-out rates. Means and standard deviations were calculated regarding the patient and therapist satisfaction.

Efficacy. A linear mixed effect model with a random intercept (to integrate the variance due to baseline differences between patients) and a random slope (to integrate the variance due to differences in response over time). was used to investigate the longitudinal response of the multidisciplinary programme ${ }^{31}$. Linear mixed models use all available longitudinal data while adjusting for within-patient correlation. So, patients with incomplete data could be included in this analysis. Since a group effect was anticipated (the intervention took place in groups), we introduced group as a separate level in the linear mixed effect model. Estimated marginal means were calculated for $t_{1}$ (baseline), $t_{4}$ (immediately after completion) and for $t_{9}(9$ months after completion). Because of multiple testing for the estimated marginal means, a significance level of $P<0.01$ was applied. In order to assess the magnitude of change, effect sizes (ES) were calculated defined as the change score divided by the baseline SD $^{32}$. For the analysis of the data, SPSS version 11.5 was used (SPSS Inc., Chicago, IL) ${ }^{33}$.

\section{Results}

Of all 105 patients who had started with the intervention, 5 patients stopped on the advice of the therapists: 1 patient could not function in a group, 2 patients experienced problems in their individual life preventing them form further participation, and 2 patients were diagnosed with psychiatric disorders. These 5 patients were not included in the subsequent analysis.

Most of the patients who completed the intervention were women, had a secondary education and had a mean age of approximately 44 years old (Table 6.1). A large proportion of the patients who started with the programme had a recent diagnosis of FM: $50 \%$ started the programme within 6 months after diagnosis, $25 \%$ were diagnosed between 6 and 12 months for the start, and only $25 \%$ of the patients were diagnosed more than 12 months before the start of therapy. Fifty-one percent of the patients indicated to have a paid job.

\section{Feasibility}

The attendance rate was very high: $97.8 \%$ for the 12 weeks programme and $97,4 \%$ for the 12 -week programme including the 5 aftercare meetings (Table 6.2). Patients and therapists were generally satisfied with the intervention. They awarded high scores for the entire programme, the group atmosphere, and the organisation of the programme. More than $90 \%$ of the patients considered the programme meeting their expectations and $98 \%$ of the patients would recommend the programme to someone else (Table 6.2). No adverse effects were reported. 
Table 6.1 Patient characteristics $(n=100)^{*}$

\begin{tabular}{lc}
\hline Characteristic & \\
\hline Sex & $94(94.0)$ \\
Female & $6(6.0)$ \\
Male & \\
Age (years) & $44.2 \pm 9.1$ \\
Mean \pm SD & $19-65$ \\
Range & \\
Time between diagnosis and start programme (months) & $18.4 \pm 28.3$ \\
Mean \pm SD & 6.5 \\
Median & $1-156$ \\
Range & \\
Level of education & $31(31.0)$ \\
Low & $54(54.0)$ \\
Middle & $14(14.0)$ \\
High & $1(1.0)$ \\
Missing & \\
Paid job & $51(51.0)$ \\
Yes & $47(47.0)$ \\
No & $2(2.0)$ \\
Missing &
\end{tabular}

* Values are the numbers (percentage) unless otherwise indicated.

Table 6.2 Feasibility $(n=100)^{*}$

\begin{tabular}{lcc}
\hline & $\begin{array}{c}\text { Patients } \\
(\mathrm{n}=100)\end{array}$ & $\begin{array}{c}\text { Therapist } \\
(\mathrm{n}=5)\end{array}$ \\
\hline Attendance & & \\
12 weeks programme & $97.8 \%$ & \\
12 weeks programme +5 post treatment care meetings & $97.4 \%$ & \\
Satisfaction (on a VAS with 1 and 10 as extremes) & $8.2 \pm 0.88$ & $8.2 \pm 0.45$ \\
Entire programme, mean \pm SD & $7.0 \pm 1.13$ & $6.8 \pm 0.45$ \\
Information before the start of the programme, mean \pm SD & $7.8 \pm 0.74$ & $7.8 \pm 0.76$ \\
Information during the programme, mean \pm SD & $7.3 \pm 1.37$ & $8.1 \pm 0.55$ \\
Accommodation, mean \pm SD & $8.4 \pm 1.17$ & $8.2 \pm 0.45$ \\
Atmosphere group, mean \pm SD & $8.3 \pm 1.01$ & $8.0 \pm 0.71$ \\
Organisation programme, mean \pm SD & $90.5 \%$ & $100 \%$ \\
Meeting expectations & $98.0 \%$ & $100 \%$ \\
Recommend the programme to someone else & & \\
\hline
\end{tabular}

* Values are the percentages unless otherwise indicated.

\section{Efficacy}

A significant longitudinal effect concerning $t_{1}-t_{9}$ was found for all outcomes measures. Table 6.3 shows the estimated marginal means (EMMs) for the different components of the FIQ at baseline $\left(t_{1}\right)$, immediately after the completion of the 12-week programme $\left(t_{4}\right)$ and 9 months after completion $\left(t_{9}\right)$. At the end of the 12-week 
programme $\left(t_{4}\right)$, the EMMs of all items of the FIQ, except the 'number of missed days at work' and 'stiffness', had significantly improved. One year after start of the programme, or 9 months after completion of the programme, the improvement obtained at $t_{4}$ had sustained or increased for almost all items. Across all FIQ items, the average effect size was 0.46 at $t_{4}$ and 0.51 at $t_{9}$. Large effect sizes were found for 'number of days felt good' and 'fatigue' $\left(0.79\right.$ at $\left.t_{9}\right)$. The smallest effect sizes were found for 'number of missed days at work' and 'stiffness' (0.19 at $\left.t_{9}\right)$. With regard to the EQ-5D, both the index and the VAS showed a significant improvement at $t_{4}$, that not only sustained but further increased upon completion of the 12-week programme. The effect sizes for the EQ-5D were moderate $(0.49$ for the index and 0.69 for the VAS at $\left.t_{9}\right)$.

Table 6.3 Estimated marginal means and effect sizes (ESs) for baseline, the end of the 12-week programme and 9 months after completion with baseline as reference category*

\begin{tabular}{|c|c|c|c|c|c|c|c|c|}
\hline & \multicolumn{2}{|c|}{ Baseline } & \multicolumn{3}{|c|}{$\begin{array}{l}\text { At the end of the } 12 \text {-week } \\
\text { programme }\end{array}$} & \multicolumn{3}{|c|}{$\begin{array}{c}9 \text { months after completion of } \\
\text { the } 12 \text {-week programme }\end{array}$} \\
\hline & Mean & SE & Mean & SE & ES & Mean & SE & ES \\
\hline \multicolumn{9}{|l|}{ FIQ } \\
\hline Physical function & 4.8 & 0.2 & $4.3 \ddagger$ & 0.2 & 0.32 & $4.2+$ & 0.3 & 0.43 \\
\hline Days feel good & 7.0 & 0.3 & $5.5 \ddagger$ & 0.3 & 0.66 & $5.2 \ddagger$ & 0.5 & 0.79 \\
\hline Days missed work & 4.0 & 0.5 & 4.7 & 0.5 & 0.20 & 3.0 & 0.5 & 0.19 \\
\hline Job ability & 7.1 & 0.3 & $6.0 \ddagger$ & 0.3 & 0.44 & $6.1+$ & 0.3 & 0.46 \\
\hline Pain & 6.9 & 0.2 & $6.2+$ & 0.2 & 0.39 & 6.3 & 0.3 & 0.44 \\
\hline Fatigue & 7.9 & 0.2 & $6.9 \ddagger$ & 0.2 & 0.62 & $6.9+$ & 0.4 & 0.78 \\
\hline Unrefreshed sleep & 7.4 & 0.2 & $6.6 \ddagger$ & 0.2 & 0.39 & $6.6^{+}$ & 0.3 & 0.54 \\
\hline Stiffness & 6.7 & 0.2 & 6.4 & 0.2 & 0.24 & 6.5 & 0.3 & 0.19 \\
\hline Anxiety & 5.2 & 0.3 & $4.3^{+}$ & 0.3 & 0.33 & 4.1 & 0.5 & 0.36 \\
\hline Depression & 4.4 & 0.3 & $3.6 \ddagger$ & 0.3 & 0.30 & $3.5 \ddagger$ & 0.3 & 0.29 \\
\hline Total & 50.7 & 1.3 & $43.5 \ddagger$ & 1.5 & 0.66 & $43.1^{+}$ & 2.7 & 0.65 \\
\hline \multicolumn{9}{|l|}{$E Q-5 D$} \\
\hline Index & 0.40 & 0.03 & $0.51 \ddagger$ & 0.03 & 0.40 & $0.55 \ddagger$ & 0.03 & 0.49 \\
\hline VAS & 46.8 & 1.8 & $55.5 \ddagger$ & 1.9 & 0.54 & $57.3 \ddagger$ & 2.0 & 0.69 \\
\hline
\end{tabular}

* FIQ = Fibromyalgia Impact Questionnaire; The items of the FIQ have been standardized and range from $0-10$. The range of FIQ total is $0-80$. Higher score values indicate worse health status; The range of the EQ-5D index score is $-0.33-1$ and of the EQ-VAS 0-100. Higher score values indicate better health status; $+P \leq 0.01 ; \ddagger P \leq 0.001$.

\section{Discussion}

We concluded that our 12-week multidisciplinary part-time day-care intervention with aftercare meetings was feasible and that the programme seems to have a positive effect on functional status and HRQoL. Further, there is an indication that the improvement sustains after the completion of the 12-week programme.

A low attrition rate and a high compliance suggest that the patients considered the programme useful and are an indication that the programme meets their 
expectations, and is not too intensive. As such, attrition rate and compliance reflect feasibility. The drop-out rate during the programme was $4.8 \%$, which is substantially lower than the average drop-out rate in studies with similar interventions and/or patients. Busch et al. found in their systematic review about exercise and FM attrition rates varying from $12.5 \%$ (range 9 to 16\%) in flexibility groups, and $14.6 \%$ (SD $11.8 \%$, range 0 to $40 \%$ ) and $14.8 \%$ (SD 9.6\%, range 0 to 27\%) in mixed exercise interventions and multimodal interventions respectively to $27 \%$ (SD $18.9 \%$, range 0 to $67 \%$ ) in aerobic exercise interventions ${ }^{33}$. A systematic review in chronic pain patients yielded a drop-out rate of $14 \%$ for cognitive behaviour therapy ${ }^{34}$. These reviews indicate that multimodal interventions has a lower attrition rate than exercise only interventions and that the attrition rate in our programme is about the lowest in FM. The patients who had not completed the multidisciplinary programme, were all stopped on the advice of the therapists. Participants who completed the multidisciplinary programme attended $97.4 \%$ of the sessions which is nearly complete attendance. This attendance rate outweighed comparable intervention programmes importantly ${ }^{35-37}$. Our compliance rate reflects a combination of the positive experiences people had at the sessions, the perceived efficacy of the programme throughout the intervention period, the benefit of the group dynamics, and commitment of the subjects to the project and themselves. As a consequence, patient satisfaction was rated as high. These findings together demonstrate the feasibility of the 12-week multidisciplinary part-time day-care intervention with 5 aftercare meetings for FM patients.

Although the design of this pilot study does not allow a formal evaluation of the efficacy of this intervention, a few remarkable findings should be discussed. First, improvement was measured on all domains of the FIQ and the EQ-5D suggesting that the effect of the multifaceted approach involves global health rather than specific domains such as pain or fatigue. The generally moderate treatment effects that we have found are comparable with treatment effects in pharmaceutical and nonpharmaceutical trials for $\mathrm{FM}^{8,38,39}$. For the $\mathrm{FIQ}$ version (range $0-80$ ) we used, the average change in total score was reported to be approximately $19 \%$ (9 points) in FM trials ${ }^{40}$. We have found a change of $15 \%$. For the EQ-5D, we found a clinically relevant improvement of $38 \%$ for the index score and $23 \%$ for the VAS. In contrast with other studies in FM patients, the majority of our patients were recently diagnosed. An early intervention in FM patients seems important, because intervening early in the course of a chronic pain condition may help prevent the vicious cycle of long-term physical and psychological suffering. Besides, maladaptive patterns of pain-coping and illness behaviours that might have ingrained after a long-lasting period of FM could make it more difficult to change behaviour ${ }^{11}$. However, we could not demonstrate that an early intervention had any influence on the response to our programme. Second, and more important, the results of this pilot study strongly suggest that there is sustained improvement over time after completion of the 12-week treatment programme, possibly also intensified by the aftercare meetings. As such, the results give an indication that the patients indeed have learned to deal with their disability (coping) and as a consequence experience a better HRQoL, which was an important goal of this intervention. This sustained improvement (after completion of the 12-week 
programme) encourages us in the idea that the observed advance is worth this moderately intensive treatment.

In the literature, we found only one related study which evaluated the feasibility of an inpatient aftercare week after a rehabilitation programme ${ }^{41}$. The scarcity of available evidence makes it difficult to recommend about an optimal number of aftercare meetings and about the optimal time interval. Expectedly, the intervals may become longer over time once the learned principles have been better incorporated.

Of course, the lack of a prognostically comparable control group limits the interpretation of efficacy importantly. Part of the measured effect is undoubtedly attributable to aspecific effects (regression towards the mean). Although most longitudinal studies with FM patients indicate an absence of spontaneous improvement in symptoms or remission in the natural course of $\mathrm{FM}^{42-45}$, aspecific improvement that sustained for at least 9 months cannot entirely be excluded.

Theoretically, it is also possible that the group contact with 'fellow patients' rather than the specific content of the programme is responsible for the measured improvement. We will further investigate this possibility in the context of a RCT, which has been started based on the results of this feasibility study.

This RCT, which examines the effectiveness and cost-effectiveness of the multidisciplinary intervention with aftercare meetings, has an extra long follow-up period of 18 months. Primary outcome measures are social participation (including work), medical consumption and HRQoL.

Although the RCT will provide definitive answers, this study showed that a 12-week multidisciplinary intervention with aftercare meetings for FM is feasible and can lead to sustained improving of functional status and HRQoL. 


\section{References}

1. Wolfe F. When to diagnose fibromyalgia. Rheum Dis Clin North Am 1994;20: 485-501.

2. Wolfe F, Smythe HA, Yunus MB, Bennett RM, Bombardier C, Goldenberg DL, et al. The American College of Rheumatology 1990 Criteria for the Classification of Fibromyalgia. Report of the Multicenter Criteria Committee. Arthritis Rheum 1990;33:160-72.

3. Mease P. Fibromyalgia syndrome: review of clinical presentation, pathogenesis, outcome measures, and treatment. J Rheumatol 2005;75:6-21.

4. Waddell G. Preventing incapacity in people with musculoskeletal disorders. Br Med Bull 2006;7778:55-69.

5. Ferrari R. The biopsychosocial model-a tool for rheumatologists. Bailliere's best practice and research. Clin Rheumatol 2000;14:787-795.

6. Allegrante JP. The role of adjunctive therapy in the management of chronic nonmalignant pain. Am J Med 1996;101:33s-9s.

7. Turk DC. Combining somatic and psychosocial treatment for chronic pain patients: perhaps $1+1$ does = 3. Clin J Pain 2001;17:281-3.

8. Rossy LA, Buckelew SP, Dorr N, Hagglund KJ, Thayer JF, McIntosh MJ, et al. A meta-analysis of fibromyalgia treatment interventions. Ann Behav Med 1999;21:180-91.

9. Karjalainen $K$, Malmivaara A, van Tulder $M$, Roine $R$, Jauhiainen $M$, Hurri $H$, et al. Multidisciplinary rehabilitation for fibromyalgia and musculoskeletal pain in working age adults. Cochrane database of systematic reviews Online Update Software 2000:Cd001984.

10. Sim J, Adams N. Systematic review of randomized controlled trials of nonpharmacological interventions for fibromyalgia. Clin J Pain 2002;18:324-36.

11. van Koulil S, Effting M, Kraaimaat FW, van Lankveld W, van Helmond $T$, Cats $H$, et al. Cognitivebehavioural therapies and exercise programmes for patients with fibromyalgia: state of the art and future directions. Ann Rheum Dis 2007;66:571-81.

12. Astin JA, Berman BM, Bausell B, Lee WL, Hochberg M, Forys KL. The efficacy of mindfulness meditation plus Qigong movement therapy in the treatment of fibromyalgia: a randomized controlled trial. J Rheumatol 2003;30:2257-62.

13. Cedraschi C, Desmeules J, Rapiti E, Baumgartner E, Cohen P, Finckh A, et al. Fibromyalgia: a randomised, controlled trial of a treatment programme based on self management. Ann Rheum Dis 2004;63:290-6.

14. King SJ, Wessel J, Bhambhani Y, Sholter D, Maksymowych W. The effects of exercise and education, individually or combined, in women with fibromyalgia. J Rheumatol 2002;29:2620-7.

15. Nicassio PM, Radojevic V, Weisman MH, Schuman C, Kim J, Schoenfeld Smith K, et al. A comparison of behavioral and educational interventions for fibromyalgia. J Rheumatol 1997;24: 2000-7.

16. Wigers SH, Stiles TC, Vogel PA. Effects of aerobic exercise versus stress management treatment in fibromyalgia, a 4,5 year prospective study. Scand J Rheumatol 1996;25:77-86.

17. Zijlstra TR, van de Laar MA, Bernelot Moens HJ, Taal E, Zakraoui L, Rasker JJ. Spa treatment for primary fibromyalgia syndrome: a combination of thalassotherapy, exercise and patient education improves symptoms and quality of life. Rheumatology 2005;44:539-46.

18. Berne E. Transactional analysis: A new and effective method of group therapy. Am J Psychother 1958;12:735-43.

19. Berne E, Steiner CM, Dusay JM. Transactional analysis. In: Groves JE, editor. (1996). Essential papers on short term dynamic therapy. Essential papers in psychoanalysis. New York, NY, US: New York University Press; 1996:149-70.

20. Cole M. Injunctions and secondary gains in chronic pain patients. Transactional Analysis Journal. 1993;23:191-4.

21. Ofman D. Core Qualities; a gateway to human resources. Schiedam: Scriptum; 2001.

22. Ellis A. Rational-emotive therapy. J Contemp Psychother 1969;1:82-90.

23. Ellis A. Overcoming resistance: A rational emotive behavior therapy integrated approach (2nd ed.). New York, NY, US: Springer Publishing Co; 2002.

24. Rothschild BH. RET and chronic pain. In: Dryden W, Hill LK, editors. Innovations in rational-emotive therapy. Thousand Oaks, CA, US: Sage Publications; 1993:91-115. 
25. Morris GB. Changing people from tender-minded to tough-minded: A PATHWAY for dealing with chronic pain. In: Klarreich S, editor. Handbook of organizational health psychology: Programs to make the workplace healthier. Madison, CT, US: Psychosocial Press 1998:139-55.

26. Burckhardt CS, Clark SR, Bennett RM. The fibromyalgia impact questionnaire: development and validation. J Rheumatol 1991;18:728-33.

27. Burckhardt CS, Mannerkorpi K, Hedenberg L, Bjelle A. A randomized, controlled clinical trial of education and physical training for women with fibromyalgia. J Rheumatol 1994;21: 714-20.

28. The EuroQol Group. EuroQol--a new facility for the measurement of health-related quality of life. Health Policy 1990;16:199-208.

29. Dolan P. Modeling valuations for EuroQol health states. Med Care 1997;35:1095-108.

30. Lamers LM, Stalmeier PF, McDonnell J, Krabbe PF, van Busschbach JJ. Kwaliteit van leven meten in economische evaluaties: het Nederlands EQ-5D-tarief [Measuring the quality of life in economic evaluations: the Dutch EQ-5D tariff]. Ned Tijdschr Geneeskd 2005;149:1574-8.

31. Landau S, Everitt BS. Analysis of repeated measures II: linear mixed effect models; computer delivery of cognitive behavioral therapy. In: A handbook of statistical analyses using SPSS. Boca Raton: Chapman \& Hall/CRC PressLLC; 2004:189-219.

32. Cohen J. Statistical power analysis for the behavioral sciences. 2 ed. Hillsdale, NJ: Lawrence Erlbaum Associates; 1988.

33. Busch AJ, Schachter CL, Overend TJ, Peloso PM, Barber KA. Exercise for fibromyalgia: a systematic review. J Rheumatol 2008;35:1130-44.

34. Morley S, Eccleston C, Williams A. Systematic review and meta-analysis of randomized controlled trials of cognitive behaviour therapy and behaviour therapy for chronic pain in adults, excluding headache. Pain 1999;80:1-13.

35. Gowans SE, deHueck A, Voss S, Richardson M. A randomized, controlled trial of exercise and education for individuals with fibromyalgia. Arthritis Care Res 1999;12:120-8.

36. van Santen M, Bolwijn P, Verstappen F, Bakker C, Hidding A, Houben $H$, et al. A randomized clinical trial comparing fitness and biofeedback training versus basic treatment in patients with fibromyalgia. J Rheumatol 2002;29:575-81.

37. Haugli L, Steen E, Laerum E, Finset A, Nygaard R. Agency orientation and chronic musculoskeletal pain: effects of a group learning program based on the personal construct theory. Clin J Pain 2000;16:281-9.

38. Carville SF, Choy EH. Systematic review of discriminating power of outcome measures used in clinical trials of fibromyalgia. J Rheumatol 2008;35:2094-105.

39. Dunkl PR, Taylor AG, McConnell GG, Alfano AP, Conaway MR. Responsiveness of fibromyalgia clinical trial outcome measures. J Rheumatol 2000;27:2683-91.

40. Burckhardt CS. Nonpharmacologic management strategies in fibromyalgia. Rheum Dis Clin North Am 2002;28:291-304.

41. Ehlebracht Konig I, Bonisch A. Stationare Nachsorge bei rheumatischen Erkrankungen--Konzept, Erprobung und Akzeptanz. [Inpatient aftercare in rheumatic diseases--concept, trial, and acceptance]. Rehabilitation (Stuttg) 2004;43:358-67.

42. Nöller V, Sprott $H$. Prospective epidemiological observations on the course of the disease in fibromyalgia patients. J Negat Results Biomed 2003;2:4.

43. Ledingham J, Doherty S, Doherty M. Primary fibromyalgia syndrome--an outcome study. $\mathrm{Br} \mathrm{J}$ Rheumatol 1993;32:139-42.

44. Baumgartner E, Finckh A, Cedraschi C, Vischer TL. A six year prospective study of a cohort of patients with fibromyalgia. Ann Rheum Dis 2002;61:644-5.

45. Wolfe F, Anderson J, Harkness D, Bennett RM, Caro XJ, Goldenberg DL, et al. A prospective, longitudinal, multicenter study of service utilization and costs in fibromyalgia. Arthritis Rheum 1997;40:1560-70. 


\section{Chapter 7}

Challenges in demonstrating effectiveness of multidisciplinary treatment on quality of life, participation and health care utilization in patients with fibromyalgia

A randomized controlled trial

Y van Eijk-Hustings, MEAL Kroese, F Tan, AERCH Boonen, MCM Bessems-Beks, RBM Landewé 


\section{Abstract}

\section{Objective}

To examine effectiveness of a multidisciplinary intervention with aftercare (MD), compared with aerobic exercise (AE) and usual care (UC) in recently diagnosed patients with fibromyalgia (FM).

\section{Methods}

In a Zelen-like design, eligible patients from the outpatient rheumatology clinics of three medical centres in the South of the Netherlands were consecutively recruited and prerandomized to $M D(n=108), A E(n=47)$ or UC $(n=48)$. MD consisted of a 12-week course of sociotherapy, physiotherapy, psychotherapy and creative arts therapy ( 3 half days per week), followed by 5 aftercare meetings in 9 months. AE was given twice a week in a 12-week course. UC varied but incorporated at least education and life style advice. Primary outcomes were health related quality of life (HRQoL), participation and health care utilization. Secondary outcome was the Fibromyalgia Impact Questionnaire (FIQ). Total follow-up in the study was 21-24 months.

\section{Results}

As willingness to participate in $A E$ was limited, this group has been analyzed but interpretation of the data is considered arguable. Within the MD group, a statistically significant improved HRQoL, and a statistically significant reduction in number of hours sick leave, number of contacts with general practitioners, and number of contacts with medical specialists were found. Moreover, statistically significant improvements were found on the FIQ, which increased after the intervention. However, no statistically significant between group differences were found at the endpoint of the study.

\section{Conclusion}

MD seemed to yield positive effects, but firm conclusions with regard to effectiveness can not be formulated due to small between group differences and limitations of the study. 


\section{Introduction}

Fibromyalgia (FM) is a chronic pain disorder with a worldwide prevalence of $0.5 \%-5 \%$, preferentially affecting women in the working age ${ }^{1}$. The most prominent manifestation of FM is widespread, persistent musculoskeletal pain. In addition, a variety of other manifestations such as fatigue, concentration problems, depression, anxiety and symptoms of irritable bowel syndrome may occur ${ }^{2}$, resulting in a loss of well-being, participation and functioning ${ }^{3,4}$. The economic burden of FM is considerable as it is associated with high utilization of health care resources and loss of working days ${ }^{5-7}$.

Because of its multifaceted nature, FM is assumed to be managed best by multimodal and/or multidisciplinary approaches ${ }^{8,9}$. A meta-analysis of non-pharmacological, multimodal interventions showed limited effects ${ }^{10}$, contributing to the ongoing discussion on the content, duration, intensity, adherence and long term effects of these programmes ${ }^{10,11}$. Increasingly, experts consider that early intervention can enhance treatment efficacy, as they expect this to prevent pain behaviour and adaptation to dysfunctioning ${ }^{12}$. Health care utilization and participation in major life areas are increasingly valued as important outcomes, in addition to classic outcome measures that concentrate on key domains of FM like pain, fatigue and physical functioning ${ }^{13}$.

An intensive, multidisciplinary intervention with aftercare for patients with recently diagnosed FM was developed and tested in a pilot study among 100 patients with nine months follow-up. The approach was found feasible and the pilot study suggested a sustained improvement in quality of life and functioning during the treatment and aftercare period ${ }^{14}$. A larger, randomized controlled study with a followup time extending the duration of the intervention was considered pivotal in order to examine the sustainability of effects and to understand non-specific effects opposed to specific effects which are attributable to the multidisciplinary intervention. In the present study, the intensive multidisciplinary programme with aftercare is tested in a randomized controlled trial (RCT) with health related quality of life (HRQoL), participation and health care utilization as primary outcomes.

\section{Patients and Methods}

\section{Study participants and design}

The study was designed as a pragmatic $\mathrm{RCT}^{15}$, comparing the effectiveness of the multidisciplinary intervention (MD) with aerobic exercise (AE) and usual care (UC). In the period from January 2004 until August 2006, recently ( $<3$ months) diagnosed FM patients according to the ACR criteria ${ }^{2}$, literate and between 18 and 65 years old, were consecutively recruited from the outpatient rheumatology clinics of three medical centres in the South of the Netherlands (Maastricht University Medical Centre (MUMC+), Atrium Medical Centre and Orbis Medical Centre). To avoid biased results 
by patients' expectations, a pre-randomized Zelen-like study-design ${ }^{16}$ was chosen. Eligible patients were asked to participate in, as they were told, 'an observational study on the natural course of FM', and at the same time they were asked whether they were willing to participate in future studies. After informed consent, they were randomly assigned to the treatment arms. Randomisation was performed using computer generated random numbers in opaque, sealed envelopes, following the order of consent to participate in the observational study. Only those who were randomized to $\mathrm{MD}$ or $\mathrm{AE}$ were invited to participate in the intervention without being informed about the alternative treatment conditions. Patients in the UC group were not informed about any intervention.

Because of the intensity of the MD programme, patients randomized to the MD group were interviewed by the research assistant and excluded from participation in the intervention in case of (1) pregnancy, (2) involvement in litigation concerning work disability procedures, (3) use of other non-pharmacological treatments such as psychological or physical treatment, interfering with the intervention, (4) alcohol or drugs abuse and (5) use of walking devices.

The study was approved by the Medical Ethical Committees of the three medical centres and is registered under number ISRCTN32542621.

\section{Interventions}

The MD intervention was designed as a two phase group programme, aiming to optimise daily functioning through coping with pain and disability.

The total programme took 1 year and was offered in an outpatient convalescence setting, affiliated to the MUMC+. Phase I consisted of a 12-week course, three half days per week, with two therapy sessions of 1.5 hours duration per day. A trained and experienced multidisciplinary team offered a programme of sociotherapy, physiotherapy, psychotherapy and creative arts therapy, using group interaction as an additional tool but also paying attention to the patient's specific needs. Sociotherapy was given twice a week at the start and at the end of the week. It included education and connected the parts of the programme. It was based on transactional analysis ${ }^{17,18}$ and aimed to increase social behaviour strategies and social support. Physiotherapy was given twice a week. The programme was focused on graded activity, based on time-contingent instead of pain-contingent training and aimed to improve physical fitness and functioning, and at learning to enjoy exercise. It comprised aerobic exercises, strength training of arms and legs, different forms of relaxation, and exercises focusing on alternative patterns of movement in order to improve awareness and reduce muscle tone during daily activities. The programme was scheduled based on the individual patient's results on the 6-min walk test, the 3-minute step test and on 3 minutes working with the shoulder press measured by the physiotherapist (PT) at the start of the programme. If necessary, instruction and support by an occupational therapist could take part of the physiotherapy. Psychotherapy was given once a week and consisted of general information about fibromyalgia and pain mechanisms. Methods of core qualities ${ }^{19}$, rational emotive therapy $^{20-22}$ and transactional analysis ${ }^{17,18}$ were used in the sessions. Creative arts 
therapy was given once a week and focussed on the opportunity to express feelings by visual arts instead of verbal expressions. The first phase was built up around 4 themes, used in all therapies: (1) communication: discover suppressed feelings and emotions; (2) take care of yourself: discover limitations and learn to draw the line; (3) stress, strength, anger and conflict: discover qualities; (4) balance: a new start.

Phase II was an aftercare programme and consisted of 5 meetings, scheduled over a period of nine months. The purpose of these meetings was to repeat the key messages about coping in order to preserve the behavioural change achieved in phase I. In addition to these meetings, a maximum of 7 individual therapy sessions with one of the therapists could be scheduled if considered necessary by therapist and patient. An MD group with 9-10 patients started every six weeks. If too small number of patients wanted to participate in the intervention, additional patients from the outpatient clinic who did not participate in the study were added to fill the groups.

The AE intervention consisted of a 12-week group course which was given twice a week by a trained PT in a community gym, on the floor. Every session started with a 10-minute warming-up, comprising aerobic exercise and stretching, followed by an aerobic part during 30 minutes. The low-intensity aerobic part aimed to reach 55-64 \% of the predicted maximum heart rate. Patients were instructed to check heart rate by self-control after the warming-up and after the aerobic part a few times during the course. They were asked to communicate this with the trainer to check if the intensity of their aerobic training was sufficient. Then, resistance training was applied during 15 minutes to strengthen major muscle groups. During the course, the intensity of the resistance training increased in weights, frequency and tempo. Finally, every session was finished with a 5-minute cool-down ${ }^{23}$. Participants received a Digital Video Disc presenting exercises to do at home, and they were advised to perform these once a week. These home exercises were not monitored. The AE group should also consist of 9-10 persons and started when enough participants for the intervention were available.

The UC arm received care as usual that comprised at least individualised education about FM and lifestyle advice by a rheumatologist or a specialized rheumatology nurse within one or two consultations, but could also include a diversity of other treatments such as physiotherapy, or social support from the rheumatology nurse.

\section{Outcome measures}

Primary outcomes were health related quality of life, participation and health care utilization. The secondary outcome was the impact of FM on daily functioning. All outcome measures were self-reported. At inflow in the study, all patients provided data on demographic and disease characteristics. Total follow-up of the study was 21-24 months for the three groups. Follow-up duration varied since patients started the intervention at different time points. Follow-up questionnaires were sent to all patients immediately following the 12 -week programme and 18 months afterwards, the endpoint of the study. Because the UC group did not receive a planned intervention, the measurements of each respondent were randomly linked to respondents in either the MD group or the $A E$ group to achieve similar time points. 
Health related quality of life (HRQoL) was measured by the five dimensional EuroQol $(E Q-5 D)^{24,25}$. The EQ-5D is a validated instrument to assess general health related quality of life. This instrument consists of two components: a descriptive system that expresses a societal value for health (range from -0.59 to 1.00 , worst possible to best possible health) and an overall impression of health, measured by a Visual Analogue Scale (VAS, range from 0 to 100, worst possible to best possible health).

Participation comprised work productivity, unpaid tasks and chores (e.g. household), leisure (e.g. sports, hobbies) and social activities. A self-developed questionnaire measured contractual hours paid work and hours sick leave retrospectively. Time spent on unpaid tasks, chores, leisure- and social activities in the past two months was measured by an adapted activity questionnaire ${ }^{26}$.

The use of FM related health care resources was measured retrospectively by a twomonthly cost questionnaire ${ }^{27}$. Questions considered number of contacts with general practitioners (GPs), medical specialists (e.g. rheumatologists, orthopaedists), PTs and other paramedical therapists (e.g. psychotherapists).

The impact of FM on daily functioning was assessed by the Fibromyalgia Impact Questionnaire $(\mathrm{FIQ})^{28,29}$, a 10 -item multidimensional instrument on function in the past week. The 10 items are physical functioning, numbers of days feel good, number of days missed work, interference of symptoms with ability to activities, pain, fatigue, unrefreshed sleep, stiffness, anxiety and depression. Each item-score was standardised on a 0-10 scale and a FIQ-total score (0-100) was calculated ${ }^{28}$.

\section{Sample size calculation}

Sample size calculation was based on results of the pilot study on health related quality of life ${ }^{14}$, because no robust data on expected change in the other primary outcomes were available in the literature. With a 0.15 units difference on the EQ-5D, standard deviation $=0.32, \beta=0.20$ and $\alpha=0.05$, and allowing for a drop-out of $30 \%$, a total of 204 patients was needed. In this three-arm pragmatic clinical trial with MD expected to show most (durable) effect, an unbalanced design was chosen in the following ratio: $M D$ vs. $A E$ vs. $U C=2$ vs. 1 vs. 1 , so that the majority of patients would get $\mathrm{MD}$ as their treatment.

\section{Statistical analyses}

Data were analyzed using the intention-to-treat principle. Due to the limited willingness to participate in the interventions after randomisation, per-protocol analyses were also performed. Patients dropping out from the intervention continued their participation in the observational study so follow-up data were obtained. Missing questionnaires appeared in the group of patients who participated in the interventions but also in the group of non-participants and within the intervention groups varied per measurement. Missing data were carefully investigated and found to be random. A multilevel analysis (mixed effects model) was used to assess longitudinal effectiveness ${ }^{30}$. In this analysis, all available data are used and therefore, 
also patients with incomplete data could be included ${ }^{31}$. As differences in the outcome variables occurred at inflow of the study, these values were added in the final models. Effect sizes (ESs) (Cohen's $d$ ) and their confidence intervals (Cls) were calculated for between group differences at the endpoint of the study ${ }^{32,33}$. Cohen defined an ES of $\geq 0.2$ as small, $\geq 0.5$ as moderate and $\geq 0.8$ as large ${ }^{32}$. ES calculations were based on the results of the mixed model analyses and were considered as statistically significant if zero was not included in the $\mathrm{Cl}^{33}$.

Data were analyzed using SPSS, version 18.0 (SPSS Inc., Chicago, IL).

\section{Results}

A study flowchart is presented in Figure 7.1. From 242 eligible patients, 203 consented to participate in the observational study. They were randomized and allocated to the MD group $(n=108)$, the AE group $(n=47)$, and the UC group $(n=48)$. After randomisation, the actual willingness to participate in the interventions was limited. In the MD group, seven patients did not attend $>70 \%$ of the scheduled sessions, as the intensity was difficult to combine with the care for their children, or interfered with other problems. Other reasons for attrition were difficulties with transportation and a lack of motivation. In the $A E$ group, less than half of the randomized patients consented to start the intervention. Reasons mentioned were a lack of interest and difficulties with transportation. With regard to 12 patients we do not know the reason. Of those who started the intervention, only eight patients attended $>70 \%$ of the scheduled sessions. Reasons mentioned were physical problems and difficulties in combining the programme with the care for their children. With regard to seven patients we do not know the reason.

Table 7.1 shows the characteristics of the study population at inflow in the study. Most participants were women and average FM-related symptom duration was seven years. Characteristics did not differ statistically significantly between patients who started the interventions and patients who did not start. As willingness to participate in the $A E$ group was limited, this group has been analyzed but interpretation of the data is considered arguable.

Overall, intention-to-treat analyses showed improvements within the MD group and small differences between the groups at the endpoint of the study. Within the MD group, statistically significant improvements were found in HRQoL and improvements increased after finishing the 12-week programme. Between the MD and the UC group, a small, not statistically significant difference at the endpoint of the study was found on the EQ-VAS in favour of the MD group (ES 0.22; $95 \% \mathrm{Cl}-0.12$ to 0.56 ) (see Table 7.2).

Results for participation are presented in Table 7.3. Within the MD group a statistically significant reduction of hours sick leave was found and this decrease continued in the course of the study. Between the MD group and the UC group, a small not statistically significant difference at the endpoint of the study was found in hours unpaid tasks and chores (ES $-0.23 ; 95 \% \mathrm{Cl}-0.57$ to 0.1 ). 


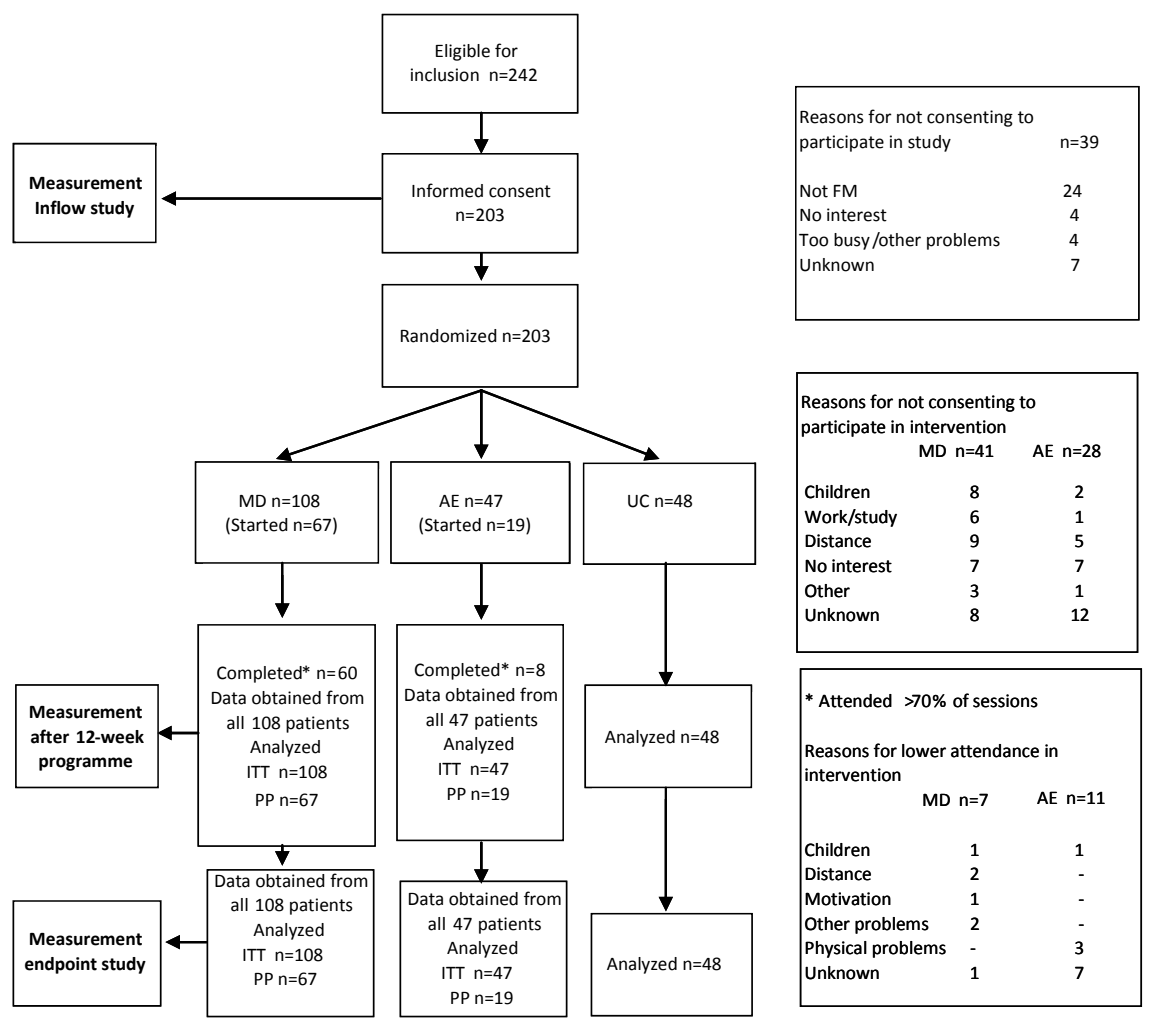

Figure 7.1 Flow chart of the study; $M D=$ multidisciplinary intervention; $A E=$ aerobic exercise; $U C=$ usual care; ITT = intention-to-treat; PP = per-protocol.

Table 7.1 Characteristics of the study population at inflow in the study*

\begin{tabular}{|c|c|c|c|c|c|}
\hline & \multicolumn{2}{|c|}{$\begin{array}{c}M D \\
n=108\end{array}$} & \multicolumn{2}{|c|}{$\begin{array}{c}A E \\
n=47\end{array}$} & \multirow[t]{2}{*}{$\begin{array}{c}\text { UC } \\
\mathrm{n}=48\end{array}$} \\
\hline & $\begin{array}{c}\text { Started } \\
\mathrm{n}=67\end{array}$ & $\begin{array}{c}\text { Not started } \\
\mathrm{n}=41\end{array}$ & $\begin{array}{l}\text { Started } \\
\mathrm{n}=19\end{array}$ & $\begin{array}{c}\text { Not started } \\
\mathrm{n}=28\end{array}$ & \\
\hline Age, mean \pm SD years & $41.6 \pm 8.8$ & $41.3 \pm 11.0$ & $43.9 \pm 7.6$ & $39.1 \pm 9.6$ & $42.9 \pm 11.0$ \\
\hline Female & 94.0 & 92.7 & 100 & 100 & 97.9 \\
\hline $\begin{array}{l}\text { Duration of FM related symptoms } \\
\text { before diagnosis, mean } \pm S D \text { years }\end{array}$ & $7.1 \pm 6.8$ & $6.1 \pm 5.4$ & $6.2 \pm 7.0$ & $7.3 \pm 6.1$ & $7.1 \pm 6.4$ \\
\hline Married or cohabiting & 80.6 & 90.2 & 84.2 & 85.7 & 83.4 \\
\hline \multicolumn{6}{|l|}{ Educational level } \\
\hline low & 56.7 & 58.5 & 68.4 & 53.6 & 38.7 \\
\hline medium & 29.9 & 31.7 & 26.3 & 35.7 & 40.9 \\
\hline high & 13.4 & 9.8 & 5.2 & 10.7 & 20.4 \\
\hline Employed & 52.5 & 48.8 & 57.9 & 57.1 & 50.0 \\
\hline
\end{tabular}

* Values are the numbers (percentage) unless otherwise indicated; $M D=$ multidisciplinary intervention; $\mathrm{AE}$ = aerobic exercise; $\mathrm{UC}=$ usual care. 
Table 7.2 Within group and between group results with regard to health related quality of life (HRQoL) for the MD, AE and UC group*

\begin{tabular}{|c|c|c|c|c|c|c|c|}
\hline & \multicolumn{3}{|c|}{ Intervention } & \multirow[t]{6}{*}{ Inflow } & \multirow{6}{*}{$\begin{array}{l}\text { After the } 12- \\
\text { week } \\
\text { programme }\end{array}$} & \multirow[t]{6}{*}{ Endpoint } & \multirow{6}{*}{$\begin{array}{l}\text { Effect size between } \\
\text { intervention group } \\
\text { and UC at endpoint } \\
\text { (Cl 95\%) }\end{array}$} \\
\hline & $M D$ & ITT & $n=108$ & & & & \\
\hline & & PP & $n=67$ & & & & \\
\hline & \multirow[t]{2}{*}{$\mathrm{AE}$} & ITT & $n=47$ & & & & \\
\hline & & PP & $n=19$ & & & & \\
\hline & UC & & $n=48$ & & & & \\
\hline \multirow[t]{5}{*}{ EQ-5D } & MD & ITT & & $0.36 \pm 0.03$ & $0.49 \pm 0.03$ & $0.55 \pm 0.03+$ & $0.12(-0.22,0.46)$ \\
\hline & & PP & & $0.34 \pm 0.04$ & $0.48 \pm 0.04$ & $0.54 \pm 0.04 \dagger$ & $0.09(-0.28,0.46)$ \\
\hline & $\mathrm{AE}$ & ITT & & $0.41 \pm 0.05$ & $0.47 \pm 0.05$ & $0.54 \pm 0.05$ & $0.10(-0.31,0.50)$ \\
\hline & & PP & & $0.40 \pm 0.05$ & $0.54 \pm 0.07$ & $0.62 \pm 0.08$ & $0.33(-0.21,0.86)$ \\
\hline & UC & & & $0.51 \pm 0.04$ & $0.50 \pm 0.04$ & $0.51 \pm 0.05$ & \\
\hline \multirow[t]{5}{*}{ EQ-VAS } & $\mathrm{MD}$ & ITT & & $48.1 \pm 1.7$ & $54.0 \pm 1.9$ & $57.3 \pm 2.3^{\dagger}$ & $0.22(-0.12,0.56)$ \\
\hline & & PP & & $45.7 \pm 2.1$ & $55.1 \pm 2.4$ & $57.6 \pm 2.8^{\dagger}$ & $0.24(-0.13,0.61)$ \\
\hline & $\mathrm{AE}$ & ITT & & $53.2 \pm 2.5$ & $53.9 \pm 3.2$ & $53.3 \pm 3.6$ & $0.05(-0.35,0.45)$ \\
\hline & & PP & & $57.1 \pm 3.1$ & $56.4 \pm 4.3$ & $59.6 \pm 5.6$ & $0.32(-0.22,0.85)$ \\
\hline & UC & & & $54.0 \pm 2.6$ & $48.3 \pm 2.9$ & $51.9 \pm 3.3$ & \\
\hline
\end{tabular}

* Estimated marginal means \pm standard error based on mixed model analysis with random intercept/random slope; The range of the EQ-5D index score is -0.59-1 and of the EQ-VAS 0-100. Higher score values indicate better health status; $M D=$ multidisciplinary intervention; $A E$ = aerobic exercise; $U C=$ usual care; ITT = intention-to-treat; $\mathrm{PP}=$ per-protocol; $\mathrm{Cl}=$ confidence interval; + difference within group = $P<0.05$.

Table 7.4 shows the results with regard to health care utilization. Within the MD group, a statistically significant reduction in number of contacts with GPs was found. Between the MD and the UC group a small, not statistically significant difference at the endpoint of the study was found in favour of the UC group (ES $-0.28 ; 95 \% \mathrm{Cl}-0.66$ to 0.09 ). Within both the MD and the UC group, a statistically significant reduction in number of contacts with medical specialists was found during the course of the study. Between the MD group and the UC group, a small, not statistically significant difference at the endpoint of the study was found with regard to number of contacts with other paramedical professionals, in favour of the UC group (ES $-0.28 ; 95 \% \mathrm{Cl}-$ 0.62 to 0.06$)$.

Differences in impact of FM on daily functioning are presented in Table 7.5. Within the MD group, statistically significant improvements were found on almost all FIQsubscales and on the FIQ-total score and improvements increased in the course of the study. Between the MD and the UC group a small, not statistically significant difference at the endpoint of the study was found with regard to the FIQ-total score in favour of the MD group (ES $0.25 ; 95 \% \mathrm{Cl}-0.09$ to 0.59 ).

Per protocol-analyses differed to some extent, but showed similar trends as is shown in the tables. 
Table 7.3 Within group and between group results with regard to participation for the MD, AE and UC group*

\begin{tabular}{|c|c|c|c|c|c|c|c|}
\hline & \multicolumn{3}{|c|}{ Intervention } & \multirow[t]{5}{*}{ Inflow } & \multirow{5}{*}{$\begin{array}{l}\text { After the } 12- \\
\text { week } \\
\text { programme }\end{array}$} & \multirow[t]{5}{*}{ Endpoint } & \multirow{6}{*}{$\begin{array}{c}\text { Effect size } \\
\text { between } \\
\text { intervention group } \\
\text { and UC at } \\
\text { endpoint (CI 95\%) }\end{array}$} \\
\hline & $\mathrm{MD}$ & ITT & $\mathrm{n}=108$ & & & & \\
\hline & & $\mathrm{PP}$ & $n=67$ & & & & \\
\hline & $\mathrm{AE}$ & ITT & $n=47$ & & & & \\
\hline & & $\mathrm{PP}$ & $n=19$ & & & & \\
\hline & UC & & $n=48$ & & & & \\
\hline \multirow{5}{*}{$\begin{array}{l}\text { Contractual hours } \\
\text { paid work per week }\end{array}$} & $\mathrm{MD}$ & ITT & & $13.1 \pm 1.3$ & $11.3 \pm 0.8$ & $11.0 \pm 0.8$ & $0.00(-0.34,0.34)$ \\
\hline & & $\mathrm{PP}$ & & $13.4 \pm 1.7$ & $10.2 \pm 1.0$ & $10.1 \pm 1.0$ & $-0.10(-0.47,0.27)$ \\
\hline & $\mathrm{AE}$ & ITT & & $13.4 \pm 2.0$ & $10.7 \pm 1.3$ & $11.4 \pm 1.3$ & $-0.01(-0.41,0.39)$ \\
\hline & & $\mathrm{PP}$ & & $13.5 \pm 1.2$ & $10.6 \pm 1.7$ & $11.4 \pm 1.9$ & $0.04(-0.49,0.57)$ \\
\hline & UC & & & $11.6 \pm 2.0$ & $12.3 \pm 1.2$ & $11.0 \pm 1.1$ & \\
\hline \multirow{5}{*}{$\begin{array}{l}\text { Hours sick leave per } \\
\text { week }\end{array}$} & $\mathrm{MD}$ & $\mathrm{ITT}$ & & $9.2 \pm 1.0$ & $4.8 \pm 0.8$ & $1.2 \pm 0.8 \ddagger$ & $0.13(-0.21,0.47)$ \\
\hline & & $\mathrm{PP}$ & & $10.4 \pm 1.2$ & $5.5 \pm 1.0$ & $0.8 \pm 1.0 \ddagger$ & $0.18(-0.19,0.55)$ \\
\hline & $\mathrm{AE}$ & ITT & & $5.8 \pm 1.2$ & $3.4 \pm 1.2$ & $2.5 \pm 1.2$ & $0.04(-0.37,0.44)$ \\
\hline & & $\mathrm{PP}$ & & $7.6 \pm 1.5$ & $3.7 \pm 1.7$ & $1.2 \pm 1.9$ & $0.13(-0.40,0.66)$ \\
\hline & UC & & & $3.3 \pm 1.2$ & $3.7 \pm 1.2$ & $2.3 \pm 1.0$ & \\
\hline \multirow{5}{*}{$\begin{array}{l}\text { Hours unpaid tasks } \\
\text { and chores per } \\
\text { week }\end{array}$} & $\mathrm{MD}$ & ITT & & $33.6 \pm 2.2$ & $28.4 \pm 1.8$ & $27.6 \pm 1.8$ & $-0.23(-0.57,0.11)$ \\
\hline & & $\mathrm{PP}$ & & $29.2 \pm 2.7$ & $26.1 \pm 2.2$ & $27.4 \pm 2.2$ & $-0.25(-0.62,0.12)$ \\
\hline & $\mathrm{AE}$ & ITT & & $35.3 \pm 3.5$ & $27.6 \pm 2.9$ & $22.2 \pm 2.9 \dagger$ & $-0.56(-0.93,-0.11)$ \\
\hline & & $\mathrm{PP}$ & & $35.0 \pm 3.6$ & $23.1 \pm 4.1$ & $16.5 \pm 4.4^{\dagger}$ & $-0.82(-1.37,-0.27)$ \\
\hline & UC & & & $28.5 \pm 2.9$ & $28.6 \pm 2.7$ & $32.0 \pm 2.6$ & \\
\hline \multirow{5}{*}{$\begin{array}{l}\text { Hours leisure and } \\
\text { social activities per } \\
\text { week }\end{array}$} & $\mathrm{MD}$ & ITT & & $12.0 \pm 0.9$ & $12.0 \pm 0.9$ & $12.7 \pm 0.9$ & $0.03(-0.31,0.37)$ \\
\hline & & $\mathrm{PP}$ & & $12.4 \pm 1.2$ & $13.0 \pm 1.1$ & $12.7 \pm 1.1$ & $0.03(-0.34,0.40)$ \\
\hline & $\mathrm{AE}$ & ITT & & $10.7 \pm 1.2$ & $11.3 \pm 1.4$ & $10.3 \pm 1.4$ & $-0.23(-0.61,0.20)$ \\
\hline & & $\mathrm{PP}$ & & $10.2 \pm 1.4$ & $11.7 \pm 1.9$ & $9.9 \pm 2.1$ & $-0.26(-0.80,0.27)$ \\
\hline & $U C$ & & & $12.4 \pm 1.4$ & $12.5 \pm 1.4$ & $12.4 \pm 1.3$ & \\
\hline
\end{tabular}

* Estimated marginal means \pm standard error based on mixed model analysis with random intercept; MD = multidisciplinary intervention; $\mathrm{AE}=$ aerobic exercise; $\mathrm{UC}=$ usual care; ITT = intention-to-treat; $\mathrm{PP}=$ perprotocol ; $\mathrm{Cl}=$ confidence interval; + difference within group $=P<0.05 ; \ddagger$ difference within group $=P<0.001$. 
Table 7.4 Within group and between group results with regard to health care utilization for the MD, $\mathrm{AE}$ and UC group*

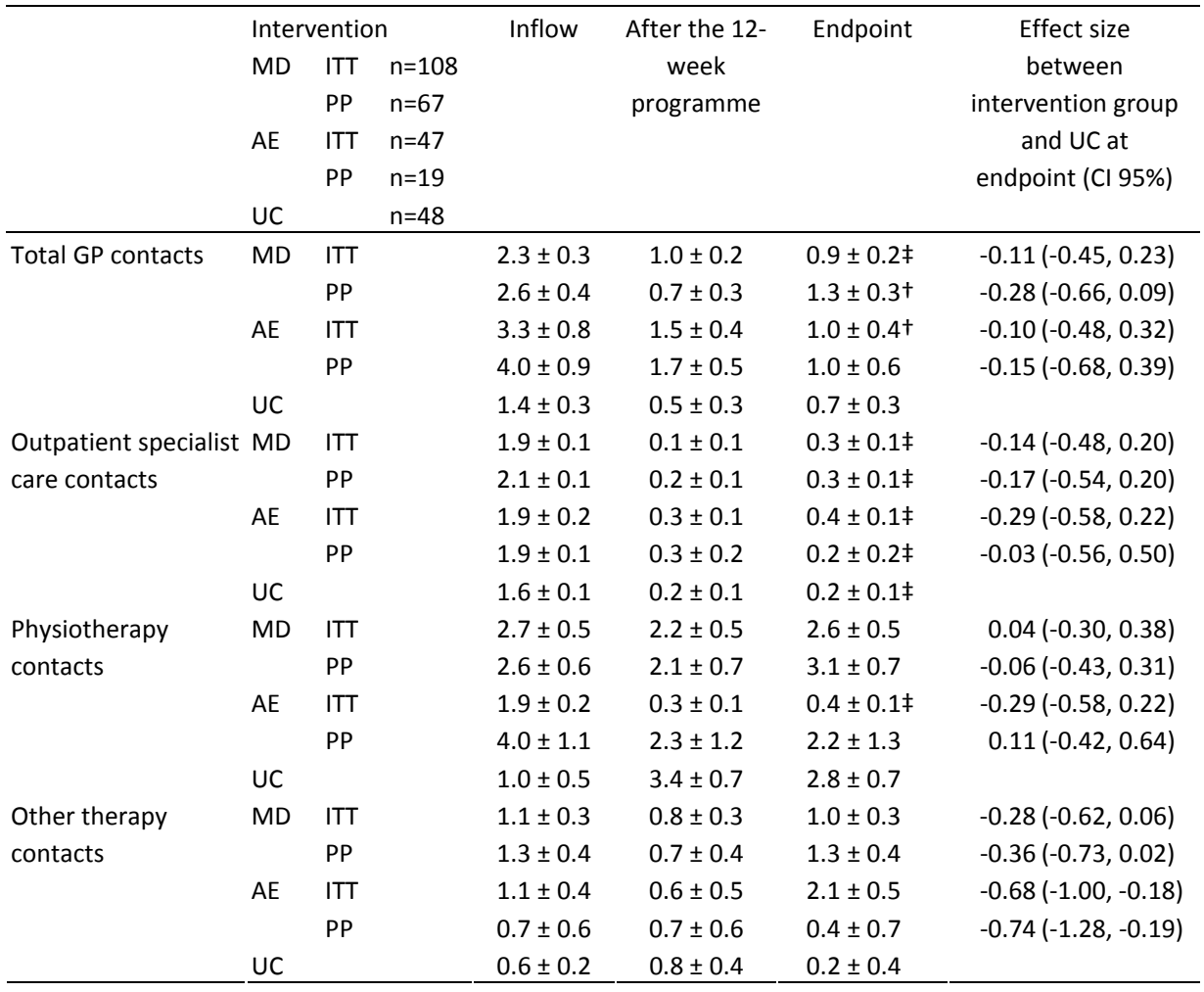

* Estimated marginal means \pm standard error based on mixed model analysis with random intercept. Total number of consultations over a period of 2 months prior to measurement; $\mathrm{MD}=$ multidisciplinary intervention; $\mathrm{AE}=$ aerobic exercise; $\mathrm{UC}=$ usual care; $\mathrm{ITT}=$ intention-to-treat; $\mathrm{PP}=$ per-protocol; $\mathrm{Cl}=$ confidence interval; + difference within group $=P<0.05 ; \ddagger$ difference within group $=P<0.001$.

\section{Discussion}

To our knowledge, this is the first trial in recently diagnosed FM patients examining the effect of a multidisciplinary intervention on HRQoL, participation, and health care utilization. Patients in the MD group experienced statistically significant improvements in HRQoL, and reduced their absence from paid work, visits to GPs and visits to medical specialists. Improvements were found immediately after completion of the intervention, largely sustained and even increased, also during the follow-up period which was one year after completion of the two phase programme. Patients in the UC group experienced no changes in HRQoL and only a statistically significantly reduction in the number of contacts with medical specialists was found. However, at the end of the study the differences between the MD group and the UC group were small and not statistically significant for any of the outcomes studied. 
Table 7.5 Within group and between group results with regard to impact of FM on daily functioning for the MD, AE and UC group*

\begin{tabular}{|c|c|c|c|c|c|c|c|}
\hline & Inter & venti & & Inflow & After the 12- & Endpoint & Effect size \\
\hline & $\mathrm{MD}$ & ITT & $n=108$ & & week & & between \\
\hline & & PP & $n=67$ & & programme & & Intervention group \\
\hline & $\mathrm{AE}$ & ITT & $\mathrm{n}=47$ & & & & and UC at \\
\hline & & PP & $n=19$ & & & & endpoint ( $\mathrm{Cl}$ 95\%) \\
\hline & UC & & $\mathrm{n}=48$ & & & & \\
\hline FIQ & & & & & & & \\
\hline Physical function & MD & ITT & & $4.2 \pm 0.2$ & $3.9 \pm 0.2$ & $3.6 \pm 0.2$ & $0.12(-0.22,0.46)$ \\
\hline & & $\mathrm{PP}$ & & $4.5 \pm 0.2$ & $4.1 \pm 0.2$ & $3.7 \pm 0.3$ & $0.08(-0.29,0.45)$ \\
\hline & $\mathrm{AE}$ & $\mathrm{ITT}$ & & $3.6 \pm 0.2$ & $3.7 \pm 0.3$ & $3.6 \pm 0.4$ & $0.11(-0.29,0.52)$ \\
\hline & & $\mathrm{PP}$ & & $3.7 \pm 0.2$ & $3.6 \pm 0.4$ & $3.6 \pm 0.6$ & $0.12(-0.41,0.65)$ \\
\hline & UC & & & $3.4 \pm 0.3$ & $4.0 \pm 0.3$ & $3.9 \pm 0.3$ & \\
\hline Days feel good & $\mathrm{MD}$ & $\mathrm{ITT}$ & & $7.3 \pm 0.2$ & $5.6 \pm 0.3$ & $5.2 \pm 0.3 \ddagger$ & $0.24(-0.10,0.58)$ \\
\hline & & $\mathrm{PP}$ & & $7.8 \pm 0.3$ & $5.7 \pm 0.3$ & $5.5 \pm 0.4 \ddagger$ & $0.15(-0.22,0.52)$ \\
\hline & $\mathrm{AE}$ & $\mathrm{ITT}$ & & $6.9 \pm 0.3$ & $5.5 \pm 0.4$ & $4.6 \pm 0.5$ & $0.41(0.00,0.81)$ \\
\hline & & PP & & $6.9 \pm 0.5$ & $5.0 \pm 0.6$ & $4.5 \pm 0.8^{\dagger}$ & $0.44(-0.09,0.98)$ \\
\hline & UC & & & $6.0 \pm 0.4$ & $6.5 \pm 0.4$ & $5.9 \pm 0.5$ & \\
\hline Days missed work & MD & $\mathrm{ITT}$ & & $2.8 \pm 0.5$ & $2.1 \pm 0.5$ & $1.0 \pm 0.4^{\dagger}$ & $-0.06(-0.40,0.28)$ \\
\hline & & $\mathrm{PP}$ & & $3.6 \pm 0.7$ & $2.4 \pm 0.6$ & $0.5 \pm 0.6+$ & $0.04(-0.33,0.41)$ \\
\hline & $\mathrm{AE}$ & ITT & & $2.0 \pm 0.5$ & $0.4 \pm 0.5$ & $1.6 \pm 0.7$ & $-0.18(-0.59,0.22)$ \\
\hline & & $\mathrm{PP}$ & & $2.8 \pm 0.9$ & $0.5 \pm 0.8$ & $1.7 \pm 1.0$ & $-0.21(-0.74,0.32)$ \\
\hline & UC & & & $0.7 \pm 0.4$ & $1.1 \pm 0.7$ & $0.7 \pm 0.7$ & \\
\hline Job ability & MD & ITT & & $7.4 \pm 0.3$ & $6.0 \pm 0.3$ & $5.6 \pm 0.3 \ddagger$ & $0.06(-0.28,0.40)$ \\
\hline & & PP & & $8.0 \pm 0.3$ & $6.4 \pm 0.4$ & $5.6 \pm 0.4 \ddagger$ & $0.06(-0.31,0.43)$ \\
\hline & $\mathrm{AE}$ & ITT & & $6.3 \pm 0.3$ & $5.6 \pm 0.4$ & $5.1 \pm 0.5$ & $0.20(-0.20,0.60$ \\
\hline & & PP & & $5.9 \pm 0.4$ & $6.0 \pm 0.6$ & $4.3 \pm 0.8$ & $0.43(-0.10,0.97)$ \\
\hline & UC & & & $5.8 \pm 0.4$ & $6.1 \pm 0.4$ & $5.8 \pm 0.5$ & \\
\hline Pain & MD & $\mathrm{ITT}$ & & $6.3 \pm 0.2$ & $5.5 \pm 0.2$ & $5.3 \pm 0.2 \ddagger$ & $-0.01(-0.35,0.33)$ \\
\hline & & $\mathrm{PP}$ & & $6.3 \pm 0.2$ & $5.4 \pm 0.2$ & $5.4 \pm 0.3+$ & $-0.06(-0.43,0.31)$ \\
\hline & $A E$ & $\mathrm{ITT}$ & & $6.2 \pm 0.3$ & $5.3 \pm 0.3$ & $5.2 \pm 0.4$ & $0.05(-0.36,0.44)$ \\
\hline & & $\mathrm{PP}$ & & $6.1 \pm 0.3$ & $5.3 \pm 0.4$ & $4.2 \pm 0.5$ & $0.46(-0.08,0.99)$ \\
\hline & UC & & & $5.5 \pm 0.3$ & $5.7 \pm 0.3$ & $5.3 \pm 0.3$ & \\
\hline Fatigue & MD & ITT & & $8.3 \pm 0.2$ & $7.5 \pm 0.2$ & $7.0 \pm 0.3 \ddagger$ & $0.18(-0.16,0.52)$ \\
\hline & & PP & & $8.3 \pm 0.2$ & $7.4 \pm 0.3$ & $7.2 \pm 0.3^{\dagger}$ & $0.12(-0.25,0.49)$ \\
\hline & $\mathrm{AE}$ & $\mathrm{ITT}$ & & $8.0 \pm 0.2$ & $7.4 \pm 0.2$ & $7.0 \pm 0.4$ & $0.18(-0.22,0.59)$ \\
\hline & & $\mathrm{PP}$ & & $7.7 \pm 0.3$ & $7.2 \pm 0.5$ & $6.0 \pm 0.6$ & $0.57(0.03,1.11)$ \\
\hline & UC & & & $7.4 \pm 0.3$ & $7.2 \pm 0.3$ & $7.5 \pm 0.4$ & \\
\hline Unrefreshed sleep & $\mathrm{MD}$ & $\mathrm{ITT}$ & & $8.2 \pm 0.2$ & $7.5 \pm 0.2$ & $7.1 \pm 0.3 \ddagger$ & $0.19(-0.15,0.53)$ \\
\hline & & $\mathrm{PP}$ & & $8.5 \pm 0.2$ & $7.3 \pm 0.3$ & $7.2 \pm 0.3 \ddagger$ & $0.16(-0.21,0.53)$ \\
\hline & $\mathrm{AE}$ & $\mathrm{ITT}$ & & $8.1 \pm 0.3$ & $7.0 \pm 0.3$ & $7.2 \pm 0.4+$ & $0.16(-0.60,0.90)$ \\
\hline & & PP & & $7.7 \pm 0.3$ & $6.8 \pm 0.5$ & $6.3 \pm 0.6$ & $0.50(-0.04,1.03)$ \\
\hline & UC & & & $7.6 \pm 0.3$ & $7.2 \pm 0.3$ & $7.6 \pm 0.4$ & \\
\hline Stiffness & $\mathrm{MD}$ & $\mathrm{ITT}$ & & $7.1 \pm 0.2$ & $6.7 \pm 0.2$ & $6.1 \pm 0.3^{\dagger}$ & $0.07(-0.27,0.41)$ \\
\hline & & PP & & $7.1 \pm 0.2$ & $6.6 \pm 0.3$ & $6.1 \pm 0.3$ & $0.07(-0.30,0.44)$ \\
\hline & $\mathrm{AE}$ & ITT & & $7.3 \pm 0.2$ & $6.2 \pm 0.3$ & $5.9 \pm 0.4^{\dagger}$ & $0.14(-0.26,0.54)$ \\
\hline & & $\mathrm{PP}$ & & $7.2 \pm 0.4$ & $5.5 \pm 0.5$ & $4.9 \pm 0.7$ & $0.49(-0.05,1.03)$ \\
\hline & UC & & & $6.8 \pm 0.4$ & $6.3 \pm 0.3$ & $6.3 \pm 0.4$ & \\
\hline
\end{tabular}




\begin{tabular}{|c|c|c|c|c|c|c|c|}
\hline & \multicolumn{3}{|c|}{ Intervention } & \multirow[t]{5}{*}{ Inflow } & \multirow{5}{*}{$\begin{array}{l}\text { After the } 12- \\
\text { week } \\
\text { programme }\end{array}$} & \multirow[t]{5}{*}{ Endpoint } & \multirow{6}{*}{$\begin{array}{c}\text { Effect size } \\
\text { between } \\
\text { Intervention group } \\
\text { and UC at } \\
\text { endpoint ( } \mathrm{Cl} 95 \%)\end{array}$} \\
\hline & MD & ITT & $n=108$ & & & & \\
\hline & & $\mathrm{PP}$ & $n=67$ & & & & \\
\hline & $\mathrm{AE}$ & ITT & $n=47$ & & & & \\
\hline & & PP & $n=19$ & & & & \\
\hline & UC & & $n=48$ & & & & \\
\hline \multirow[t]{5}{*}{ Anxiety } & $M D$ & ITT & & $5.9 \pm 0.3$ & $5.0 \pm 0.2$ & $4.7 \pm 0.3^{\dagger}$ & $0.03(-0.31,0.37)$ \\
\hline & & PP & & $6.0 \pm 0.3$ & $4.9 \pm 0.3$ & $4.4 \pm 0.4{ }^{\dagger}$ & $0.14(-0.24,0.51)$ \\
\hline & $\mathrm{AE}$ & ITT & & $4.9 \pm 0.3$ & $4.6 \pm 0.4$ & $5.0 \pm 0.5$ & $-0.06(-0.46,0.34)$ \\
\hline & & $\mathrm{PP}$ & & $5.2 \pm 0.4$ & $4.9 \pm 0.6$ & $4.9 \pm 0.7$ & $-0.03(-0.56,0.50)$ \\
\hline & UC & & & $4.8 \pm 0.4$ & $5.2 \pm 0.4$ & $4.8 \pm 0.4$ & \\
\hline \multirow[t]{5}{*}{ Depression } & $\mathrm{MD}$ & $\mathrm{ITT}$ & & $5.2 \pm 0.3$ & $4.1 \pm 0.3$ & $3.9 \pm 0.3+$ & $0.10(-0.24,0.44)$ \\
\hline & & $\mathrm{PP}$ & & $5.2 \pm 0.3$ & $4.0 \pm 0.3$ & $3.9 \pm 0.3 \dagger$ & $0.10(-0.27,0.47)$ \\
\hline & $\mathrm{AE}$ & $\mathrm{ITT}$ & & $4.8 \pm 0.3$ & $4.6 \pm 0.4$ & $5.0 \pm 0.5$ & $0.09(-0.31,0.49)$ \\
\hline & & $\mathrm{PP}$ & & $4.9 \pm 0.4$ & $4.1 \pm 0.6$ & $3.6 \pm 0.7$ & $0.20(-0.33,0.73)$ \\
\hline & UC & & & $4.2 \pm 0.4$ & $4.5 \pm 0.4$ & $4.2 \pm 0.4$ & \\
\hline \multirow[t]{5}{*}{ FIQ-total } & $\mathrm{MD}$ & ITT & & $64.5 \pm 1.4$ & $55.1 \pm 1.5$ & $50.9 \pm 2.0 \ddagger$ & $0.25(-0.09,0.59)$ \\
\hline & & PP & & $66.3 \pm 1.8$ & $54.6 \pm 1.9$ & $51.2 \pm 2.3 \ddagger$ & $0.25(-0.12,0.62)$ \\
\hline & $\mathrm{AE}$ & ITT & & $60.0 \pm 2.1$ & $53.2 \pm 2.4$ & $52.0 \pm 3.2+$ & $0.22(-0.20,0.61)$ \\
\hline & & $\mathrm{PP}$ & & $59.2 \pm 2.5$ & $52.3 \pm 3.6$ & $47.4 \pm 4.7$ & $0.42(-0.12,0.95)$ \\
\hline & UC & & & $55.4 \pm 2.3$ & $58.1 \pm 2.3$ & $56.2 \pm 2.9$ & \\
\hline
\end{tabular}

* Estimated marginal means \pm standard error based on mixed model analysis with random intercept/random slope; FIQ = Fibromyalgia Impact Questionnaire. The items of the FIQ have been standardized and range from $0-10$. The range of FIQ total is $0-100$. Higher score values indicate worse health status; $\mathrm{MD}=$ multidisciplinary intervention; $\mathrm{AE}=$ aerobic exercise; $\mathrm{UC}=$ usual care; ITT = intention-totreat; $\mathrm{PP}=$ per-protocol; $\mathrm{Cl}=$ confidence interval; + difference within group $=P<0.05 ; \ddagger$ difference within group $=P<0.001$.

Despite relevant improvements, HRQoL was still low at the end of the trial confirming the large impact of FM on quality of life ${ }^{34}$. While overall health care utilization tended to decrease, the high number of visits to PTs during the study may be explained by the advice to perform physical activity and muscle training which was given in both groups as usual. In the Dutch health care system, patients may prefer reimbursed opportunities, like physiotherapy, above community programmes. Results from interventions in FM patients with regard to health care utilization are limited ${ }^{35,36}$. It is arguable if diagnosing the disorder may have some treatment effect in itself ${ }^{37}$. However, improvements in the UC group suggest that it influenced our results with regard to the reduction in health care utilization. Results on the FIQ are largely comparable with results from other studies but in contrast to other studies the found results sustained and even increased in the MD group, also during the follow-up period, which was one year after finishing the two phased programme ${ }^{11}$.

The MD intervention was characterised by a low attrition, resembling the situation in the pilot-study which suggests that the treatment indeed has met the needs and expectations of the patients that consented to participate ${ }^{14}$. The limited consent to participate in the AE group is similar to what was seen in other studies and suggests that $A E$ meets the needs of only a select group of FM patients ${ }^{38}$. We mainly aimed to 
study the impact of the intervention in patients in the early stages of the disease. Surprisingly, the mean symptom duration in the study population turned out to be seven years. Apparently, patients retrospectively recognised earlier symptoms as FM symptoms.

Some methodological challenges appeared in the study. First, in view of known difficulties to perform blinded or placebo-control group studies in multidisciplinary interventions a Zelen-design was chosen in order to avoid bias by expectation. Following this design, patients were invited to participate in the interventions only after randomisation, immediately after they were diagnosed by the rheumatologist. Some patients asked for a time period to learn more about FM and to get more insight in their needs before starting the intervention. Consequently, they sometimes decided not to start after all. Although this likely reflects what happens in clinical practice it also affected the power of the study. More insight in the variation of expectations and attitudes from patients towards non-pharmacological interventions is needed, preferably in the light of available evidence about such interventions. An in-depth exploration of the patient's expectations and attitude may be an alternative for the Zelen-design to address the issue of expectation-bias in future research on effective interventions for $\mathrm{FM}^{39}$. Expectation-bias in RCTs is usually ignored since patients can refuse to participate when they are invited. Second, invariably the largest changes were found in the MD group. Despite randomisation the MD group turned out to be group with the worst condition at inflow and thus had the largest potential for improvement. Although these data are suggestive for regression to the mean, the choice for mixed model analysis results in an accurate representation of the improvements over time. However, the baseline differences affect the interpretation of the study results as it cannot be excluded that improvements would have been similar if the groups were comparable at inflow in the study. Third, as in many studies heterogeneity of the study population appeared. Some literature showed more homogeneity and promising results, due to selection of patients ${ }^{40}$ or to intangible effects $^{41,42}$. However, given the large number of studies, discussion about the tools to classify FM patients into different phenotypic subgroups is still going on. Finally, when interpreting results it should be taken into account that these results apply to patients referred to rheumatology outpatient clinics and cannot be generalised to patients in other settings such as patients in a general practitioner setting.

In summary, this pragmatic trial in recently diagnosed patients with FM which comprised several outcomes of societal relevance was not able to show statistically significantly between group differences at the end of the study. The absence of between group differences can be partially explained by both (a) a lack of statistical power of our study, attributable to a limited willingness for participation in the interventions, and (b) baselines between group differences despite randomisation. Notwithstanding, the study findings do give insight in changes that occur in longitudinal outcomes, independent from interventions. They furthermore contribute to insight in barriers for the implementation of care programmes for patients with FM. Methodological limitations of the study prevent to draw a firm conclusion about specific effects attributable to the multidisciplinary intervention. 


\section{References}

1. White KP, Harth M. Classification, epidemiology, and natural history of fibromyalgia. Curr Pain Headache Rep 2001;5:320-9.

2. Wolfe F, Smythe HA, Yunus MB, Bennett RM, Bombardier C, Goldenberg DL, et al. The American College of Rheumatology 1990 Criteria for the Classification of Fibromyalgia. Report of the Multicenter Criteria Committee. Arthritis Rheum 1990;33:160-72.

3. Arnold LM, Crofford LJ, Mease PJ, Burgess SM, Palmer SC, Abetz L, et al. Patient perspectives on the impact of fibromyalgia. Patient Educ Counsel 2008;73:114-20.

4. Assefi NP, Coy TV, Uslan D, Smith WR, Buchwald D. Financial, occupational, and personal consequences of disability in patients with chronic fatigue syndrome and fibromyalgia compared to other fatiguing conditions. J Rheumatol 2003;30:804-8.

5. Boonen A, van den Heuvel R, van Tubergen A, Goossens M, Severens JL, van der Heijde D, et al. Large differences in cost of illness and wellbeing between patients with fibromyalgia, chronic low back pain, or ankylosing spondylitis. Ann Rheum Dis 2005;64:396-402.

6. White KP, Speechley M, Harth M, Ostbye T. The London Fibromyalgia Epidemiology Study: comparing the demographic and clinical characteristics in 100 random community cases of fibromyalgia versus controls. J Rheumatol 1999;26:1577-85.

7. White LA, Birnbaum HG, Kaltenboeck A, Tang J, Mallett D, Robinson RL. Employees with fibromyalgia: medical comorbidity, healthcare costs, and work loss. J Occup Environ Med 2008;50:13-24.

8. Burckhardt CS. Multidisciplinary approaches for management of fibromyalgia. Curr Pharm Des 2006;12:59-66.

9. Clauw DJ. Fibromyalgia: update on mechanisms and management. J Clin Rheumatol 2007;13:102-9.

10. Hauser W, Bernardy K, Arnold B, Offenbacher M, Schiltenwolf M. Efficacy of multicomponent treatment in fibromyalgia syndrome: a meta-analysis of randomized controlled clinical trials. Arthritis Rheum 2009;61:216-24.

11. van Koulil S, Effting M, Kraaimaat FW, van Lankveld W, van Helmond $T$, Cats $H$, et al. Cognitivebehavioural therapies and exercise programmes for patients with fibromyalgia: state of the art and future directions. Ann Rheum Dis 2007;66:571-81.

12. van der Werf SP, de Vree B, Alberts M, van der Meer JW, Bleijenberg G. Natural course and predicting self-reported improvement in patients with chronic fatigue syndrome with a relatively short illness duration. J Psychosom Res 2002;53:749-53.

13. Carville SF, Choy EH. Systematic review of discriminating power of outcome measures used in clinical trials of fibromyalgia. J Rheumatol 2008;35:2094-105.

14. Kroese M, Schulpen G, Bessems M, Nijhuis F, Severens J, Landewe R. The feasibility and efficacy of a multidisciplinary intervention with aftercare meetings for fibromyalgia. Clin Rheumatol 2009;28: 923-9.

15. Schwartz D, Lellouch J. Explanatory and pragmatic attitudes in therapeutical trials. J Chronic Dis 1967;20:637-48.

16. Zelen M. A new design for randomized clinical trials. N Eng J Med 1979;300:1242-5.

17. Berne E. Transactional analysis: A new and effective method of group therapy. Am J Psychoth 1958;12:735-43.

18. Berne E, Steiner CM, Dusay JM. Transactional analysis. In: Groves JE, (ed). Essential papers on short term dynamic therapy Essential papers in psychoanalysis. New York, NY, US: New York University Press; 1996:149-70.

19. Ofman D. Core Qualities; a gateway to human resources. Schiedam: Scriptum. 2001.

20. Ellis A. Rational-emotive therapy. J Cont Psychoth 1969;1:82-90.

21. Ellis A. Overcoming resistance: A rational emotive behavior therapy integrated approach (2nd ed.). New York, NY, US: Springer Publishing Co. 2002.

22. Rothschild BH. RET and chronic pain. In: Dryden W, Hill LK, (ed). Innovations in rational-emotive therapy. Thousand Oaks, CA, US: Sage Publications. 1993:91-115.

23. American College of Sports Medicine. Position Stand. The recommended quantity and quality of exercise for developing and maintaining cardiorespiratory and muscular fitness, and flexibility in healthy adults. Medicine \& science in sports \& exercise 1998;30:975-91. 
24. The EuroQol Group. EuroQol-a new facility for the measurement of health-related quality of life. Health Policy 1990;16:199-208.

25. Dolan P. Modeling valuations for EuroQol health states. Med Care 1997;35:1095-108.

26. Post MWM. Utrechtse activiteitenlijst in: van Asbeck F.W.A. (ea) Handboek dwarslaesierevalidatie. Houten/Diegum: Bohn, Stafleu\&van Longum; 1998.

27. Goossens MEJB, Mölken MPMHR-v, Vlaeyen JWS, van der Linden SMJP. The cost diary: a method to measure direct and indirect costs in cost-effectiveness research. J Clin Epid 2000;53:688.

28. Bennett R. The Fibromyalgia Impact Questionnaire (FIQ): a review of its development, current version, operating characteristics and uses. Clin Exp Rheumatol 2005;23(5 Suppl 39):S154-62.

29. Burckhardt CS, Clark SR, Bennett RM. The fibromyalgia impact questionnaire: development and validation. J Rheumatol 1991;18:728-33.

30. Tan FES. Best practices in analysis of longitudinal data: a multilevel approach. Jason W Osborne: Best practices in quantitative methods. Los Angeles: Sage publications. 2008:451-71.

31. Molenberghs G, Kenward ME. Missing Data in Clinical Studies. Chapter III 7: Wiley. 2007.

32. Cohen J. Statistical power analysis for the behavioral sciences. 2 ed. Hillsdale, NJ: Lawrence Erlbaum Associates. 1998.

33. Nakagawa S, Cuthill IC. Effect size, confidence interval and statistical significance: a practical guide for biologists. Biological review 2007;82:591-605.

34. Verbunt JA, Pernot DH, Smeets RJ. Disability and quality of life in patients with fibromyalgia. Health Qual Life Outcomes 2008;6:8.

35. Hammond A, Freeman K. Community patient education and exercise for people with fibromyalgia: a parallel group randomized controlled trial. Clin Rehabil 2006;20:835-46.

36. Lorig KR, Ritter PL, Laurent DD, Plant K. The internet-based arthritis self-management program: a oneyear randomized trial for patients with arthritis or fibromyalgia. Arthritis Rheum 2008;59:1009-17.

37. Kroese M, Severens J, Schulpen G, Bessems M, Nijhuis F, Landewe R. Specialized Rheumatology Nurse Substitutes for Rheumatologists in the Diagnostic Process of Fibromyalgia: A Cost-Consequence Analysis and a Randomized Controlled Trial. J Rheumatol 2011;38:1413-22.

38. van Santen $M$, Bolwijn $P$, Landewe R, Verstappen F, Bakker $C$, Hidding A, et al. High or low intensity aerobic fitness training in fibromyalgia: does it matter? J Rheumatol 2002;29:582-7.

39. Campbell M, Fitzpatrick R, Haines A, Kinmonth AL, Sandercock P, Spiegelhalter D, Tyrer P. Framework for design and evaluation of complex interventions to improve health. BMJ 2000;321:694-6.

40. van Koulil S, van Lankveld W, Kraaimaat FW, van Helmond T, Vedder A, van Hoorn H, et al. Tailored cognitive-behavioral therapy and exercise training for high-risk fibromyalgia patients. Arthritis Care Res 2010;62:1377-85.

41. van Eijk-Hustings $\mathrm{Y}$, Boonen A, Landewé R. A randomized trial of Tai Chi for fibromyalgia (author reply 2266-7). N Engl J Med 2010;363; 2266-7.

42. Wang C, Schmid CH, Rones R, Kalish R, Yinh J, Goldenberg DL, et al. A Randomized Trial of Tai Chi for Fibromyalgia. N Engl J Med 2010;363:743-54. 


\section{Chapter 8}

General discussion 
114 Chapter 8 


\section{Introduction}

The overall objective of this thesis was to evaluate two health care innovations in the care for patients with FM, a nurse-led diagnostic process and a multidisciplinary intervention with aftercare meetings. In both health care innovations 'timing' is important: an early diagnosis and an early treatment. Both studies were divided into a process evaluation and an effect evaluation.

The main findings reported in the individual chapters are summarised below. Subsequently, general conclusions are drawn and methodological strengths and limitations of the presented studies are discussed. This chapter ends with implications for health care practice and recommendations for further research.

\section{Main findings}

Our feasibility study of substituting specialized rheumatology nurses (SRNs) for rheumatologists (RMTs) in the diagnostic process of FM showed that substituting is a trustworthy and successful approach, which is secure in terms of initial agreement on diagnosis between SRN and RMT and no missed diagnoses after 12-24 months of follow-up, which saves waiting time, provides additional patient satisfaction and is cost-effective.

From the health care and societal perspectives, the nurse-led diagnostic process is a profitable approach regarding the costs and consequences. Patients in the SRN group were significantly more satisfied, while no differences in change in health status between the two groups were observed during 9 months of follow-up. Total health care consumption costs and patient and family costs were significantly lower in the SRN group. Also, total societal costs (including absenteeism) were considerably lower in the SRN group.

Another main finding is that a diagnosis of FM in itself is associated with worse health outcomes such as functional status, health related quality of life (HRQoL), and painrelated anxiety before diagnosis as well as worse health outcomes and higher health care costs during 9 months of follow-up. We did not find significant differences in the prognosis of early (SRN) vs. delayed (RMT) diagnosed patients, neither for patients with FM nor for patients in which another diagnosis was made. Concerning costs, it looks as if an early diagnosis, not being FM, may prevent future health care and societal costs.

The study gathering information from five disciplines (general practitioners (GPs), RMTs, rehabilitation specialists, physiotherapists, and psychologists) on their usual management methods of FM showed that between 1998 and 2005 treatment regimes have been changed in the Netherlands. Despite the fact that most changes were in concordance with evidence in the literature, the implementation of recommended therapies is still very poor, and considerable differences between the several disciplines are found. A noteworthy detail is that GPs frequently refer patients to 
RMTs, while these RMTs nearly always refer these patients back to the GPs after confirming the diagnosis.

The feasibility and long-term results of a 12-week multidisciplinary part-time day-care intervention with 5 aftercare meetings in $105 \mathrm{FM}$ patients were considered promising. We found a low drop-out rate, a high attendance rate, and a high level of patient- and therapist satisfaction. After the 12-week programme, significant improvements from baseline were seen in both the Fibromyalgia Impact Questionnaire (FIQ) and the EQ-5D instrument. More importantly, this improvement had maintained after 9 months of follow-up, and we considered this result a promising starting point for a randomized controlled trial.

Unfortunately, the effectiveness of our multidisciplinary (MD) intervention with aftercare meetings in recently diagnosed FM patients compared with aerobic exercise (AE) and usual care (UC) seems limited. Although improvements on several primary and secondary outcome measures were noted in all three intervention groups, especially in the MD group, after 21-24 months of follow-up, between-group differences were small at the endpoint of the study and were considered clinically not very meaningful by us.

\section{Overall conclusion}

Based on the findings concerning the nurse-led diagnostic process it can be concluded that it does not matter when and by whom the diagnosis FM is made. The early nurseled diagnostic process is feasible and leads to lower costs than the usual rheumatologist-led consultation, both from a health care and a societal perspective, whilst neither approach was better in terms of functional status and HRQoL. In contrast with our hypothesis, an early diagnosis made by a SRN has practically no impact on health outcomes. In fact, it looks as if a diagnosis of FM implies a rather poor prognosis (at least poorer than another rheumatological diagnosis). Our studies do not allow a conclusion about whether this is a reflection of the disorder itself, whether it is caused by having a label of FM, or whether patients with FM have a different perception of the severity of their disorder that is rather benign in the eyes of the RMT and GP because it is non-inflammatory and non-destructive.

According to the findings of this thesis, it can also be concluded that our multidisciplinary intervention with aftercare meetings is feasible. Although significant sustaining effects of the multidisciplinary intervention were found on HRQoL, participation, health care utilization and self-reported health outcomes, the between group differences were small. Therefore we have concluded that the effects of our multidisciplinary programme seem to be limited although sustained improvements could be found, sometimes at a similar level with aerobic exercise and/or usual care, which are importantly cheaper. However, the patients who consented in participation in the MD group were motivated and completed the entire programme, both in the 
pilot-study and in the RCT, indicating that the treatment has met the needs and expectations of the participating patients. In contrast, there was a high drop out rate in the $A E$ group, suggesting that this intervention meets only the needs of a selected group of FM patients.

\section{Methodological considerations}

Several methodological considerations arise when we look at the applied methods in our research.

\section{Internal versus external validity in pragmatic trials}

First, the design of the two main studies of this thesis was a pragmatic randomized trial. Pragmatic trials measure the beneficial effect of an intervention in real practice in contrast to explanatory trials which measure the effect in an ideal research situation ${ }^{1}$. These trials provide evidence for health care providers and policy makers to make policy decisions ${ }^{2}$. Therefore, pragmatic trials seek to maximize external validity to ensure that the results can be generalized by comparing the intervention with usual or best care and keeping selection criteria of patients to a minimum to reflect variations between patients that occur in real practice. This was also the case in our trials where usual care varied and patients could receive other interventions besides the proposed or allocated one. However, optimising external validity will jeopardise the internal validity of the trial, which may have influenced the results ${ }^{3}$. We have tried to guarantee a sufficient level of internal validity by four choices: 1) random allocation of patients to intervention and control group, 2) a pre-randomized Zelen-like design in the MD intervention trial ${ }^{4}$, 3) baseline data collection prior to randomization, and 4) blinding of data collection and data analysis as far as possible. As such, all variables are assumed to be equally distributed among the two groups at baseline. However, whilst patient characteristics were indeed comparable between the randomized groups, analyses of baseline data showed that in both trials baseline variables reflecting health outcome were different between intervention and control group. In the diagnostic trial, the health outcomes were worst in the UC group and in the multidisciplinary intervention trial the health outcomes were worst in the MD group. This could have caused bias, in the diagnostic trial in an overestimation in favour of the nurse-led diagnostic process and in the multidisciplinary intervention trial in an underestimation of the multidisciplinary intervention. Most likely, this difference is coincidental and due to relatively low patient numbers. However, this baseline imbalance urged us to perform adjustments for baseline differences, with lack of precision and impaired interpretability as a consequence. 


\section{Blinding}

Furthermore, blinding of health care providers and patients obviously was not possible in our trials. Since the performance of the RMT could be influenced by knowledge about the patient being in a study, the doctor was kept 'blind' for the study. RMTs only became aware that the patient participated in the study after the consultation by completing an evaluation form. Blinding of the SRN and her supervisor was not feasible in the diagnostic trial because diagnostic consultations were not 'normal clinical practice' for nurses.

In pragmatic trials, placebos are generally not used, as these trials aim to give insight into the beneficial effect of a new treatment compared to the best current treatment. Additionally, in a pragmatic trial clinician and patient biases are not necessarily seen as disadvantageous, but accepted as part of physicians' and patients' responses to treatment and included in the overall assessment ${ }^{3}$. Therefore, in this approach the treatment response includes both treatment- and associated placebo effects, as this will best reflect the likely clinical response in practice. However, we think that the effect of the nurse-led diagnostic process in terms of attention is minimal. First, we found similar improvements in health status in both groups. Second, although the visits in the SRN group took on average 20 minutes more than the visits in the RMT group, patients in the SRN group had fewer contacts with a rheumatologist or a nurse than patients in the RMT group.

In the trial on the effectiveness of our multidisciplinary intervention, a prerandomized Zelen-like design ${ }^{4}$ was used to avoid biased results due to patients expectations when patients were aware of the different treatment options. Eligible patients were asked to participate in -as they were told- 'an observational study on the natural course of FM' and at the same time they were asked whether they were willing to participate in future studies. In case of consent, they were randomly assigned to one of the treatment groups. Although this approach may eliminate the danger of 'bias by expectation' to some extent, it has important disadvantages: we encountered a high number of patients that were not willing to participate to the group to which they were assigned by randomization, which resulted in important analytical problems.

\section{Compliance}

Compliance with the intervention is an important outcome of pragmatic trials ${ }^{3}$. If physicians and/or patients do not comply with the intervention, it does not matter that it can work in the ideal world, because in daily practice it does not. Lack of compliance in the daily practice frequently renders an efficacious intervention ineffective. In our study, patients often had a legitimate reason for their limited willingness to participate in the multidisciplinary programme or the aerobic exercise intervention because of problems to fit the intervention in daily life (work, children or travel distance). Sometimes they simply wanted to have more time before starting the intervention. Consequently, a reasonable number of patients decided not to start at 
all. It is likely this reflects what happens in real life. Normally, these patients would not have entered a RCT on the effectiveness of a treatment. Because of the limited willingness to take part in the intervention after randomization, both intention-totreat and per-protocol analyses were performed. In the intention-to-treat analysis patients randomized but not participating do not add to any meaningful effect over time, and the low percentages of patients who started with the multidisciplinary programme and especially aerobic exercise had important consequences for the statistical power of our study with regard to the per-protocol analysis. We think we would not have been able to demonstrate any clinically important between-group differences if they would exist.

\section{Missing data}

A related problem is missing data in our studies. Cost/health care use and participation data were collected by two-monthly questionnaires, in the diagnostic trial over a period of 9 months and in the intervention trial over a period of 21 to 24 months. During this time period, for both studies health outcomes were measured 5 times by a questionnaire. It is likely that the frequency of the questionnaires and the length of the time period in especially the intervention trial have contributed to the large amount of missing data. We attempted to minimize data loss by written and telephonic reminders and encouraging patients to complete questionnaires after dropping out. Nevertheless, missing data in the diagnostic trial amounted to $13.5 \%$ and in the intervention trial to $21.6 \%$ at the endpoint of the study. We have carefully checked these missing values and they were found to be at random.

In the diagnostic trial, patients with low levels of HRQoL and high levels of disability were generally more likely to have missing data at some time point. Since FM patients seem to experience lower levels of HRQoL and higher levels of disability than non-FM patients, and the SRN group contained more FM patients, the HRQoL scores of the SRN group could be an underestimation. Therefore, the incremental difference between the RMT group and the SRN group could also be a conservative estimation. Although we also found more missing values in non-FM patients and therefore in the RMT group, we assume the effect on the scores is limited because of the small number of missing non-FM patients on the total of the group.

The mixed model approach was used in our association- and effectiveness analyses (chapter 4 and 7 respectively) to reduce the chance of bias due to dropout, since in such an analysis all available data, including those from patients with incomplete data, are used to estimate the marginal means and their standard error. Baseline values of the dependent variables were added as covariates in the model, because of the previously mentioned baseline differences.

In the cost-consequence analysis, the mixed model approach was not yet technical applicable. The use of naïve methods, like last observation carried forward (LOC-F), is proven to be inappropriate for economic evaluations ${ }^{5-7}$. Especially since cost data tend to be highly skewed, naïve methods could severely bias the results. Therefore we used a non-parametric multiple imputation (MI) method which creates multiple datasets over which any imputed data can vary, reflecting the uncertainty in the true values. 


\section{Validity of FM diagnosis}

Another consideration is the fact that FM was more frequently diagnosed in the SRN group. One of the possibilities is that the RMT tried to avoid making a diagnosis of FM. A second explanation can be that the RMT or the SRN is more thorough in the diagnostic process. A third explanation can be that during the SRN approach the focus is on FM (yes or no) both with the SRN and with the supervising RMT, whereas the RMT during a regular visit may be more open to other diagnoses. Before the study started, we hypothesized that this 'unbiased RMT approach' might lead to a higher percentage of medically important diagnoses in the RMT group, such as inflammatory rheumatic diseases. What we actually found was that RMTs more often than SRNs rejected the diagnosis of FM, but not in favour of inflammatory or systemic rheumatic diseases, or unrelated but medically important diseases. They also did not choose the option of no diagnosis. They rather made a diagnosis of degenerative rheumatological conditions or a condition belonging to the spectrum of "soft-tissue rheumatism". This observation may reflect a better insight of the RMT in the entire spectrum of musculoskeletal problems as compared with the SRN, but does not necessarily reflect better patient care.

\section{Implications for practice}

Findings from our research support the implementation of the nurse-led diagnostic process and to some extent the multidisciplinary intervention with aftercare meetings in regular care. However, several issues should be considered before the actual implementation takes place. These implications are partly based on the before mentioned considerations and experiences in our research, but also on recent developments in clinical/scientific literature and in the organization of care.

\section{Diagnostic process of FM}

The ACR criteria for FM were originally designed to standardize patient classification in clinical trials. With widely accepted criteria, it was possible to conduct research studies on uniform patient populations recruited from diverse sites around the world. Because of the uniformity, there was reasonable certainty that study patients were comparable. However, these classification criteria have a lot of problems and therefore have met a lot of criticism ${ }^{8-10}$. The most important problem is that the ACR criteria were never validated for clinical diagnosis. Despite that, physicians in clinics around the world began to use the ACR criteria to make the diagnosis of FM. It is believed that many physicians are not properly performing or interpreting the examination of tender points ${ }^{11}$. Besides, the ACR criteria focus on pain and tenderness, ignoring many important complaints As a result, many clinicians do not rely on just ACR criteria for diagnosis and base the FM diagnosis primarily on the patient's report of widespread musculoskeletal pain and tenderness in the absence of 
an other somatic diagnosis ${ }^{9,12}$. In addition, epidemiologic assessment in the community requires examination of tender points.

Therefore, new clinical diagnostic criteria for FM in clinical practice were desirable. Very recently new diagnostic criteria have been proposed by Wolfe et al. (ACR 2010 criteria) ${ }^{13}$. They do not rely on counting tender points, take not only pain into account but also other FM-related symptoms and are intended to assess the severity of those symptoms. Research to determine the clinical usefulness of these proposed criteria is ongoing $^{14}$. At first sight, the new criteria seem to have several advantages.

First, the recognition that additional FM-related symptoms besides pain are important in determining a diagnosis of FM adds to the clinical belief that FM is more than tender points and widespread pain alone.

Second, an indication about the severity of complaints will be useful and can be guiding in choosing the most suitable treatment strategy. Next, until now, using the 1990 ACR FM diagnostic criteria, FM may be diagnosed in one occasion and not diagnosed in another, depending on change in clinical status. There were no criteria for FM remission, while practice often shows that FM characteristics may become more prominent during periods of physical and/or mental stress and may decrease during periods of better health or tranquillity.

Finally, these new criteria will make a diagnosis easier, especially in primary care, by eliminating the tender point examination. Applying these new clinical criteria as a survey can be attractive because they do not require physical examination. Wolfe et al. proposed a modification of the new ACR 2010 criteria which will allow their use in epidemiologic and clinical studies without the requirement for an examiner ${ }^{14}$. Applying these new criteria hopefully paves the way to earlier and better recognition of complaints and in that way also to earlier treatment.

However, the risk of possible under- and overdiagnosis by using these ACR 2010 criteria deserves attention. A diagnosis of FM may be made to easily in patients presenting with musculoskeletal pain that does not fit into a well defined musculoskeletal disease pattern. Besides, the populations identified by the two criteria are similar but not identical. Applying these new criteria, the incidence and prevalence of FM will probably increase and the inclusion of patients with milder disease will change prognosis. As a consequence, using the new criteria for research can possibly generate other results. Therefore, for some time it could be advisable to use the ACR 1990 criteria as entry criteria for FM research studies and the new ACR 2010 criteria for routine clinical care, and to facilitate formal comparison in studies.

\section{Who is the right person for making a FM diagnosis?}

Our research showed that our SRNs were skilled to diagnose FM in patients referred to the RMT with generalized musculoskeletal symptoms in terms of safety, patient satisfaction and costs. One can argue that the SRN is not the only discipline besides a RMT who can make a diagnosis of FM. As most patients with FM-like symptoms are first seen in primary care, it seems a logical option that also GPs can make the FM diagnosis. The recognition of FM by GPs is important, since the early detection of this 
disorder will prevent costly and unnecessary tests and referrals, and delay in making the diagnosis and starting an appropriate treatment. Several studies have investigated the accuracy of a FM diagnosis made by $\mathrm{GPs}^{15-18}$. The early studies showed a poor accuracy of FM diagnosis ${ }^{15-17}$, but the most recent one has reported a good agreement on FM diagnosis between GPs and RMTs ${ }^{18}$. A symptom-based diagnosis of FM without tender point examination can be helpful for primary care.

However, the lack of familiarity of GPs with FM has been recognized before ${ }^{19,20}$ and therefore the need for education in chronic pain, and FM in particular, for GPs has been stressed in several studies ${ }^{17,19-21}$.

In primary care, a nurse practitioner (NP) or a physiotherapist (PT) may play a role in the diagnostic process. A prerequisite for making a diagnosis of FM is having knowledge of signs and symptoms of FM and related conditions, knowledge of rheumatic conditions that may present with FM-like symptoms and knowledge of conditions that should be excluded (red flags). Fitzcharles and Boulos reported a high percentage of diagnoses that were overlooked covering the spectrum of rheumatological conditions as well as some non-rheumatological ones ${ }^{15}$.

However, by thinking about the right person for making the FM diagnosis, one should consider that the specific nurse competencies aimed at enhancing self-management are the added value and these combined with the diagnostic protocol are the conditions for success of this approach.

\section{Need to change the health care delivery system?}

Since 2001, we have been trying to improve the quality of FM care in the region Maastricht-Heuvelland by means of a stepwise development of a care programme for FM patients. The Chronic Care Model (CCM) provides a structure for the approach of changes in chronic care ${ }^{22,23}$. It is a guide that can be used in developing effective chronic care and covers 3 overlapping 'galaxies': 1) the community with resources and policies, 2) the health care system, and 3) the provider organizations (Figure 8.1). The health care system exists of 4 components: self-management support for patients, delivery system (re)design, decision support for health care professionals, and clinical information systems. Improved outcomes of care are a result of combined and effective interventions focused on community services, health care services, health care professionals, and patients. We recently started to use the CCM for the development of our care programme.

The interventions described in this thesis focused on early diagnosis and early intervention and were both aiming at 'delivery system (re)design'. Besides making the diagnosis, the SRN also adds nursing care, including self-management support, another component of the CCM. The multidisciplinary intervention also intended to optimise self-management, with a view of an informed and activated patient. 


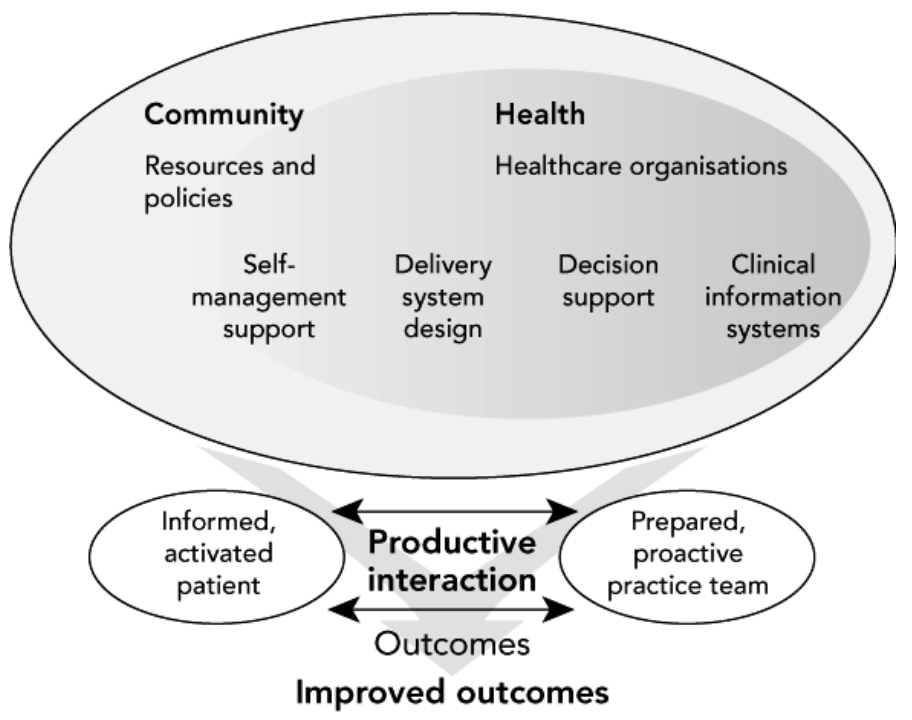

Figure 8.1 Chronic Care Model (Wagner, 1996)

It is important that all elements of the CCM are represented in our approach of managing FM and that these elements are interlocked because the connection between the elements enhances the results of the separate interventions.

The nurse-led diagnostic process and the multidisciplinary intervention are a valuable supplement in FM care, but provide the GP only short-lived support. Therefore, a focus specifically on primary care seems necessary. After diagnosis and eventually treatment in secondary care, the patient is referred back to primary care and sooner or later will visit the GP again ${ }^{24}$. The fact that GPs refer many patients to RMTs is probably not only due to diagnostic uncertainty, but rather to therapeutic uncertainty. Although most patients with FM are managed in primary care, many GPs experience they lack appropriate tools enabling them to help patients with non-specific muscular pain $^{25}$. They feel they have inadequate training, limited confidence in their ability to provide effective treatment, and a low level of satisfaction with their care of chronic pain patients as reported in studies on primary care treatment of chronic pain ${ }^{26,27}$. This often creates helplessness and frustration, which can weaken the patientcenteredness and the motivation to respond. It may also undermine the ability to perceive success ${ }^{25}$.

Furthermore, the ongoing state of flux in family practice, like the introduction of chain care for COPD and diabetes, needs a lot of attention of GPs. This may be one of the reasons that the GP is not always able to play his role as a 'constant attendant' or 'coach' and 'gate-keeper' which is essential in FM care ${ }^{28}$. Also the fact that FM is not considered to be 'trendy', and GPs often seem to have limited interest in this topic, can play a part. This may contribute to a delay in diagnosing FM and therefore to a 
delay in receiving an appropriate treatment. The often delayed referral of problematic FM patients to multidisciplinary interventions is associated with this ${ }^{29}$. Because of the non-systematic pathway by which patients arrive in a multidisciplinary intervention, it is likely a significant number of patients will not be reached, in particular those with limited access to information regarding the possibilities offered by the health care system. So, guidelines for referral to appropriate interventions are urgently needed in order to optimize the management of FM patients. Besides, strengthening the role of the GP in the management of FM is a pressing challenge.

Therefore, we have conducted a project aimed at improving quality of FM management in primary care through support for health care professionals ${ }^{30}$.

To improve knowledge about FM and its underlying mechanisms and treatment, an educational programme for GPs and PTs has been developed. In the educational programme, we also worked on collaboration and fine tuning between GPs and PTs, as well as between the health care providers and their patients. To support agreement about appropriate treatment strategies, a multidisciplinary guideline has been developed, and to support referral to appropriate interventions, a checklist for referral has been designed. In CCM language, this project was aimed at delivery system redesign, decision support and professional support which should lead to a prepared proactive team. After the educational programme, the practice teams of collaborating GPs and PTs tested the guideline and the checklist for referral in daily practice during six months.

The project showed that redesign of FM management was achieved by the collaborating GPs and PTs ${ }^{31}$. The practice teams showed a perceived improvement on all elements of FM care according to the CCM (Figure 8.1), although the interventions focused only on professional support and decision support. Also the integration of care elements improved. However, additional quality improvement activities are needed, because the willingness of GPs to participate in the project was limited and the appliance in daily practice was perceived to be difficult ${ }^{31}$. An adaptation of routine is needed which requires more time for professionals. The integration of these new elements with existing care and the dissemination in primary care are considerable challenges for the coming years. Efforts remain needed to improve basic knowledge about FM management, but also training in consultation skills with regard to (early) recognition of the problem by means of a biopsychosocial approach for exploration of symptoms.

Furthermore, to optimize FM management, primary care should be strengthened and interventions should preferably and as much as possible be situated in primary care, in spite of the currently declining health insurance coverage. As earlier mentioned, most patients with FM are treated in the primary care setting and a referral to secondary care seems to have no substantial added value to primary care. Besides, interventions in primary care are cheaper.

Therefore, we should focus on stepped care. Not all patients need the same type and intensity of intervention. Some may be helped importantly by reading a self-help book, watching an instructional video, or using a computer programme. Others could 
benefit from a brief self-management programme conducted in primary care, and still others may require a multidisciplinary treatment.

Stepped care provides a framework for the care of patients with chronic illnesses that uses limited resources to their greatest effect on a population basis ${ }^{32}$. Stepped care is based on three assumptions: different people require different levels of care; finding the right level of care often depends on monitoring outcomes; and moving from lower to higher levels of care based on patient outcomes often increases effectiveness and lowers costs overall ${ }^{32}$. Donavon and Marlett defined stepped care processes as "the least costly, least intensive and least restrictive treatment judged sufficient to meet the person's needs and goals should be attempted initially before more costly and restrictive treatments are attempted"33. Anyway, this does not mean patients should always start with the less intensive and cheapest treatment. At all times health care providers should aim at applying the most effective treatment considering the complexity of the complaints, and the needs and possibilities of the patient.

As aid for a proper indication and referral process, we introduced in the before mentioned project on the development of the regional multidisciplinary guideline and the referral checklist, five Complexity Complaints Profiles (CCPs), based on the existing 'quality profiles pain rehabilitation' of the 'Working Group Pain' (WPN-profiles) of the Dutch Association of Rehabilitation Medicine (VRA) ${ }^{34}$. The difference between the CCPs is based on the level of perceived limitations, the patient's understanding and insight in his or her own problems, attitude towards self-management, and the complexity of the problem ${ }^{31}$. The different levels of the CCPs are connected with different treatment strategies (Table 8.1).

Table 8.1 CCPs and the connected treatment strategies ${ }^{34}$.

\begin{tabular}{ll}
\hline CCP 1 & Information is needed \\
CCP 2 & Information and education are needed \\
CCP 3 & Intensive support for behavioral change is needed \\
CCP 4 & Intensive support for behavioral change together with system treatment is needed \\
CCP 5 & Complex individual treatment in combination with psychiatry is needed \\
\hline
\end{tabular}

$\mathrm{CCP}$, Complexity complaints profile

As less complex patients should be treated in primary care, a self-management primary care programme that empowers patients to take ownership of their pain and its management, coupled with regular encouragement and support may fill a gap in FM care in our region. Efforts to develop and implement such a programme are currently undertaken.

However, a declining health insurance coverage bears the danger that the less complex FM patients will wait to start with such a self-management programme, and may experience increasing problems in terms of physical and psychological functioning over time, ultimately resulting in sick-leave, impaired worker productivity, job loss and 'loss of participation'. Those patients may need a much more expensive therapeutic intervention in secondary care. 
One part of the CCM is not discussed, the clinical information system. In FM care, it also can have a supplementary value. The information system is not only useful as a reminder system that can help health care professionals with follow-up of practice guidelines or as an instrument to give insight in the functioning of patients, but also as a web-based information programme for patients. Computerized information can support the process of shared decision-making ${ }^{35}$. We therefore expect that a webbased self-management programme with e-coach may fill another gap in FM care. This programme should aim at offering tailored education, supporting patients in motivation for change and formulate targets, giving homework assignments and referral to available exercise programmes.

Although numerous interventions have been implemented in an effort to improve (pain) outcomes, little attention has been devoted to the role of the provider of these services. To overcome the patient's feeling of defragmentation of care and to support the GP in his role as a 'constant attendant' or 'coach', a care manager can be added to the FM care ${ }^{36}$. The care manager has to be someone who is equipped with the training and resources to guide FM patients in self-management, problem solving, goal setting, and other activities involved with the management of chronic pain. The care manager can be a NP or specialized nurse. Nurse consultants have shown to be of crucial value in redesign of health care services ${ }^{37}$. But also other health care professionals can fill this position, like a social psychiatric nurse. Support for patients and fostering patient engagement to enable patients to become adequately informed and activated are core concepts of the $\mathrm{CCM}^{36,38}$. Patients themselves have to become the principal caregivers. The patient as an active partner in the decision-making process improves agreement between patient's values and choices and might be of influence on patient's perceived health status ${ }^{39}$.

\section{Future research}

FM is continuing to be a challenging and confusing disorder for clinicians and researchers with its multifaceted nature, poorly understood etiology and pathophysiology. Besides, FM patients are an intricate population for research because of the often contradictory and inconsistent outcomes, which complicates the evaluation of the effects of interventions. Multiple outcome variables are used which reflect the complexity of FM. However, this variability in outcome measures across clinical trials hinders evaluations of the efficacy and effectiveness of treatments and slows progress in developing a solid foundation for evidence-based practice. Additionally, researchers mostly have to rely on patients' self-reported outcome data, which is prone to error and bias. Despite the burgeoning theoretical literature and the large number of instruments for measuring various health status domains, no unified approach has been developed and little agreement exists concerning the meaning of the results. Therefore, there is still a need for further consensus and the development of a core set of measures with response criteria, more objective measuring 
instruments, and the introduction of standardized quantitative measurements into routine clinical care ${ }^{40}$. Including a standard set of outcome measures in clinical trials makes meaningful comparisons between treatments possible, provides a basis for systematic reviews, permits pooling of data from different studies and facilitates the process of developing research protocols ${ }^{41}$. This aligns with the key objectives of the Outcome Measures in Rheumatology Clinical Trials (OMERACT) Fibromyalgia Syndrome working group ${ }^{42}$ as well as the Initiative on Methods, Measurement, and Pain Assessment in Clinical Trials (IMMPACT) ${ }^{43}$. Both initiatives initially focused on identifying core outcome domains, specific outcome measures and specific methods that can be used for interpreting the clinical importance of treatment outcomes in respectively $\mathrm{FM}$ and chronic pain clinical trials ${ }^{41,44-48}$. Fine tuning and cooperation between both initiatives would be desirable, so core outcome domains and outcome measures are comparable for disorders on the continuum of poly-symptomatic distress and can be applied to a wide variety of painful conditions. Further, linking the outcome domains and outcome measures to the International Classification of Functioning, Disability and Health $(\mathrm{ICF})^{49}$ will be helpful for a comprehensive measurement of the disease burden and the outcomes of treatment from a biopsychosocial perspective.

It is important that all key concepts of the ICF, namely body function and structure, activity, participation and contextual factors, are covered in outcome measures, so a broad perspective reflecting the whole health experience of patients is presented (Figure 8.2).

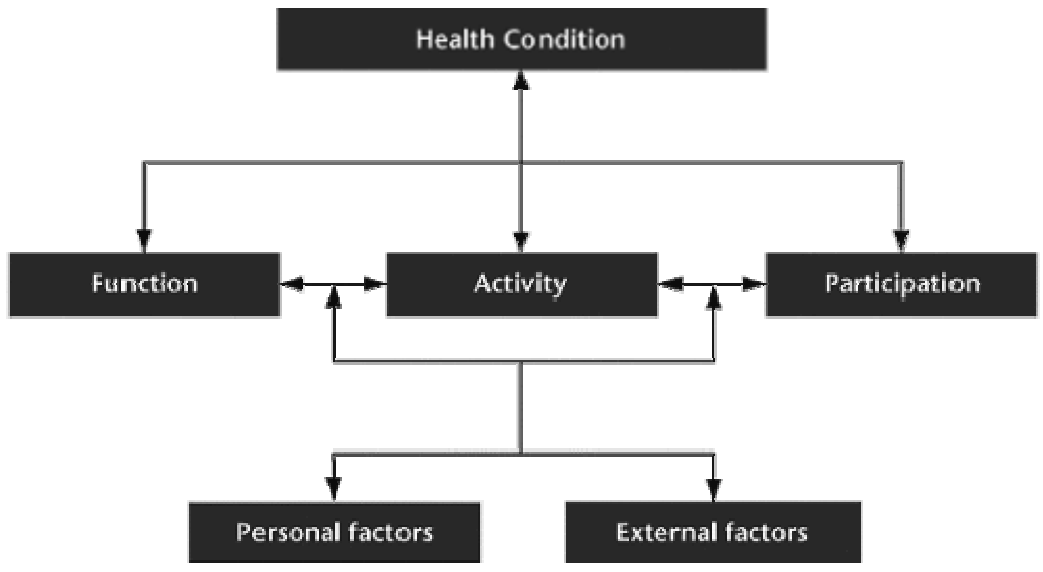

Figure 8.2 International Classification of Functioning, Disability and Health 
The ICF can serve as a conceptual model to define functioning and disability. It also can be applied as external reference to identify and compare the concepts contained in different outcome measures used in published clinical studies. Furthermore, the ICF can be used to evaluate the adequacy of the recommended measures. The gathered information can be useful to identify both the health areas most frequently addressed in clinical studies of patients with FM and the areas that have sparsely been measured despite the fact that they are relevant from the clinical point of view. When selecting or developing an instrument, careful consideration needs to be taken into account by researchers and clinicians regarding which aspects of health should be included ${ }^{50}$.

Besides the recommendation for outcome research, more research is required to identify the vast number of biological, psychological and social factors that seem to cause and perpetuate FM. Moreover, further research is needed to identify subgroups of FM patients. Differentiation of FM patients into several subgroups might be helpful for a more selective and hopefully more successful therapeutical approach. Subgroups can provide guidance for treatment decisions so patients can be offered a tailored treatment option. The evidence of the stepped care approach needs to be extended. In addition, the screening and classification criteria, including the checklist for referral to an appropriate intervention, require optimising and validating. A better insight in factors associated with improvement or worsening due to treatment is essential and can enhance treatment response.

The complexity of the treatment of FM requires multidisciplinary consensus that guides health care professionals. In the recent years, at least 3 sets of guidelines have been developed by different medical organizations in an attempt to standardize the treatment of FM (American Pain Society, European League Against Rheumatism, Association of the Scientific Medical Societies of Germany) ${ }^{51-53}$. Besides our regional multidisciplinary guideline, there is no recent national multidisciplinary FM guideline available in Dutch. Therefore, we recommend the development of a evidence-based Dutch national multidisciplinary FM guideline made by selected representatives and supported by the principal medical and health care professional associations that intervene in its treatment (e.g. GP, RMT, rehabilitation specialist, psychiatrist, psychologist, PT) and a representative of the Dutch patient association for FM (FES). In this guideline, based on the stepped care approach, consensus should be achieved about diagnostics, management and referral to appropriate interventions. The further practice details should be established in regional collaboration agreements in close consultation with the health care insurers.

Given the changing environment of $\mathrm{FM}$ in combination with the findings of the research projects presented in this thesis, it can be concluded that the diagnosis of FM can be made by another health care professional than a RMT on condition that he is well trained. An uniform and regional stepped care model seems the best way of managing FM, with a multidisciplinary intervention for complex patients. In such a stepped care model, empowerment of patients by self-management should take a prominent place. In this way, high quality care at acceptable costs can be best guaranteed for FM patients. 


\section{References}

1. Roland M, Torgerson DJ. What are pragmatic trials? BMJ 1998;316:285.

2. Tunis SR, Stryer DB, Clancy CM. Practical clinical trials: increasing the value of clinical research for decision making in clinical and health policy. JAMA 2003;290:1624-32.

3. Godwin M, Ruhland L, Casson I, MacDonald S, Delva D, Birtwhistle R, et al. Pragmatic controlled clinical trials in primary care: the struggle between external and internal validity. BMC Med Res Methodol 2003;3:28.

4. Zelen M. A new design for randomized clinical trials. N Engl J Med 1979;300:1242-5.

5. Briggs A, Clark T, Wolstenholme J, Clarke P. Missing... presumed at random: cost-analysis of incomplete data. Health Econ 2003;12:377-92.

6. Oostenbrink JB, Al MJ. The analysis of incomplete cost data due to dropout. Health Econ 2005;14: 763-76.

7. Oostenbrink JB, Al MJ, Rutten-van Molken MP. Methods to analyse cost data of patients who withdraw in a clinical trial setting. Pharmacoeconomics 2003;21:1103-12.

8. Bidari A, Ghavidel-Parsa B, Ghalehbaghi B. Reliability of ACR criteria over time to differentiate classic fibromyalgia from nonspecific widespread pain syndrome: a 6-month prospective cohort study. Mod Rheumatol 2009;19:663-9.

9. Katz RS, Wolfe F, Michaud K. Fibromyalgia diagnosis: a comparison of clinical, survey, and American College of Rheumatology criteria. Arthritis Rheum 2006;54:169-76.

10. Wolfe F. Stop using the American College of Rheumatology criteria in the clinic. J Rheumatol 2003;30:1671-2.

11. Wolfe F, Hauser W. Fibromyalgia diagnosis and diagnostic criteria. Ann Med 2011;43:495-502.

12. Hauser W, Hayo S, Biewer W, Gesmann M, Kuhn-Becker H, Petzke F, et al. Diagnosis of fibromyalgia syndrome-a comparison of Association of the Medical Scientific Societies in Germany, survey, and American College of Rheumatology criteria. Clin J Pain 2010;26:505-11.

13. Wolfe F, Clauw DJ, Fitzcharles MA, Goldenberg DL, Katz RS, Mease P, et al. The American College of Rheumatology preliminary diagnostic criteria for fibromyalgia and measurement of symptom severity. Arthritis Care Res 2010;62:600-10.

14. Wolfe F, Clauw DJ, Fitzcharles MA, Goldenberg DL, Hauser W, Katz RS, et al. Fibromyalgia Criteria and Severity Scales for Clinical and Epidemiological Studies: A Modification of the ACR Preliminary Diagnostic Criteria for Fibromyalgia. J Rheumatol 2011;38:1113-22.

15. Fitzcharles MA, Boulos P. Inaccuracy in the diagnosis of fibromyalgia syndrome: analysis of referrals. Rheumatology (Oxford) 2003;42:263-7.

16. Gamez-Nava JI, Gonzalez-Lopez L, Davis P, Suarez-Almazor ME. Referral and diagnosis of common rheumatic diseases by primary care physicians. Br J Rheumatol 1998;37(11):1215-9.

17. Sanchez Molla M, Tovar J, Medina MA. [Diagnostic consistency between primary care physicians and rheumatologists]. Aten Primaria 1994;13:446-8.

18. Shleyfer E, Jotkowitz A, Karmon A, Nevzorov R, Cohen H, Buskila D. Accuracy of the diagnosis of fibromyalgia by family physicians: is the pendulum shifting? J Rheumatol 2009;36:170-3.

19. Blotman F, Thomas E, Myon E, André E, Caubere JP, Taieb C. Awareness and knowledge of fibromyalgia among French rheumatologists and general practitioners. Clin Exp Rheum 2005;23: 697-700.

20. Buskila D, Neumann L, Sibirski D, Shvartzman P. Awareness of diagnostic and clinical features of fibromyalgia among family physicians. Fam Pract 1997;14:238-41.

21. Schulpen GJ, Vierhout WP, van der Heijde DM, Landewe RB, Winkens RA, van der Linden S. Joint consultation of general practitioner and rheumatologist: does it matter? Annals of the rheumatic diseases 2003;62:159-61.

22. Wagner EH, Austin BT, Von Korff M. Organizing care for patients with chronic illness. Milbank Quarterly 1996;74:511-44.

23. Wagner EH, Austin BT, Von Korff M. Improving outcomes in chronic illness. Manag Care Q 1996;4: $12-25$. 
24. Kroese ME, Schulpen GJ, Sonneveld HM, Vrijhoef HJ. Therapeutic approaches to fibromyalgia in the Netherlands: a comparison between 1998 and 2005. Journal of evaluation in clinical practice 2008;14:321-5.

25. Lundh C, Segesten K, Bjorkelund C. To be a helpless helpoholic--GPs' experiences of women patients with non-specific muscular pain. Scand J Prim Health Care 2004;22:244-7.

26. Ponte $C D$, Johnson-Tribino J. Attitudes and knowledge about pain: an assessment of West Virginia family physicians. Fam Med 2005;37:477-80.

27. Upshur CC, Luckmann RS, Savageau JA. Primary care provider concerns about management of chronic pain in community clinic populations. J Gen Intern Med 2006;21:652-5.

28. Schulte E, Hermann K, Berghofer A, Hagmeister H, Schuh-Hofer S, Schenk M, et al. Referral practices in patients suffering from non-malignant chronic pain. Eur J Pain 2010;14:308 e1-308 e10.

29. Chenot JF, Leonhardt C, Keller S, Scherer M, Donner-Banzhoff N, Pfingsten M, et al. The impact of specialist care for low back pain on health service utilization in primary care patients: a prospective cohort study. Eur J Pain 2008;12:275-83.

30. http://www.rosrobuust.nl/Robuust.aspx?id=1150\&idvp=38. In; 2011.

31. van Eijk-Hustings $Y$, Kroese $M$, Bessems-Beks $M$, Landewe R, Vrijhoef B. Supporting health care professionals to improve the quality of fibromyalgia management in primary care. submitted to Scandinavian Journal of Primary Health Care 2012.

32. Von Korff M, Tiemens B. Individualized stepped care of chronic illness. West J Med 2000;172:133-7.

33. Donovan DM, Marlatt GA. Recent developments in alcoholism: behavioral treatment. Recent Dev Alcohol 1993;11:397-411.

34. van Eijk-Hustings $Y$, Bessems $M$, Kroese $M$. Samenwerken bij chronische pijn in het bewegingsapparaat. Regionale multidisciplinaire richtlijn. Maastricht: Transmurale Zorg, MUMC+; 2011.

35. Hochlehnert A, Richter A, Bludau HB, Bieber C, Blumenstiel K, Mueller K, et al. A computer-based information-tool for chronic pain patients. Computerized information to support the process of shared decision-making. Patient Educ Couns 2006;61:92-8.

36. Bodenheimer T. Helping patients improve their health-related behaviors: what system changes do we need? Dis Manag 2005;8:319-30.

37. Ryan S, Stevenson K, Hassell AB. Assessment of clinical nurse specialists in rheumatology using an OSCE. Musculoskeletal Care 2007;5:119-29.

38. Bodenheimer T, Lorig K, Holman H, Grumbach K. Patient self-management of chronic disease in primary care. JAMA 2002;288:2469-75.

39. Joosten EA, DeFuentes-Merillas L, de Weert GH, Sensky T, van der Staak CP, de Jong CA. Systematic review of the effects of shared decision-making on patient satisfaction, treatment adherence and health status. Psychother Psychosom 2008;77:219-26.

40. Salaffi F, Sarzi-Puttini P, Ciapetti A, Atzeni F. Assessment instruments for patients with fibromyalgia: properties, applications and interpretation. Clin Exp Rheumatol 2009;27(5 Suppl 56):S92-105.

41. Dworkin RH, Turk DC, Wyrwich KW, Beaton D, Cleeland CS, Farrar JT, et al. Interpreting the clinical importance of treatment outcomes in chronic pain clinical trials: IMMPACT recommendations. J Pain 2008;9:105-21.

42. Tugwell P, Boers M, Brooks P, Simon L, Strand V, Idzerda L. OMERACT: an international initiative to improve outcome measurement in rheumatology. Trials 2007;8:38.

43. Turk DC, Dworkin RH, Allen RR, Bellamy N, Brandenburg N, Carr DB, et al. Core outcome domains for chronic pain clinical trials: IMMPACT recommendations. Pain 2003;106:337-45.

44. Choy EH, Arnold LM, Clauw DJ, Crofford L, Glass JM, Simon LS, et al. Content and criterion validity of the preliminary core dataset for clinical trials in fibromyalgia syndrome. J Rheumatol 2009;36:2330-4.

45. Dworkin RH, Turk DC, Farrar JT, Haythornthwaite JA, Jensen MP, Katz NP, et al. Core outcome measures for chronic pain clinical trials: IMMPACT recommendations. Pain 2005;113:9-19.

46. Mease P, Arnold LM, Choy EH, Clauw DJ, Crofford L, Glass JM, et al. Fibromyalgia syndrome module at OMERACT 9: domain construct. J Rheumatol 2009;36:2318-29.

47. Mease PJ, Clauw DJ, Christensen R, Crofford LJ, Gendreau RM, Martin SA, et al. Toward development of a fibromyalgia responder index and disease activity score: OMERACT module update. J Rheumatol 2011;38:1487-95. 
48. Turk DC, Dworkin RH, Burke LB, Gershon R, Rothman M, Scott J, et al. Developing patient-reported outcome measures for pain clinical trials: IMMPACT recommendations. Pain 2006;125:208-15.

49. World Health Organization. ICF: International Classification of Functioning, Disability and Health. Geneva: World Health Organization; 2001.

50. Prodinger B, Cieza A, Williams DA, Mease P, Boonen A, Kerschan-Schindl K, et al. Measuring health in patients with fibromyalgia: content comparison of questionnaires based on the International Classification of Functioning, Disability and Health. Arthritis Rheum 2008;59:650-8.

51. Carville SF, Arendt-Nielsen S, Bliddal H, Blotman F, Branco JC, Buskila D, et al. EULAR evidence-based recommendations for the management of fibromyalgia syndrome. Ann Rheum Dis 2008;67:536-41.

52. Goldenberg DL, Burckhardt C, Crofford L. Management of fibromyalgia syndrome. JAMA 2004;292:2388-95.

53. Klement A, Hauser W, Bruckle W, Eidmann U, Felde E, Herrmann M, et al. [Principles of treatment, coordination of medical care and patient education in fibromyalgia syndrome and chronic widespread pain]. Schmerz 2008;22:283-94. 

Summary 


\section{Summary}

This thesis describes the evaluation of two health care innovations in the care for patients with fibromyalgia (FM). The two health care innovations concern a nurse-led diagnostic process and a multidisciplinary intervention with aftercare meetings. The main objective was to investigate the feasibility and the effectiveness of these innovations. In both innovations 'timing' is important: an early diagnosis and an early treatment.

The general introduction of this thesis, chapter 1, discusses the background to and relevance of the conducted studies. FM is a common benign musculoskeletal disorder characterized by widespread pain, stiffness, fatigue, depressed mood and disturbed sleep. The prevalence in the general population has been estimated at $0.5 \%$ to $5 \%$ and most patients with FM are women. The pathogenesis of FM is still unclear, but the disorder may result in disability and a significantly reduced perceived quality of life. The economic burden of FM is also considerable because of reduced productivity or ability to work and a high use of health care resources.

An accurate and timely diagnosis seems a critical first step to more effective care and better outcomes for patients with FM. Little is known about the impact and prognosis after a diagnosis of FM. It is possible that making a definite diagnosis will reduce the number of referrals, the use of multiple health care providers, and costs. On the other hand, acquiring the FM label might lead to increased illness behaviour, dependence on health care providers, and increased health service costs.

Currently, there are no curative treatments available for patients with FM. Both pharmacological and non-pharmacological approaches are used to relieve complaints, to improve patients' quality of life and to coach patients to deal with the disorder. Because of its multifaceted nature, FM is assumed to be managed best by multimodal and/or multidisciplinary approaches. Although a number of studies has investigated the effect of multimodal or multidisciplinary therapy for FM, the systematic reviews performed in this area concluded that the evidence is scarce because of few studies, low quality of these studies, high drop out rates and varying elements of therapy. More and more, it is believed that early intervention for patients at risk of developing persistent pain can prevent pain behaviour and adaptation to dysfunctioning.

In the beginning of 2001, the FM care (diagnostics and treatment) in the region Maastricht-Heuvelland showed several bottlenecks and shortcomings like an enormous waiting list and lack of satisfying treatment options.

In order to relief these problems, a stepwise development of a care programme for patients with FM has been proposed. The programme focused on early diagnosis and early intervention. First, the focus was on improvement of accessibility of the rheumatology outpatient clinic. The high number of patients with FM, the shortage of rheumatologists (RMTs), and the substantial time demands per patient have prompted us to consider whether the RMT should have the primary role in 
establishing a diagnosis of FM. Possibly, other trained health care workers, like the specialized rheumatology nurse (SRN), could contribute to the diagnostic process.

Over the last decade, the role of specialized nurses has evolved. Apart from their role in providing clinical care and education, specialized nurses may also assist the physician in the care for patients with chronic but stable diseases. International studies on the role and added value of SRNs show that they can have a feasible and efficacious role in additional care or care substitution. Appointing the SRN in the diagnostic process has many potential advantages, such as shortening the waiting list, making a timely diagnosis and providing better care by the specific competencies of a nurse. Therefore a nurse-led diagnostic process has been developed in which the SRN makes the diagnosis with supervision of the RMT.

Additionally to the improvement of accessibility of the rheumatology outpatient clinic to secure an early FM diagnosis, an early treatment is important. Notwithstanding the weaknesses in evidence for this treatment option like the disappearance of positive outcomes in the long-term, multidisciplinary interventions are increasingly applied and recommended in the care for patients with FM. To meet the need for an early and intensive intervention, and to preserve the benefits of the treatment on the long term, a multidisciplinary programme with aftercare meetings has been developed. The aftercare meetings were aimed at internalisation of the learned skills and maintenance of self-management and daily functioning.

\section{Diagnostic process of fibromyalgia}

To evaluate to what extent SRNs can substitute for RMTs in diagnosing FM, we conducted a pragmatic randomized controlled trial (RCT). Patients who were referred by the general practitioner (GP) to the rheumatology outpatient clinic of the Maastricht University Hospital with symptoms of FM $(n=193)$ were randomized to a study group (SRN) ( $n=97$ ) or a usual care (RMT) group ( $n=96)$.

The SRN patients were seen within 3 weeks by an experienced SRN who was trained in the diagnosis of FM. The SRN took a structured history using a checklist in detecting symptoms of FM as well as conditions that should be excluded and initiated routine lab tests. During a 5-minute supervision session, the RMT was informed by the SRN about medical history, performed a brief physical examination and confirmed or rejected the diagnosis of the SRN. The RMT patients were invited for a RMT visit after a regular waiting period of about 3 months. This visit included extensive history taking, physical examination, and additional tests if considered necessary. In both groups FM was diagnosed according to the American College of Rheumatology (ACR) criteria.

Chapter 2 presents the results of the process evaluation in which we assess whether the substitution of SRNs for RMTs in the diagnostic process of FM is feasible with regard to safety, patient satisfaction and diagnostic costs compared with a regular consultation. Outcome measures were initial agreement on diagnosis between SRN 
and RMT in the SRN group, final diagnosis after 12-24 months of follow-up, patient satisfaction, and diagnostic costs.

The mean waiting time after randomization was 2.8 weeks in the SRN group and 12.1 weeks in the RMT group. Eight patients cancelled their appointment because of the waiting time (all RMT group). In the SRN group, the initial agreement between the SRN and the RMT with regard to the diagnosis was 0.91. FM was significantly more diagnosed in the SRN group (SRN group 92\% vs. RMT group $72 \%$ ). Five patients (1 in SRN group and 4 in RMT group) were diagnosed with an inflammatory rheumatological condition, and 12 patients (5 in SRN group and 7 in RMT group) were diagnosed with a non-rheumatological condition. After 12-24 months of follow-up, 6 additional diagnoses in 6 patients were made: FM in 3 patients ( 1 in SRN group, 2 in RMT group), low back pain, axial osteoarthritis, pseudoradicular syndrome in $3 \mathrm{FM}$ patients (all SRN group). Patients in the SRN group were significantly more satisfied than patients in the RMT group (e.g., they found that the SRN gave more usable advices and paid more attention to the (psycho)social aspects of the disorder than the RMT. Mean diagnostic costs were significantly lower in the SRN than in the RMT group (€62). We concluded that substituting SRNs for RMTs in the diagnostic process of FM is a trustworthy and successful approach. The nurse-led diagnostic process saved waiting time for the patients, improved patient satisfaction, and was cheaper compared with a regular consultation, while there was no indication at follow-up that medically important diagnoses had been missed by the SRN.

Chapter 3 describes the cost-consequence analysis of substituting SRNs for RMTs in the diagnostic process of FM, using both a health care and societal perspective and a 9-month time horizon. Alongside the RCT, we measured costs and consequences of the nurse-led diagnostic consult versus the rheumatologist-led diagnostic consult. Costs included health care consumption, patient and family costs, and productivity costs. Consequences included patient satisfaction and health outcomes (including health related quality of life (HRQoL) and functional status). Total health care consumption costs and patient and family costs were significantly lower in the SRN group (€346). Also, costs from a societal perspective (including absenteeism) were lower in the SRN group compared with the RMT group (€1440).Patients in the SRN group were significantly more satisfied. Improvements in health status were similar in both groups after 9 months of follow-up. We concluded that, from both a health care and societal perspective, the nurse-led diagnostic process is a recommendable approach. We could not prove that a timely diagnosis had a positive effect on health outcomes and social participation in terms of hours spent. Since the time horizon of our analysis was only 9 months, a longer follow-up may be necessary to confirm these findings.

In the analysis of the RCT it was not distinguished whether a diagnosis of FM or another diagnosis was made. In order to further investigate the impact of a diagnosis of FM in comparison to another diagnosis, we performed a post-hoc analysis of these trial data after 9 months of follow-up, comparing the patients in whom a diagnosis of FM was made with those in whom another diagnosis was made (non-FM) with respect 
to health outcomes and health care costs. Further, we investigated the impact of an early diagnosis by the SRN in comparison with a regular (delayed) diagnosis by the RMT. Chapter 4 presents the analyses of this study. Of all patients ( $n=193), 159$ (82.4\%) met the ACR criteria for FM, in 33 patients (17.1\%) another diagnosis (non-FM) was made and of 1 patient the diagnosis remained unknown. FM patients had a significantly longer duration of complaints (6.3 yrs vs. $4.2 \mathrm{yrs}$ ) and indicated significantly more additional health problems than non-FM patients. Before the diagnosis was made, FM patients also scored consistently worse than non-FM patients. The timing of diagnosis (early vs. delayed) did not influence these results. During 9 months of follow-up, FM patients showed a stable course in almost all health outcomes, while non-FM patients improved in almost all these outcomes. FM patients created $€ 183$ more health care costs than non-FM patients, but costs related to absenteeism from work were $€ 701$ higher in the non-FM patients. An early diagnosis, however, importantly saved costs in patients with a non-FM diagnosis both from a health care and a societal perspective ( $€ 5725$ saving of total societal costs). The main conclusion of the post-hoc analysis of this RCT is that patients in whom a FM diagnosis was confirmed reported far worse scores for almost all measured health outcomes in comparison with patients diagnosed with any other condition. An important finding is that these differences were already existent at baseline, before the diagnosis was made. Another important finding is that in the period of 9 months of follow-up patients with a confirmed diagnosis of FM fared a stable -but far worse- course than patients in whom another diagnosis was made. In fact, health outcomes tended to improve in this latter group. A timing of diagnosis did not have any impact on health outcomes, neither at baseline nor after follow up. An early diagnosis, however, saved costs, especially in patients with a non-FM diagnosis.

\section{Management of fibromyalgia}

Chapter 5 reports on 2 surveys conducted in 1998 and 2005 among health care professionals involved in FM to get insight in regularly applied interventions for FM. In these surveys information was gathered from 5 disciplines on their usual management methods of FM in order to assess whether treatment regimens have changed in the Netherlands during this period of 6 years. In addition, insight was gained into the therapeutic motives of the professionals. A questionnaire was sent to a sample of 150 persons per discipline: GPs, RMTs, rehabilitation specialists, physiotherapists, and psychologists. The overall response rate was $40.4 \%$. The referral behaviour changed (significantly), especially between GPs and RMTs. Rehabilitation specialists showed a significantly increased choice for aerobic exercise and RMTs for multidisciplinary therapy. RMTs and rehabilitation specialists showed decreased medication prescribing. Preferences of treatment for FM differ per discipline. The choice is principally made on the basis of subjective, profession group-bound factors, like own experiences and refresher courses. Particularly for GPs, dynamic patient factors are an important motive in the management of FM. On the basis of this study, we concluded 
that the management of FM in the Netherlands between 1998 and 2005 has remained unchanged. The societal problem is not reduced, but rather made more serious by the moving of patients back and forth between doctors. Despite the published systematic reviews in this 6-years period, only a few items in the therapeutic approach have been changed, some in conformity with the literature, others not. We found a significant increase in the application of some of the international recommended treatments, however the absolute application percentages are still very low. The increase is a trend which hopefully will persist. The differences in practice between the several disciplines seem explicable on the basis of the factors that for the professionals have a prominent role in the choice of a therapy for FM. This study underlines the need for further research into methods and processes of the management of FM, and their clinical effectiveness. An effective way of dissemination, especially of guidelines, is essential.

As highlighted in chapter 1 , to meet the need for an early and intensive intervention, and to preserve the benefits of the treatment on the long term, a 12-week multidisciplinary part-time daycare programme ( 3 half days per week) with 5 aftercare meetings has been developed. The multidisciplinary intervention was aimed at optimizing daily functioning through coping with pain and disability. A multidisciplinary team offered a programme of sociotherapy, physiotherapy, psychotherapy and creative arts therapy, using group interaction as an additional tool but also paying attention to the patient's specific needs. Sociotherapy (twice a week) was aimed at education and increasing social behaviour strategies and social support. Physiotherapy (twice a week) was based on time contingent graded activity and comprised fitness training, strength training and relaxation. Psychotherapy (once a week) consisted of information about pain mechanisms and used methods of core qualities, rational emotive therapy and transactional analysis. Creative arts therapy (once a week) focussed on the opportunity to express feelings by visual arts instead of verbal expressions. The purpose of the aftercare meetings, scheduled over a period of 9 months, was to repeat the key messages about coping in order to preserve the behavioural change achieved in the 12-week programme.

Before the effectiveness and cost-effectiveness of our multidisciplinary programme could be examined in a RCT, a study was performed to get an impression about the feasibility of the multidisciplinary intervention in terms of attendance and drop-out rates, as well as about the level of efficacy and sustainability that could be expected. This study is described in chapter 6 . One hundred and five patients diagnosed with FM started with the multidisciplinary programme and were assessed for functional status and HRQoL until 9 months after completion. The drop-out rate was $4.8 \%$. The attendance rate of 100 patients who completed the 12-week programme and 5 aftercare meetings was high (97.4\%), just like patient and therapist satisfaction. After the 12-week programme statistically significant improvement was seen for both functional status and HRQoL. This improvement maintained after 9 months of followup. On average, only moderate improvements were observed. We concluded that our 12-week multidisciplinary intervention with 5 aftercare meetings for FM patients is 
feasible and it is indicated that it can lead to sustained improvement in functional status and HRQoL.

Chapter 7 illustrates the challenges of demonstrating effectiveness in a RCT of our multidisciplinary treatment with aftercare meetings on quality of life, participation and health care utilization in recently diagnosed patients with FM. In the RCT, we compared, in a Zelen-like design, the multidisciplinary programme (MD) with aerobic exercise (AE) and usual care (UC). Recently diagnosed patients from the outpatient rheumatology clinics of three medical centres in the South of the Netherlands were consecutively recruited and pre-randomised to MD $(n=108), \operatorname{AE}(n=47)$ or UC $(n=48)$. $A E$ was given twice a week in a 12-week course. UC varied but incorporated at least education and life style advices. Primary outcomes were HRQoL, participation and health care utilization. Secondary outcome was functional status. Total follow-up in the study was 21-24 months. As willingness to participate in AE was limited, this group has been analyzed but the interpretation of the data is considered arguable. Within the MD group, a statistically significant improved HRQoL, and a statistically significant reduction in number of hours sick leave, number of contacts with GPs, and number of contacts with medical specialists were found. Moreover, statistically significant improvements were found for functional status, which increased after the intervention. However, no statistically significant between group differences were found at the endpoint of the study. The multidisciplinary intervention seemed to yield positive effects, but firm conclusions with regard to effectiveness can not be formulated due to small between group differences and limitations of the study.

In the last chapter (chapter 8, the general discussion), the main findings are summarised, discussed and combined into an overall conclusion. Based on the findings concerning the nurse-led diagnostic process it became clear that it does not matter when and by whom the diagnosis FM is made. The early nurse-led diagnostic process is feasible and leads to lower costs than the usual rheumatologist-led consultation, both from a health care and a societal perspective, whilst neither approach was better in terms of functional status and HRQoL. In contrast with our hypothesis, an early diagnosis made by a SRN has practically no impact on health outcomes. In fact, it looks as if a diagnosis of FM implies a rather poor prognosis (at least poorer than another rheumatological diagnosis). Our studies do not allow a conclusion about whether this is a reflection of the disorder itself, whether it is caused by having a label of FM, or whether patients with FM have a different perception of the severity of their disorder that is rather benign in the eyes of the RMT and GP because it is non-inflammatory and non-destructive.

With respect to the multidisciplinary intervention we concluded that it was feasible. Although significant sustaining effects of the multidisciplinary intervention were found on HRQoL, participation, health care utilization and self-reported health outcomes, the between group differences were small. Therefore we had to conclude that the effects of our multidisciplinary intervention seem to be limited although sustained improvements could be found, sometimes at a similar level with AE and/or UC, which are importantly cheaper. However, the patients who consented in participation in the 
MD group were motivated and completed the entire programme, both in the pilotstudy and in the RCT, indicating that the treatment has met the needs and expectations of the participating patients. In contrast, there was a high drop out rate in the $A E$ group, suggesting that this intervention meets only the needs of a selected group of FM patients.

Findings from our research support the implementation of the nurse-led diagnostic process and to some extent the multidisciplinary intervention in regular care.

We presented also implications for practice and research. Concerning the diagnostic process, attention needs to be given to the diagnostic criteria of FM. The ACR 1990 criteria were developed for research, but quickly used in clinical practice although they were never validated for clinical diagnosis. The recent proposal of new clinical diagnostic criteria (ACR 2010 criteria) is a good initiative. They do not rely on tender points, take besides pain other FM-related symptoms into account and are intended to assess the severity of those symptoms. Research to determine the clinical usefulness of these proposed criteria is ongoing.

The diagnosis of FM can safely be made by another health care professional than a RMT on condition that he is well trained. One can argue that the SRN is not the only discipline besides a RMT who can make a diagnosis of FM. As patients with FM-like symptoms are first seen in primary care, it seems a logical option that also GPs can make the FM diagnosis. The recognition of FM by GPs is important since the early detection will prevent costly and unnecessary tests and referrals, and delay in making the diagnosis and starting an appropriate treatment. However, by thinking about the right person for making the FM diagnosis, one should consider that the specific nurse competencies aimed at enhancing self-management are the added value and these combined with the diagnostic protocol are the conditions for success of this approach. The Chronic Care Model (CCM) provides a structure for the approach of changes in chronic care. We recently started to use this model for the development of our care programme. It is important that all elements of the CCM are represented in the approach of managing FM and that these elements are interlocked because the connection between the elements enhances the results of the separate interventions. To optimize FM management, primary care should be strengthened and interventions should preferably and as much as possible be situated in primary care.

Research is needed for the development of a core set of measuring instruments so that for example meaningful comparisons between treatments are possible. The Outcome Measures in Rheumatology Clinical Trials (OMERACT) Fibromyalgia Syndrome working group as well as the Initiative on Methods, Measurement, and Pain Assessment in Clinical Trials (IMMPACT) are working on such a core set. Fine tuning and cooperation between both initiatives would be desirable as well as linking the outcome domains and outcome measures to the International Classification of Functioning, Disability and Health (ICF). Besides the recommendation for outcome research, more research is required to identify the vast number of biological, psychological and social factors that seem to cause and perpetuate FM. Moreover, further research is needed to identify subgroups of FM patients. Also, the development of a evidence-based Dutch national multidisciplinary FM guideline is recommended. 
Samenvatting 


\section{Samenvatting}

Dit proefschrift beschrijft de evaluatie van twee zorginnovaties voor patiënten met fibromyalgie (FM). De twee innovaties betreffen: een diagnostisch proces uitgevoerd door een verpleegkundig reumaconsulent onder supervisie van een reumatoloog en een multidisciplinaire interventie met nazorgbijeenkomsten. Het hoofddoel van de studies was om de haalbaarheid en de effectiviteit van deze innovaties te onderzoeken. 'Timing' is heel belangrijk in beide innovaties: een zo snel mogelijke diagnose en een zo snel mogelijke start van de behandeling.

De algemene inleiding van dit proefschrift, hoofdstuk 1, bespreekt de achtergrond en de relevantie van de uitgevoerde studies. FM is een veel voorkomende aandoening van het bewegingsapparaat, gekenmerkt door wijdverspreide pijn, stijfheid, moeheid, depressieve klachten en slaapstoornissen. De aandoening komt bij $0.5 \%$ tot $5 \%$ van de bevolking voor en de meeste patiënten met FM zijn vrouwen. Het ontstaansmechanisme van FM is nog steeds niet bekend. De aandoening kan echter resulteren in beperkingen in het dagelijks leven en in een belangrijke verminderde ervaren kwaliteit van leven. Ook de economische gevolgen van FM zijn aanzienlijk als gevolg van een verminderde productiviteit of verminderde arbeidsmogelijkheden en hoge gezondheidszorgkosten.

Een accurate en snelle diagnose lijkt een kritische eerste stap naar een effectievere zorg en betere behandeluitkomsten voor patiënten met FM. Weinig is bekend over de impact en de prognose van het diagnosticeren van FM. Het is mogelijk dat door het stellen van de diagnose FM het aantal verwijzingen, het aantal contacten met zorgprofessionals en de gezondheidszorgkosten verminderen. Aan de andere kant kan het krijgen van het FM label leiden tot een toename in ziektegedrag, afhankelijkheid van zorgprofessionals en een toename van de gezondheidszorgkosten.

Momenteel zijn er geen curatieve behandelingen beschikbaar voor patiënten met FM. Zowel farmacologische als niet-farmacologische behandelingen worden ingezet om de klachten te verlichten, kwaliteit van leven te verbeteren en patiënten te coachen in het leren omgaan met hun ziekte. Vanwege het veelzijdige karakter van FM wordt verondersteld dat deze aandoening het best behandeld wordt met multimodale en/of multidisciplinaire zorgprogramma's. Hoewel een aantal studies het effect van multimodale of multidisciplinaire programma's voor FM heeft onderzocht, concludeerden de systematische reviews dat de evidentie schaars is vanwege het lage aantal studies, de lage kwaliteit van de studies, de hoge uitval en de variërende elementen van de programma's. Er wordt meer en meer geloofd dat door snel een behandeling te starten pijngedrag en disfunctioneren voorkomen kunnen worden bij patiënten met een risico op het ontwikkelen van chronische pijn.

Begin 2001 liet de zorg voor patiënten met FM (diagnose en behandeling) in de regio Maastricht-Heuvelland meerdere knelpunten en tekortkomingen zien zoals een enorme wachtlijst en een gebrek aan toereikende behandelmogelijkheden. Om deze problemen op te lossen werd de ontwikkeling van een zorgprogramma voor patiënten 
met FM voorgesteld. Het zorgprogramma spitst zich toe op het snel stellen van de diagnose en het snel starten met de behandeling. Het eerste doel was het verminderen van de wachttijd voor een poliklinisch consult reumatologie. Het hoge aantal patiënten met FM, het tekort aan reumatologen en de aanzienlijke tijdsinvestering per patiënt hebben ons ertoe aangezet te overwegen of een reumatoloog de primaire rol moet hebben in stellen van de diagnose FM. Mogelijk kunnen andere getrainde zorgprofessionals, zoals de verpleegkundig reumaconsulent, een bijdrage leveren aan het diagnostisch proces.

De laatste 10 jaar heeft zich de rol van gespecialiseerde verpleegkundigen geleidelijk ontwikkeld. Los van hun rol in de klinische zorg en patiënteneducatie kunnen gespecialiseerde verpleegkundigen de arts helpen in de zorg voor patiënten met een chronische, maar stabiele ziekte. Internationale studies naar de rol en toegevoegde waarde van verpleegkundig reumaconsulenten tonen aan dat zij een haalbare en effectieve rol in aanvullende zorg of zorgsubstitutie kunnen hebben. Het aanstellen van een verpleegkundig reumaconsulent in het diagnostisch proces heeft vele potentiële voordelen zoals het verkorten van de wachtlijst, het snel stellen van een diagnose en het leveren van betere zorg door middel van de specifieke competenties van verpleegkundigen. Daarom hebben we een diagnostisch proces ontwikkeld dat geleid wordt door een verpleegkundige die een diagnose stelt onder supervisie van een reumatoloog.

Naast het verminderen van de wachttijd voor een poliklinisch consult reumatologie zodat een snelle diagnose gewaarborgd wordt, is het snel starten met behandeling belangrijk. Ondanks de zwakke bewijslast voor multidisciplinaire interventies, zoals het verdwijnen van positieve resultaten op lange termijn, wordt deze behandeling meer en meer aanbevolen en toegepast in de zorg voor patiënten met FM. Om te voldoen aan de noodzaak van een snelle en intensieve behandeling werd een multidisciplinair zorgprogramma met nazorgbijeenkomsten ontwikkeld. Deze nazorgbijeenkomsten werden georganiseerd om de positieve effecten van de multidisciplinaire behandeling op lange termijn vast te houden. Zij zijn gericht op het internaliseren van de geleerde vaardigheden en het behoud van zelfmanagement en dagelijks functioneren.

\section{Diagnostisch proces van fibromyalgie}

Om te evalueren in welke mate een reumatoloog door een verpleegkundig reumaconsulent vervangen kan worden bij het stellen van de diagnose FM voerden we een pragmatisch gerandomiseerd gecontroleerd onderzoek (RCT) uit. Patiënten met symptomen van FM $(n=193)$, verwezen door de huisarts naar de polikliniek reumatologie van het MUMC+, werden gerandomiseerd naar een studiegroep en een controlegroep. De patiënten in de studiegroep werden gezien door de verpleegkundig reumaconsulent (VRC-groep; $n=97$ ). De patiënten in de controlegroep werden gezien door de reumatoloog (RMT-groep; $n=96$ ) 
De patiënten uit de VRC-groep werden binnen 3 weken gezien door een ervaren verpleegkundig reumaconsulent die geschoold was in het stellen van de diagnose FM. De verpleegkundig reumaconsulent nam een gestructureerde anamnese af, gebruikmakend van een checklist met FM symptomen en uit te sluiten aandoeningen. Ook werden door de verpleegkundig reumaconsulent routine bloedonderzoek aangevraagd. Gedurende een 5-minuten durende supervisie werd de reumatoloog door de verpleegkundig reumaconsulent geïnformeerd over de ziektegeschiedenis. De reumatoloog voerde een kort klinisch onderzoek uit en bevestigde al dan niet de diagnose gesteld door de verpleegkundig reumaconsulent. De patiënten uit de RMTgroep werden uitgenodigd op de polikliniek reumatologie na een reguliere wachttijd van ongeveer 3 maanden. Tijdens dit poliklinisch consult werd een uitgebreide anamnese afgenomen, klinisch onderzoek uitgevoerd en bijkomende onderzoeken aangevraagd indien de reumatoloog dit nodig vond. In beide groepen werd FM gediagnosticeerd volgens de criteria van het American College of Rheumatology (ACR).

Hoofdstuk 2 presenteert de resultaten van de procesevaluatie waarbij we beoordelen of de vervanging van reumatologen door verpleegkundig reumaconsulenten haalbaar is in het kader van veiligheid, patiënttevredenheid en kosten van het diagnostisch proces in vergelijking met een regulier polikliniekbezoek. De uitkomstmaten waren overeenstemming over de diagnose tussen verpleegkundig reumaconsulenten en reumatologen in de VRC-groep, de definitieve diagnose na 12-24 maanden follow-up, patiënttevredenheid en kosten van het diagnostisch proces.

De gemiddelde wachttijd na randomisatie was 2.8 weken in de VRC-groep en 12.1 weken in de RMT-groep. Acht patiënten uit de RMT-groep hebben hun afspraak afgezegd vanwege de wachttijd. In de VRC-groep bedroeg de overeenstemming over de diagnose tussen verpleegkundig reumaconsulenten en reumatologen 0.91. De diagnose FM werd significant vaker gesteld in de VRC-groep (VRC-groep 92\% vs. RMTgroep $72 \%$ ). Bij 5 patiënten (1 in de VRC-groep en 4 in de RMT-groep) werd een reumatologische diagnose gesteld en bij 12 patiënten ( 5 in de VRC-groep en 7 in de RMT-groep) werd een niet-reumatologische diagnose gesteld. Na 12-24 maanden follow-up werden 6 bijkomende diagnoses bij 6 patiënten gesteld: FM bij 3 patiënten ( 1 in de VRC-groep en 2 in de RMT-groep), en lage rug pijn, axiale osteoartritis en een pseudoradiculair syndroom bij 3 FM patiënten (allen in de VRC-groep). In beide groepen werd geen enkele van de oorspronkelijk gestelde diagnoses herzien. Patiënten in de VRC-groep waren beduidend meer tevreden dan patiënten in de RMTgroep (ze vonden bijvoorbeeld dat ze van de verpleegkundig reumaconsulent nuttigere adviezen kregen en dat de verpleegkundig reumaconsulent meer aandacht besteedde aan de (psycho)sociale aspecten van de aandoening). De gemiddelde kosten van het diagnostisch proces waren significant lager in de VRC-groep dan in de RMT-groep (€62).

We concludeerden dat het inschakelen van verpleegkundig reumaconsulenten als vervanging van reumatologen in het diagnostisch proces van FM een betrouwbare en succesvolle benadering was. Het diagnostisch proces uitgevoerd door de verpleegkundig reumaconsulent zorgde voor een kortere wachttijd, verhoogde de 
patiënttevredenheid en was goedkoper dan een regulier consult terwijl er bij de follow-up geen indicatie was dat door de verpleegkundig reumaconsulent medisch belangrijke diagnoses gemist werden.

Hoofdstuk 3 beschrijft de uitvoering van een cost-consequence analyse met betrekking tot de vervanging van reumatologen door verpleegkundig reumaconsulenten in het diagnostisch proces van FM, zowel vanuit gezondheidszorg als maatschappelijk perspectief. De tijdshorizon bedroeg 9 maanden. Naast de RCT hebben we de kosten en consequenties gemeten van het diagnostisch proces uitgevoerd door de verpleegkundig reumaconsulent versus het diagnostisch proces uitgevoerd door de reumatoloog. Het betrof kosten van gezondheidszorgconsumptie, patiënt- en familiekosten en productiviteitskosten. De consequenties betroffen patiënttevredenheid en gezondheidsuitkomsten (inclusief gezondheidsgerelateerde kwaliteit van leven en functionele status). Kosten voor gezondheidszorgconsumptie en patiënt- en familiekosten waren significant lager in de VRC-groep (€346). Ook de maatschappelijke kosten (o.a. ziekteverzuim) waren lager in de VRC- groep dan in de RMT-groep (€1440). Patiënten in de VRC-groep waren aanzienlijk meer tevreden. De verbetering van de gezondheidstoestand was in beide groepen hetzelfde na 9 maanden follow-up. We concludeerden dat, zowel vanuit gezondheidszorg als maatschappelijk perspectief, het diagnostisch proces geleid door een verpleegkundige een aan te bevelen benadering is. We konden niet aantonen dat een snelle diagnose een positief effect had op de gezondheidsuitkomsten en maatschappelijke participatie. Omdat de tijdspanne van onze analyse slechts 9 maanden bedroeg, kan een langere follow-up nodig zijn om deze effecten te bevestigen.

In de analyse van de RCT werd geen verschil gemaakt tussen patiënten waarbij de diagnose FM werd gesteld of patiënten waarbij een andere diagnose werd gesteld. Om de impact van een FM diagnose in vergelijking met een andere diagnose te onderzoeken werd na 9 maanden follow-up een post-hoc analyse van deze trialdata uitgevoerd. De patiënten met de diagnose FM werden vergeleken met de patiënten met een andere diagnose met betrekking tot gezondheidsuitkomsten en gezondheidszorgkosten. Verder onderzochten we de impact van een snelle diagnosestelling binnen 3 weken door de verpleegkundig reumaconsulent vergeleken met een reguliere (vertraagde) diagnosestelling na 3 maanden door de reumatoloog. Hoofdstuk 4 presenteert de analyses van deze studie. Van alle patiënten $(n=193)$ hadden er 159 (82.4\%) de diagnose FM volgens de ACR criteria, 33 (17.1\%) een andere diagnose en van 1 patiënt was de diagnose onbekend. FM patiënten hadden significant langer klachten (6.3 vs. 4.2 jaar) en hadden vaker andere gezondheidsproblemen dan patiënten zonder FM. Voordat de diagnose gesteld werd, deden FM patiënten het op die uitkomstmaten slechter dan patiënten zonder FM. De timing van de diagnose (snel vs. laat) had geen invloed op deze resultaten. Gedurende 9 maanden follow-up toonden FM patiënten op bijna alle gezondheidsuitkomsten geen vooruitgang, terwijl patiënten zonder FM op bijna alle gezondheidsuitkomsten verbeterden. De gezondheidszorgkosten van FM patiënten waren $€ 183$ hoger dan die van patiënten zonder FM, maar de kosten door afwezigheid op het werk waren €701 
hoger bij patiënten zonder FM. Een snelle diagnose spaarde veel kosten bij patiënten zonder FM zowel vanuit gezondheidszorg als maatschappelijk perspectief ( $€ 5725$ minder maatschappelijke kosten). De belangrijkste conclusie van de post-hoc analyse van deze RCT was dat patiënten bij wie een diagnose FM bevestigd werd veel slechter scoorden op bijna alle gemeten gezondheidsuitkomsten in vergelijking met patiënten gediagnosticeerd met enige andere aandoening. Een belangrijke bevinding is dat deze verschillen reeds bestonden voordat de diagnose gesteld werd. Een andere belangrijke bevinding is dat over een periode van 9 maanden follow-up patiënten met een bevestigde diagnose FM een stabiel ziekteverloop hadden, weliswaar veel slechter dan patiënten met een andere diagnose. In deze laatste groep neigden de gezondheidsuitkomsten te verbeteren. De timing van de diagnose had geen invloed op de gezondheidsuitkomsten, noch bij de startmeting, noch bij follow-up meting. Nochtans spaarde een snelle diagnose kosten, vooral bij patiënten zonder FM.

\section{Behandeling van fibromyalgie}

Hoofdstuk 5 rapporteert over 2 enquêtes die uitgevoerd werden in 1998 en 2005 onder gezondheidszorg professionals die betrokken waren in de FM zorg om inzicht te krijgen in FM behandelingen die veel toegepast werden. In deze enquêtes werd informatie verzameld onder 5 disciplines over hoe ze gewoonlijk omgaan met FM om te beoordelen of de behandelprincipes in Nederland veranderd waren over deze 6 jaar. Daarbij werd bij professionals inzicht verworven in de achterliggende beweegredenen voor de keuze van een behandeling. Steekproefsgewijs werd een vragenlijst verzonden aan 150 personen per discipline: huisartsen, reumatologen, revalidatieartsen, fysiotherapeuten en psychologen. In het totaal heeft $40,4 \%$ gereageerd. Het verwijsgedrag veranderde aanzienlijk vooral tussen huisartsen en reumatologen. Revalidatieartsen kozen significant vaker voor aerobe oefentherapie en reumatologen voor multidisciplinaire therapie. Reumatologen en revalidatieartsen schreven minder vaak medicatie voor. Per discipline verschilt de voorkeur voor welke behandeling wordt ingezet. De keuze wordt vooral bepaald op basis van subjectieve, beroepsgroepgebonden factoren zoals eigen ervaring en bijscholingen. Vooral bij huisartsen zijn dynamische patiëntfactoren een belangrijk motief om te bepalen hoe om te gaan met FM. Op basis van deze studie concludeerden we dat de zorg voor FM in Nederland tussen 1998 en 2005 niet veranderd is. De maatschappelijke problemen zijn niet verminderd maar eerder erger geworden omdat patiënten vaker over en weer worden verwezen tussen artsen. Ondanks de gepubliceerde systematische reviews in deze 6 jaar zijn maar een paar items in de therapeutische benadering veranderd, sommige conform de literatuur, andere niet. We vonden een significante toename in het gebruik van een aantal internationaal aanbevolen behandelingen, echter de absolute percentages zijn nog altijd heel laag. Deze toename is een trend die zich hopelijk doorzet. De verschillen in de dagelijkse praktijk tussen de verschillende disciplines lijken te verklaren op basis van de factoren die voor de professionals een prominente rol spelen in de therapiekeuze. Deze studie 
onderstreept de noodzaak voor verder onderzoek naar methoden en processen in de zorg rond FM en hun klinische effectiviteit. Een effectieve manier om kennis te verspreiden, vooral via richtlijnen, is essentieel.

Zoals aangegeven in hoofdstuk 1 werd een 12-weken durend multidisciplinair parttime dagbehandelingsprogramma ( 3 halve dagen per week) met 5 nazorgbijeenkomsten ontwikkeld om te voldoen aan de behoefte aan een snelle en intensieve behandeling en om de positieve effecten van de behandeling op lange termijn te behouden. Het doel van de multidisciplinaire interventie was het dagelijks functioneren te optimaliseren door beter te kunnen omgaan met de pijn en de beperkingen. Het multidisciplinair programma bestond uit sociotherapie, fysiotherapie, psychotherapie en creatieve therapie. De groepsinteractie was een bijkomend voordeel, maar er werd ook aandacht besteed aan de specifieke behoeften van de patiënten. Sociotherapie ( 2 maal per week) richtte zich op educatie en het verbeteren van sociale gedragsstrategieën en sociale steun. Fysiotherapie ( 2 maal per week) was gebaseerd op tijdcontingente graded activity en bestond uit fitness, krachttraining en relaxatie. Psychotherapie (1 maal per week) gaf informatie over pijnmechanismen en gebruikte methoden als kernkwaliteiten, rationele emotieve therapie en transactionele analyse. Creatieve therapie (1 maal per week) richtte zich op de mogelijkheden om gevoelens visueel uit te drukken in plaats van verbaal. Het doel van de nazorgbijeenkomsten ( 5 in 9 maanden) was om de sleutelelementen met betrekking tot coping te herhalen om de gedragsverandering bereikt in het 12-weken durend programma te behouden.

Voordat de effectiviteit en de kosteneffectiviteit van ons multidisciplinair programma onderzocht kon worden in een RCT, werd een studie uitgevoerd om een indruk te krijgen over de haalbaarheid van de multidisciplinaire interventie voor wat betreft de aanwezigheids- en uitvalpercentages alsook om een indruk te krijgen over het niveau van het effect en de duurzaamheid van het effect dat verwacht kon worden. Deze studie wordt beschreven in hoofdstuk 6 . Honderd en vijf patiënten met de diagnose FM startten met het multidisciplinair programma en werden beoordeeld op functionele toestand en gezondheidsgerelateerde kwaliteit van leven tot 9 maanden na beëindiging van het programma. Het uitvalpercentage bedroeg $4.8 \%$. Het aanwezigheidspercentage van de 100 patiënten die het 12-weken durend programma met 5 nazorgbijeenkomsten volledig volgden, was hoog $(97.4 \%)$, net zoals de tevredenheid van de patiënten en therapeuten. Na het 12-weken durend programma werd een statistisch significante vooruitgang gezien voor functionele status en gezondheidsgerelateerde kwaliteit van leven. Deze vooruitgang bestond nog na 9 maanden follow-up. Gemiddeld was de vooruitgang slechts matig. We concludeerden dat onze 12-weken durende multidisciplinaire interventie met 5 nazorgbijeenkomsten voor FM patiënten haalbaar is en dat er indicaties zijn dat de interventie kan leiden tot een aanhoudende verbetering in functionele status en kwaliteit van leven.

Hoofdstuk 7 illustreert de uitdagingen om de effectiviteit van ons multidisciplinair programma met nazorgbijeenkomsten bij recent gediagnosticeerde FM patiënten in een RCT aan te tonen. In de RCT vergeleken we in een Zelen-achtig design het 
multidisciplinair programma met aerobe oefentherapie en gebruikelijke zorg. Op de poliklinieken reumatologie van 3 ziekenhuizen in het zuiden van Nederland werden recent gediagnosticeerde patiënten achtereenvolgens gerekruteerd en voorgerandomiseerd naar multidisciplinair $(n=108)$, aerobe oefentherapie $(n=47)$ en gebruikelijke zorg $(n=48)$. De aerobe oefentherapie vond gedurende 12 weken 2 maal per week plaats. De gebruikelijke zorg varieerde maar omhelsde ten minste educatie en levensstijladviezen. De primaire uitkomsten waren gezondheidsgerelateerde kwaliteit van leven, participatie en het gebruik maken van de gezondheidszorg. De secundaire uitkomst was functionele status. De totale follow-up bedroeg 21-24 maanden. Omdat de bereidheid deel te nemen aan de aerobe oefentherapie beperkt was, beschouwen wij de interpretatie van deze data als bediscussieerbaar. Binnen de multidisciplinaire groep werden een statistisch significant verbeterde gezondheidsgerelateerde kwaliteit van leven en een statistisch significante vermindering in het aantal uren ziekteverzuim, het aantal contacten met huisartsen en het aantal contacten met medisch specialisten gevonden. Bovendien werden statistisch significante verbeteringen gevonden voor functionele status die zelfs toenam na de interventie. Echter op het einde van de studie werden geen statistisch significante verschillen tussen de groepen gevonden. Het multidisciplinaire programma lijkt positieve effecten op te leveren, maar stevige conclusies met betrekking tot de effectiviteit kunnen niet worden geformuleerd vanwege de kleine verschillen tussen de groepen en de beperkingen van de studie.

In het laatste hoofdstuk (hoofdstuk 8, de algemene discussie), worden de belangrijkste bevindingen samengevat, bediscussieerd en samengevoegd tot een algemene conclusie. Op basis van de bevindingen betreffende het diagnostisch proces geleid door een verpleegkundige werd het duidelijk dat het er niet toe doet wanneer en door wie de diagnose FM gesteld wordt. Het snelle diagnostische proces geleid door een verpleegkundige is goed uitvoerbaar en de kosten zijn lager dan bij het gebruikelijke polikliniek bezoek aan de reumatoloog, zowel vanuit gezondheidszorgperspectief als vanuit maatschappelijk perspectief. Geen van beide benaderingen kwam er beter uit met betrekking tot functionele status en gezondheidsgerelateerde kwaliteit van leven. In tegenstelling tot onze hypothese heeft een snelle diagnose gesteld door een verpleegkundige praktisch geen impact op de gezondheidsuitkomsten. In feite lijkt het erop dat de diagnose FM op zich een eerder slechte prognose heeft (tenminste slechter dan bij een andere reumatologische diagnose). Onze studies laten niet toe de conclusie te trekken of dit te maken heeft met de aandoening zelf, of met het label FM dat een patiënt opgeplakt krijgt, of dat patiënten met FM een andere perceptie hebben over de ernst van hun aandoening die in de ogen van de reumatoloog en huisarts eerder benigne is omdat het een niet-inflammatoire en niet-destructieve aandoening betreft.

Met betrekking tot de multidisciplinaire interventie concludeerden we dat ons multidisciplinair programma haalbaar is. We vonden significante blijvende effecten van ons programma op gezondheidsgerelateerde kwaliteit van leven, maatschappelijke participatie, gezondheidszorgconsumptie, en zelfgerapporteerde gezondheidsuitkomsten. De verschillen tussen de groepen waren echter klein. 
Daarom moesten we concluderen dat de effecten van ons multidisciplinair programma beperkt leken hoewel blijvende verbetering gevonden kon worden, soms op hetzelfde niveau als aerobe oefentherapie en/of gebruikelijke zorg die beiden veel goedkoper zijn. Echter de patiënten die besloten deel te nemen aan de multidisciplinaire behandeling waren gemotiveerd en volgden het programma volledig, zowel in de pilotstudie als in de RCT. Dit gaf een indicatie dat het programma voldeed aan de behoeften en verwachtingen van de deelnemende patiënten. De aerobe oefengroep echter had een hoge uitval. Dit suggereerde dat deze interventie slechts voldeed aan de behoeften van een geselecteerde groep FM patiënten.

Bevindingen van ons onderzoek onderbouwen de implementatie van het diagnostisch proces geleid door de verpleegkundige en in enige mate ook de implementatie van het multidisciplinair programma in de reguliere zorg.

We stelden ook implicaties voor de praktijk en verdere wetenschappelijk onderzoek voor. Betreffende het diagnostische proces verdienen de diagnostische criteria voor FM aandacht. De ACR 1990 criteria waren ontwikkeld voor wetenschappelijk onderzoek maar werden al vlug gebruikt in de klinische praktijk hoewel ze hier nooit voor gevalideerd zijn. Het is een goed initiatief dat heel recent nieuwe klinische diagnostische criteria (ACR 2010 criteria) werden voorgesteld. Zij baseren zich niet op drukpunten, nemen naast pijn ook andere FM gerelateerde symptomen in beschouwing en zijn bedoeld om de ernst van deze symptomen te beoordelen. Wetenschappelijk onderzoek om de klinische bruikbaarheid te bepalen loopt momenteel.

De diagnose FM kan veilig gesteld worden door een andere gezondheidszorg professional dan de reumatoloog op voorwaarde dat deze goed getraind is. Je zou ook kunnen stellen dat de verpleegkundig reumaconsulent naast de reumatoloog niet de enige discipline is die de diagnose FM kan stellen. Omdat patiënten met FM-achtige symptomen allereerst in de eerste lijn worden gezien, lijkt het een logische optie dat ook de huisarts de diagnose kan stellen. De herkenning van FM door de huisarts is belangrijk omdat het vroeg vaststellen van FM dure en onnodige onderzoeken en verwijzingen voorkomt, evenals een vertraging in het stellen van de diagnose en het starten van een geschikte behandeling. Echter bij het overwegen wie de juiste persoon is om de diagnose FM te stellen, moet in beschouwing genomen worden dat de specifieke verpleegkundige competenties gericht op het versterken van zelfmanagement de toegevoegde waarde zijn. Deze gecombineerd met het diagnostische protocol zijn de voorwaarden voor het succes van deze benadering.

Het Chronic Care Model (CCM) voorziet in een structuur voor de benadering van veranderingen in de chronische zorg. We zijn recent gestart dit model te gebruiken voor de ontwikkeling van ons zorgprogramma. Het is belangrijk dat alle elementen van het Chronic Care Model vertegenwoordigd zijn in de benadering van de zorg voor FM en dat deze elementen in elkaar grijpen omdat de verbinding tussen de elementen de resultaten van de aparte interventies versterkt. Om de zorg rond FM te verbeteren zou de eerstelijnszorg versterkt moeten worden en zouden interventies zo veel als mogelijk in de eerste lijn moeten plaatsvinden.

Wetenschappelijk onderzoek naar de ontwikkeling van een basisset meetinstrumenten is nodig zodat onder andere betekenisvolle vergelijkingen tussen 
behandelingen mogelijk zijn. De werkgroep FM Outcome Measures in Rheumatology Clinical Trials (OMERACT) alsook de Initiative on Methods, Measurement, and Pain Assessment in Clinical Trials (IMMPACT) werken aan een dergelijke basisset. Afstemming en samenwerking tussen beide initiatieven zou wenselijk zijn, alsook het linken van de uitkomstdomeinen en -maten aan de International Classification of Functioning, Disability and Health (ICF). Naast de aanbeveling voor wetenschappelijk onderzoek naar uitkomstmaten is er meer onderzoek nodig naar het enorme aantal biologische, psychosociale en maatschappelijke factoren die FM mogelijk veroorzaken en in stand houden. Bovendien is verder onderzoek noodzakelijk om subgroepen van FM patiënten te definiëren. Ook de ontwikkeling van een nationale Nederlandse evidence-based multidisciplinaire FM richtlijn verdient aanbeveling. 
Dankwoord 


\section{Dankwoord}

Het begon allemaal met een half A4-tje waarop de 2 zorginnovaties kort stonden beschreven. Die moesten worden geëvalueerd, en dat mocht ik gaan doen. Met mijn copromotor heb ik veel gebrainstormd hoe het onderzoek er uit zou moeten zien: één of twee gerandomiseerde studies met twee, drie of vier armen. Ondertussen/tegelijkertijd heb ik de twee onderzoeksvoorstellen geschreven, werden promotoren gezocht en werd goedkeuring aan de medisch ethische toetsingscommissie gevraagd. Tegen de tijd dat dit allemaal rond was, waren we bijna anderhalf jaar verder en kon het 'echte' onderzoek beginnen. En nu is het boekje eindelijk af!

Terugziend op mijn promotietraject stel ik vast dat het een lange weg is geweest die heel anders is verlopen dan ik en menig ander had gedacht. Het was een uniek avontuur, maar ook een lange en soms moeilijke weg van hollen en stilstaan. Gelukkig waren er mensen die tijdens deze intervaltraining met me zijn meegelopen. Sommigen een stukje, anderen het hele eind. Voordat ik een aantal mensen hiervoor meer persoonlijk bedank, wil ik eerst een algemeen dankwoord uitspreken aan iedereen die mij in de gelegenheid heeft gesteld en eraan heeft bijgedragen om dit werk tot een goed einde te brengen.

Allereerst wil ik de promotiecommissie, Prof. dr. R.B.M. Landewé, Prof. dr. J.L. Severens en Dr. G.J.C. Schulpen, bedanken. Beste Robert, Hans en Guy, eindelijk is het zover: het boekje is klaar! Jullie bereidheid mee te denken was stimulerend en jullie inbreng en kritische blik heb ik altijd zeer op prijs gesteld.

Guy, bedankt voor de vruchtbare brainstormsessies en de manier waarop je me stimuleerde ook in mijn formuleringen dichtbij de praktijk te blijven.

Robert, toen Guy naar de RHZ vertrok, was jij bereid mijn eerste begeleider te worden. Ik heb bewondering voor je wetenschappelijke kennis en de wijze waarop je dit in begrijpelijke taal kunt weergeven.

Hans, bedankt voor je aanmoedigingen, ook al vroeg je je soms af of het ooit klaar zou komen. Je scherpe analyses heb ik altijd erg gewaardeerd.

Vervolgens wil ik diegenen bedanken die coauteur zijn bij verschillende artikelen die onderdeel zijn van dit proefschrift: Prof. dr. Frans Nijhuis, Prof. dr. Bert Vrijhoef, drs. Yvonne van Eijk, Dr. Annelies Boonen, drs. Henk Sonneveld, Prof. dr. Piet Geussens en dr. Frans Tan.

Beste Frans, jij bent bij de beginfase van het onderzoek betrokken geweest, vooral toen het ging over de wijze waarop maatschappelijke participatie goed te meten is. Bedankt voor je inzet en energie die je erin hebt gestoken. Beste Bert, het was fijn om met jou samen te werken. Jammer dat onze wegen zich scheiden, maar wie weet komen we in de toekomst elkaar nog wel weer eens tegen. Beste Yvonne, jouw proefschrift zal voor een gedeelte in het verlengde liggen van dit proefschrift. Fijn dat ik voor een deel de zorg en het onderzoek voor fibromyalgie verder met jou heb 
kunnen uitbouwen. Beste Annelies, bedankt voor het prettige brainstormen. Dat EQ$5 \mathrm{D}$ artikel ga ik nog een keer submitten!

Ook wil ik alle deelnemers aan dit wetenschappelijk onderzoek bedanken. Dit waren zowel fibromyalgie patiënten alsook behandelaars van patiënten met fibromyalgie. De gegevens die door middel van jullie medewerking zijn verkregen, vormen de basis voor dit proefschrift.

De verpleegkundig reumaconsulenten van het $M U M C+$ en de reumatologen van zowel het MUMC+ als het Atrium MC en Orbis MC vulden altijd trouw de gegevens in die ik voor mijn onderzoek nodig had. De poli-assistentes reumatologie van het MUMC+, Maddy en Edith, hebben mij trouw voorzien van de benodigde formulieren en verwijzingen. Ook voor jullie mijn hartelijke dank.

In het bijzonder wil ik het multidisciplinaire behandelteam FM van azM Herstelzorg (voorheen 'Huize Blankenberg') noemen. Ik heb bewondering voor de passie en gedrevenheid waarmee jullie het multidisciplinaire programma hebben vormgegeven en waarmee jullie je inzetten voor de cliënten.

Verder dank ik de mensen die de data voor me hebben ingevoerd: Henk Sonneveld, Margriet Theunissen, Chris Reijnders, Greet Willemsen, Heleen Schillingst en Diana Kernert.

De leden van de beoordelingscommissie Prof. dr. Sjef van der Linden, Prof. dr. Job Metsemakers en Dr. Annelies Boonen dank ik voor hun bereidheid het conceptproefschrift te lezen en te beoordelen. Tiny Wouters, hartelijk dank voor het vormgeven van dit proefschrift. Het is heerlijk dat jij me zoveel werk uit handen hebt genomen.

Hans Fiolet, directeur van de RVE Patiënt en Zorg van het MUMC+, hartelijk bedankt voor het vertrouwen dat je in mij stelde en de ruimte die je gaf, ook financieel, om het onderzoek uit te voeren. Zeker in de laatste fase van het proefschrift heb ik gevoeld hoe je naast me bent blijven staan.

Een speciaal woord van dank aan Ton van Attekum die niet meer bij ons is. Hij bleef geloven in mijn herstel én in de afronding van dit boekje. Hij heeft vanuit zijn positie mij de bescherming geboden die ik in die tijd nodig had.

Het onderzoek is uitgevoerd vanuit de onderzoeksafdeling van de RVE Patiënt en Zorg. De vele (ex-)collega's dank ik voor hun praktische hulp, interesse en medeleven. In het bijzonder noem ik mijn (ex-)kamergenoten Monique Bessems, Yvonne van Eijk, Anneke Dijk en Wendy Engering.

Lieve Monique, jij was al aangesteld op het project als onderzoeksassistent toen ik nog helemaal niet in beeld was. Gedurende de rit naar de promotie hebben we heel wat meegemaakt en samen gedeeld. Bedankt voor alles! Ik ben heel blij dat je me ook tijdens de promotie ter zijde zult staan. 
Lieve familie, vrienden, kennissen en buren, bedankt voor jullie meeleven en jullie interesse in mijn werk. Door de drukte van de afgelopen jaren heb ik contacten soms wel wat verwaarloosd. Hopelijk komen er nu betere tijden!

Lieve Aleida, we zijn al vriendinnen vanaf de zomer van 1994, net voordat mijn Maastrichtse avontuur begon. Wat hebben we samen veel beleefd en ondernomen. Bedankt voor je warme belangstelling en steun in de afgelopen jaren waarin we alle lief en leed samen gedeeld hebben. Ik vind het een eer dat ook jij mijn paranimf zult zijn.

Lieve Geert-Daan \& Marinca, fijn dat jullie mijn broer en schoonzus zijn. Bij jullie kon ik altijd terecht, ook als het moeilijk was. Samuel en Joëlle, wat zijn jullie mij dierbaar! Ik geniet van jullie vrolijkheid en liefde. Tante 'Jelle' hoopt nog veel met jullie te kunnen ondernemen.

Lieve papa en mama, hartelijk dank voor jullie liefde, vorming en voortdurende steun. Jullie staan altijd voor me klaar. Ik ben dankbaar en blij met jullie! Daarom draag ik graag dit proefschrift aan jullie op.

Lieve Edwin, bedankt dat je er bent. Zonder het fibromyalgie-onderzoek zouden we elkaar waarschijnlijk niet zijn tegengekomen, dus daar is het hele avontuur in ieder geval goed voor geweest. Het is te bijzonder om toeval te zijn! Jij kwam in de eindspurt in mijn leven en hebt die van zeer dichtbij meegemaakt. Ontzettend bedankt voor de momenten waarop ik even met jou kon uitblazen, onze fietstochten en etentjes, maar ook voor je liefde en je humor, je steun en je hulp. Nu is het boekje klaar en kan ik niks meer veranderen... Het is tijd voor een nieuw hoofdstuk!

Soli Deo Gloria! 
Curriculum Vitae 
156 


\section{Curriculum Vitae}

Mariëlle Kroese was born on April 16th, 1972 in Utrecht, the Netherlands and grew up in Vinkeveen, where she completed primary school. After finishing secondary school (VWO) at the Van Lodenstein College in Amersfoort, she studied Nursing at the Christelijke Hogeschool Ede from 1990 to 1994.

After her graduation, she started to study Health Sciences at Maastricht University (main subjects: Nursing Science and Epidemiology). During her study, she worked as a teacher assistant at the statistical department and as a research assistant at the department of Nursing Science. She completed her study with a research project at the department of Epidemiology of Maastricht University on the association between reproductive factors and the risk of postmenopausal endometrial cancer, using data from the Netherlands Cohort Study. She obtained her Master of Science degree in September 1997 (cum laude) and was registered as epidemiologist A in December 1997.

Before her graduation, she started to work as a researcher at the department of Epidemiology of Maastricht University: first on the project 'An inventory of (the need for) efficacy studies for treatments of chronic pain disorders' and afterwards on the project 'Etiology and prognosis of pregnancy-related pelvic girdle pain'.

In October 2002, she was appointed to the department of Integrated Care (now Patient and Care) of Maastricht University Medical Centre (MUMC+) for the research that led to this thesis.

Since 2008 she started to participate in various other research projects in the field of redesigning health care and improving quality of care. She was project manager of the Robuust project 'development of chain care for fibromyalgia patients'. Furthermore in 2010 she became the project manager of the project 'Fibromyalgie, een stepped care model voor Zuid-Limburg', a collaboration between azM Herstelzorg and Adelante together with the regional hospitals, health professionals in primary care and the patient association 'Fibromyalgie en Samenleving' (FES). 
